Aus der Klinik für Nephrologie und Rheumatologie

(Prof. Dr. med. G. A. Müller)

der Medizinischen Fakultät der Universität Göttingen

\title{
Effekte der Barorezeptoraktivierungs- therapie auf Marker des Endoplasmatischen Retikulum Stresses
}

\author{
INAUGURAL-DISSERTATION \\ zur Erlangung des Doktorgrades \\ der Medizinischen Fakultät der \\ Georg-August-Universität zu Göttingen
}

vorgelegt von

Kathrin Anina Schierke

aus

Ibbenbüren

Göttingen 2019 
Dekan:

Referent:

Ko-Referent/in:

Promotor:
Prof. Dr. med. W. Brück

Prof. Dr. med. M. Koziolek

Prof. Dr. med. M. R. Schroeter

Prof. Dr. med. M. Oppermann

Datum der mündlichen Prüfung: $\quad$ 12.11.2019 
Hiermit erkläre ich, die Dissertation mit dem Titel "Effekte der Barorezeptoraktivierungstherapie auf Marker des Endoplasmatischen Retikulum Stresses" eigenständig angefertigt und keine anderen als die von mir angegebenen Quellen und Hilfsmittel verwendet zu haben.

Göttingen, den 


\section{Inhaltsverzeichnis}

Abbildungsverzeichnis ..............................................................................II

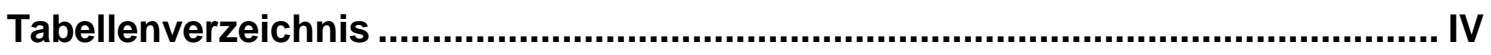

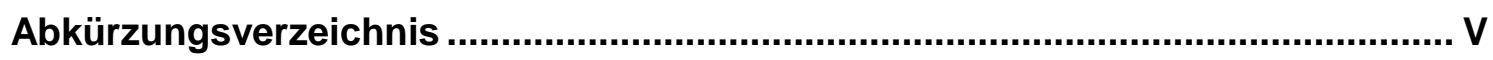

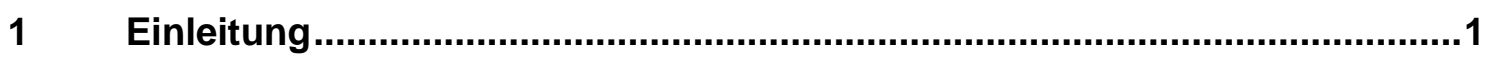

$1.1 \quad$ Die therapieresistente arterielle Hypertonie ................................................

1.2 Überaktivität des sympathischen Nervensystems ......................................

1.3 Stressreaktion im Endoplasmatischen Retikulum ........................................

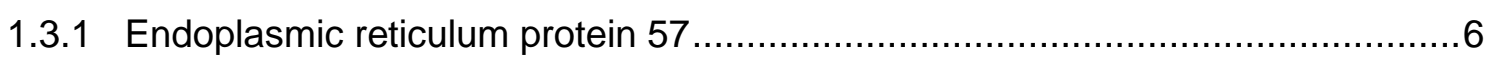

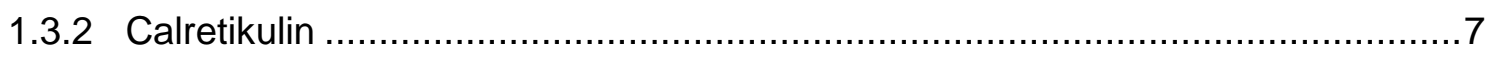

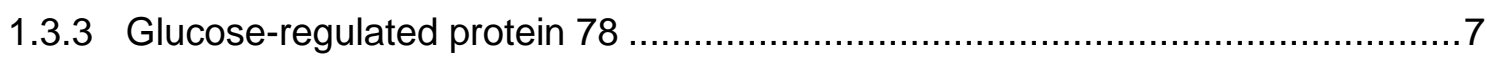

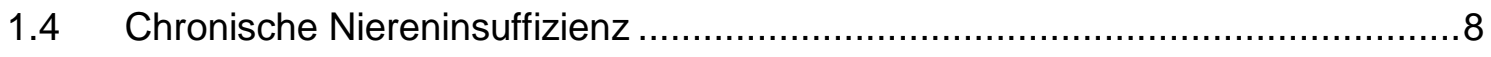

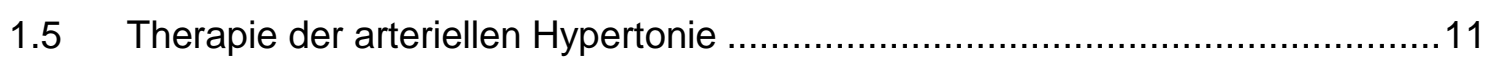

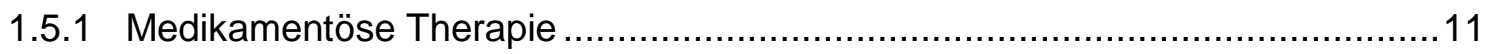

1.5.2 Renale Denervation......................................................................... 12

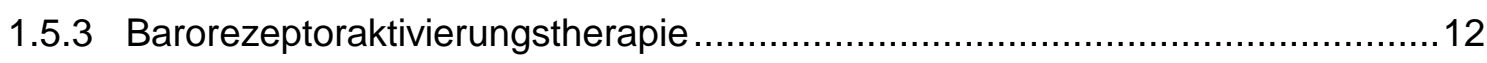

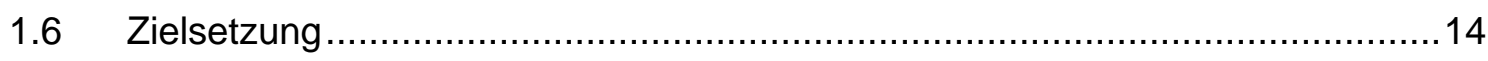

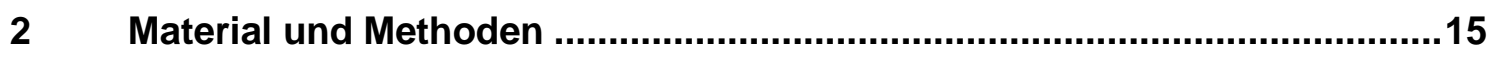

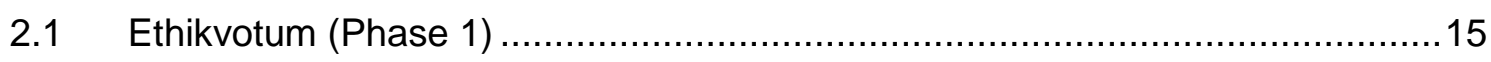

$2.2 \quad$ Klinische Studie (Phase 2) ............................................................... 16

2.2.1 Patientenrekrutierung ........................................................................... 16

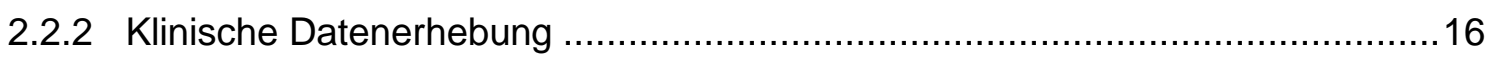

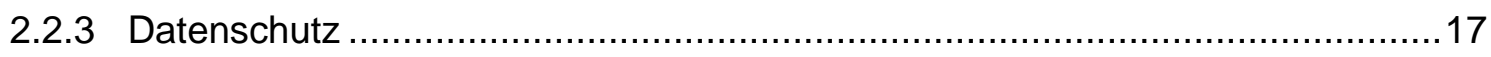

2.2.4 Kontrollkollektiv ................................................................................. 17

$2.3 \quad$ Experimente (Phase 3) ..................................................................... 17

2.3.1 Verbrauchsmaterialien und Geräte .......................................................... 18

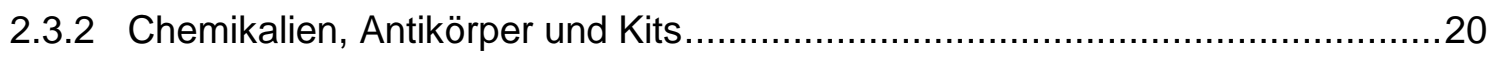

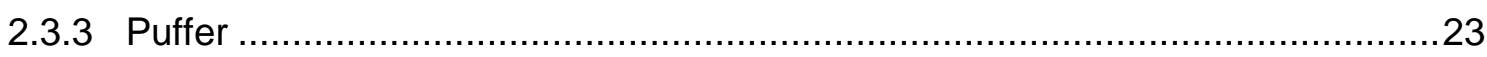

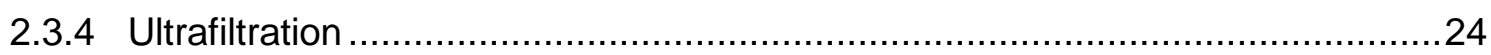

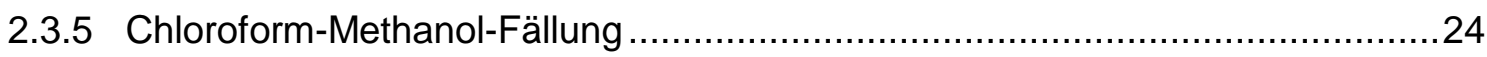

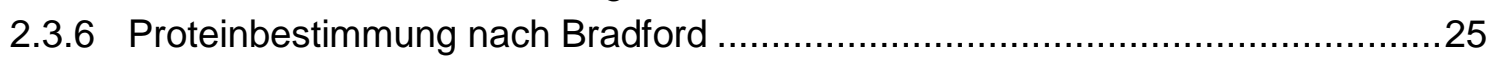

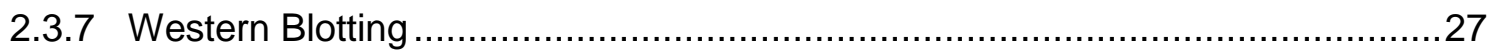

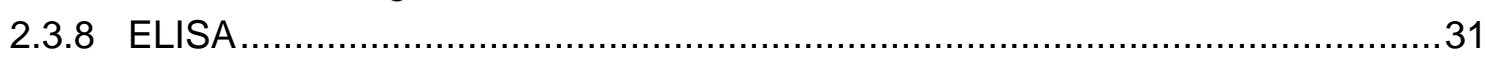

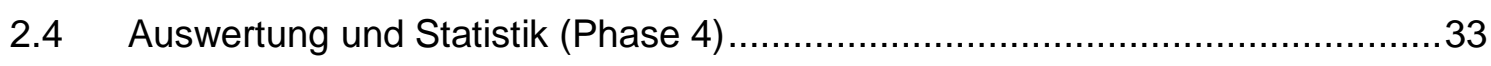

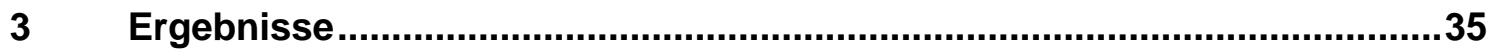

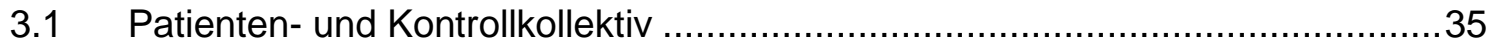

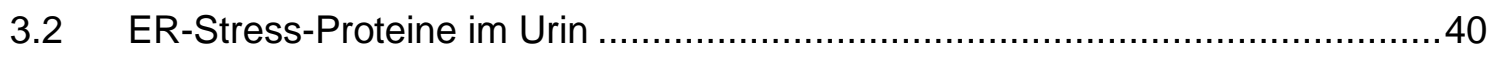




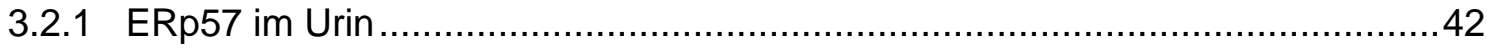

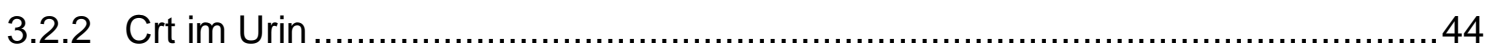

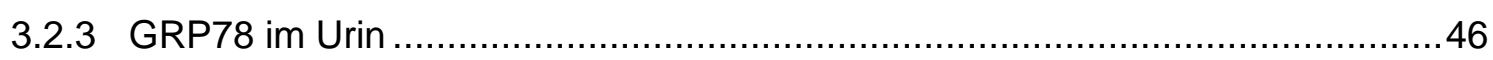

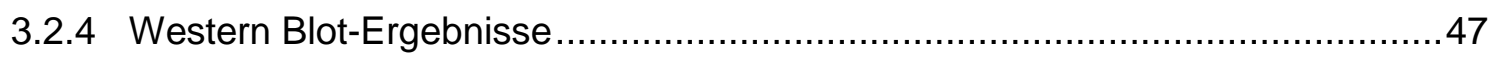

3.3 ER-Stress-Proteine im Serum ................................................................ 49

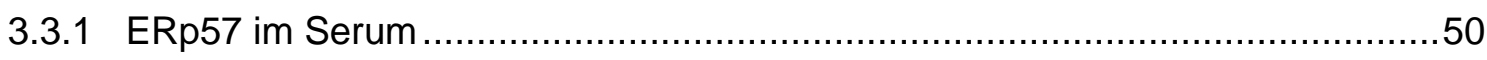

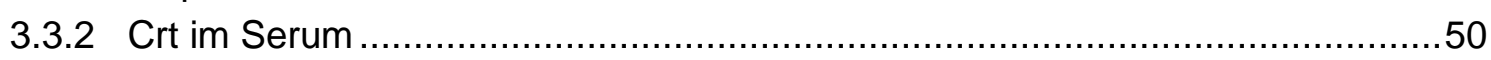

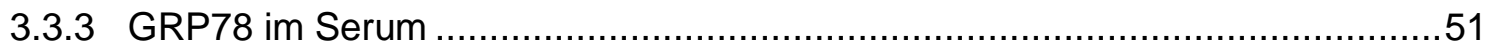

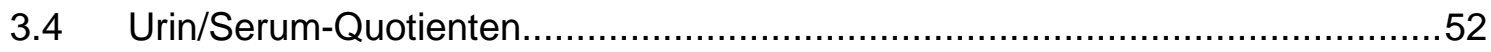

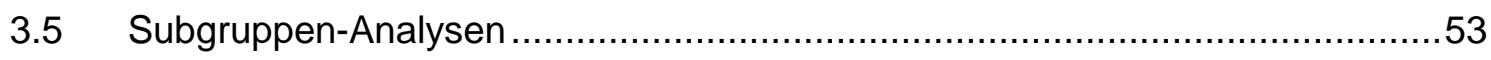

3.5.1 Subgruppen-Analysen im Urin ............................................................... 53

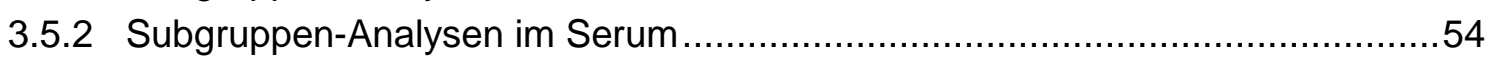

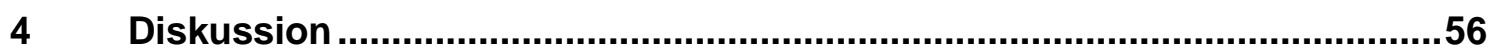

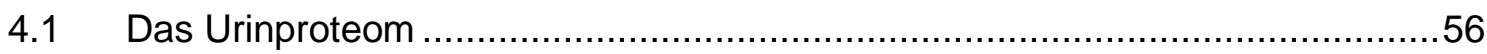

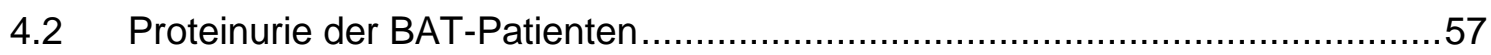

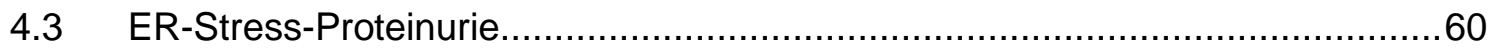

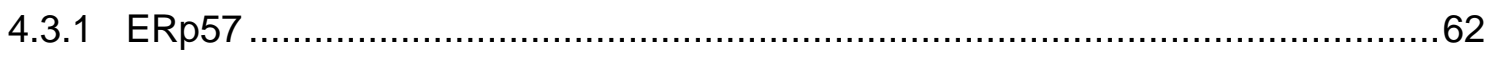

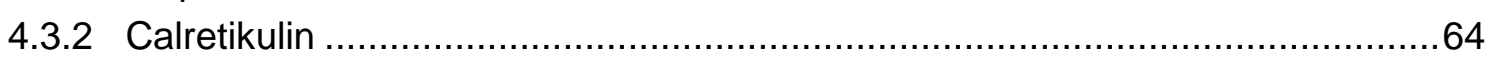

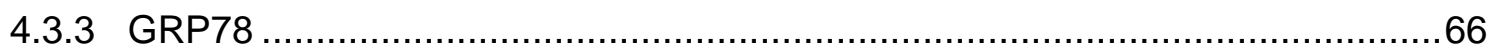

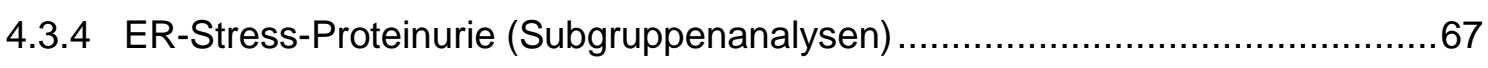

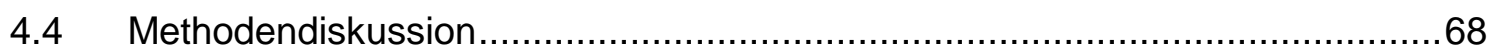

4.5 ERp57, Crt und GRP78- neue renale Biomarker? ..................................... 71

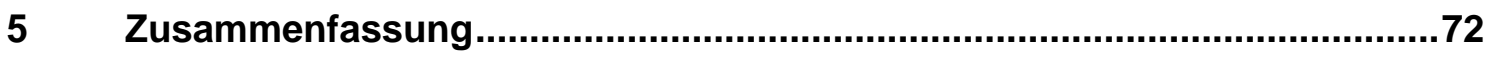

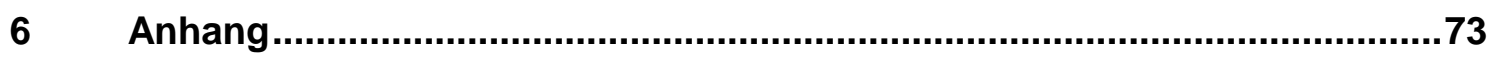

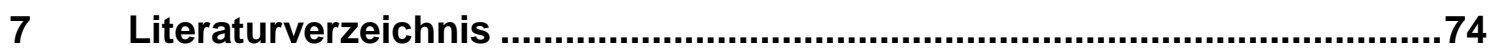

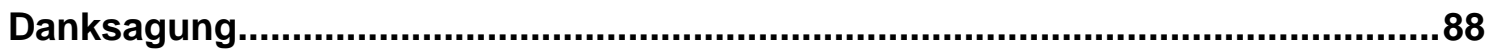




\section{Abbildungsverzeichnis}

Abbildung 1: Kardiovaskuläre Folgen einer chronisch erhöhten

Sympathikusaktivität

Abbildung 2: Stufenschema zur Therapie der arteriellen Hypertonie .........................11

Abbildung 3: Zeitlicher Ablauf der BAT-Studie ................................................. 15

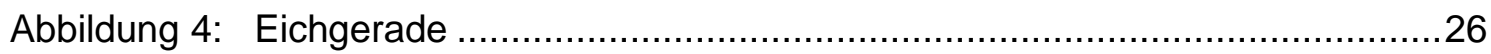

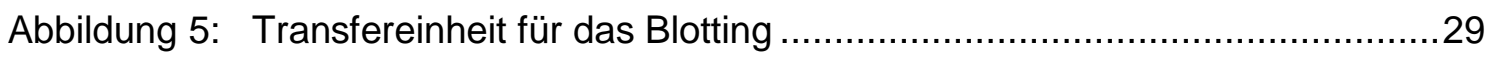

Abbildung 6: Herstellung einer Verdünnungsreihe (GRP78-ELISA-Kit) ......................31

Abbildung 7: Korrelation zwischen $\Delta \mathrm{RR}$ (Praxisblutdruck) und $\Delta$ Gesamt-

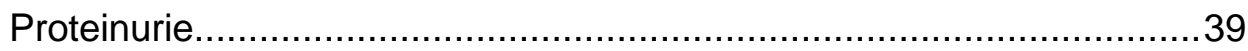

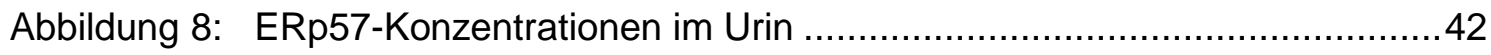

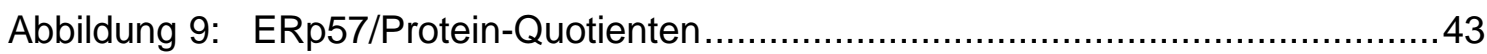

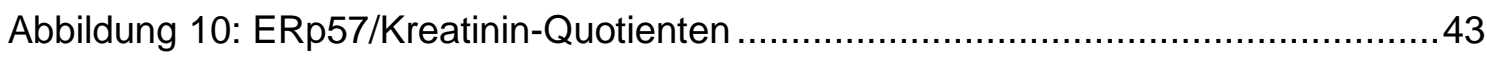

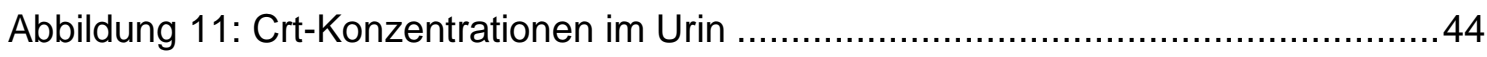

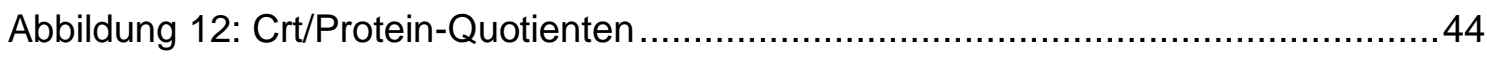

Abbildung 13: Crt/Kreatinin-Quotienten ........................................................... 45

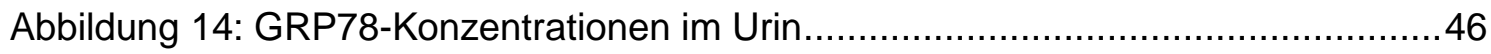

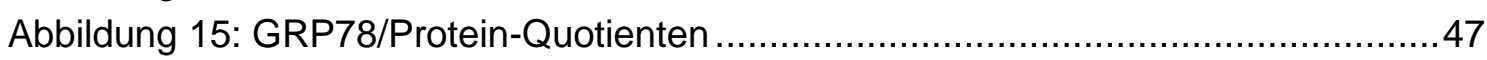

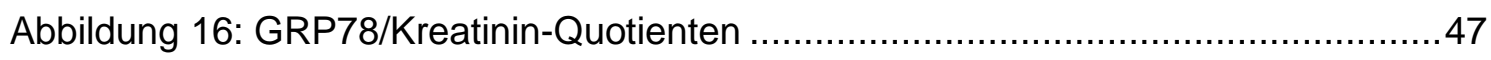

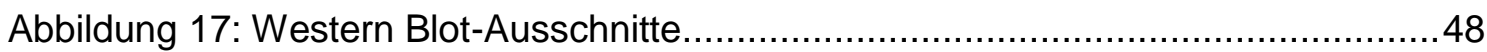

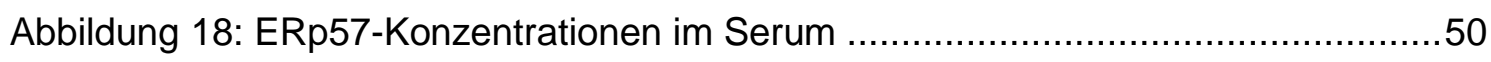

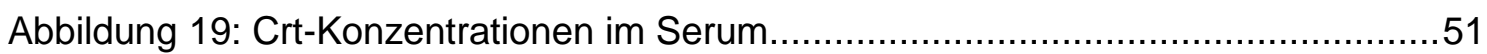

Abbildung 20: GRP78-Konzentrationen im Serum ............................................ 52

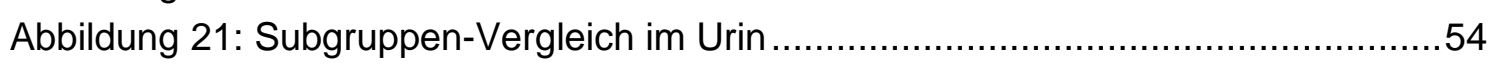

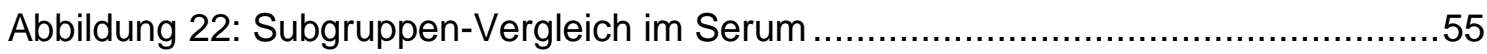

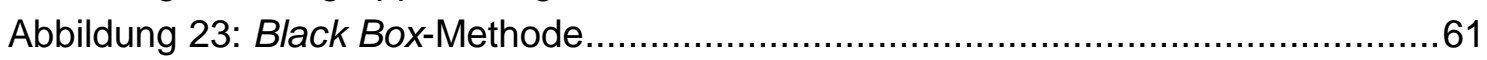

Abbildung 24: Unspezifische Bande im Bereich von 50 bis $70 \mathrm{kDa}$..........................69 


\section{Tabellenverzeichnis}

Tabelle 1: Klassifikation der arteriellen Hypertonie ...............................................

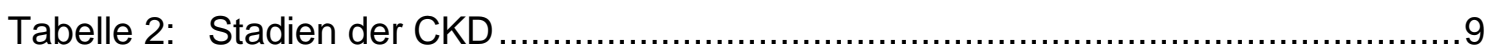

Tabelle 3: Proteinurie als Leitsymptom der CKD .................................................. 10

Tabelle 4: Ein- und Ausschlusskriterien der BAT-Studie ........................................ 16

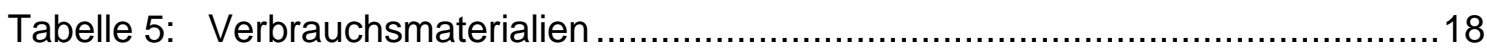

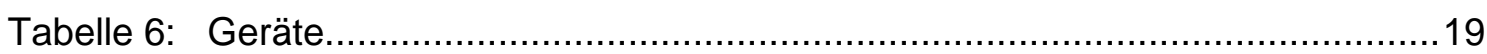

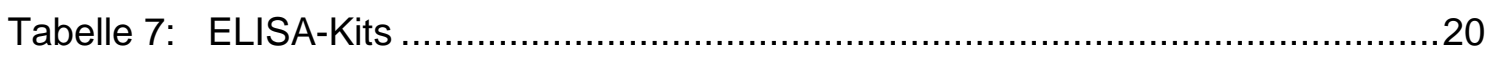

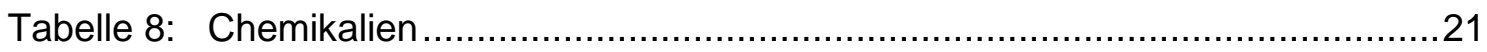

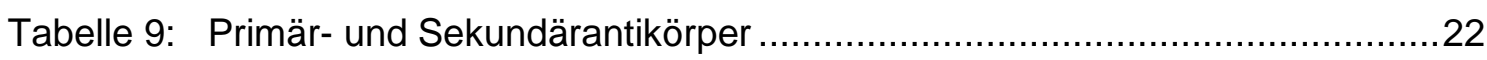

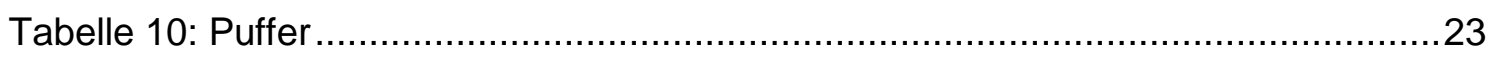

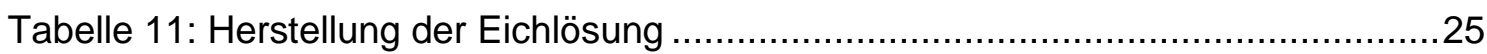

Tabelle 12: Farbstoff Coomassie Brilliant-Blau G-250 …............................................26

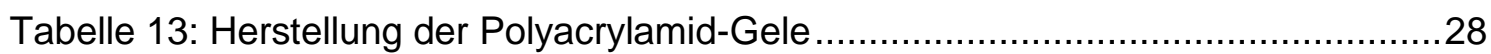

Tabelle 14: Demografische Daten der BAT-Patienten und des Kontrollkollektivs ........35

Tabelle 15: Klinische Parameter der BAT-Patienten .................................................. 37

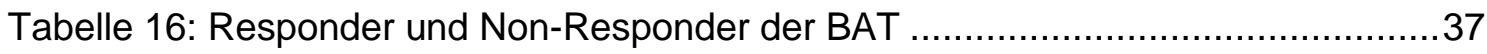

Tabelle 17: Korrelation zwischen arteriellem Blutdruck und Proteinurie..........................38

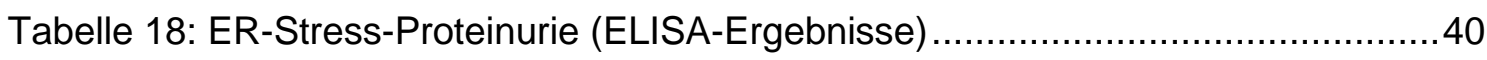

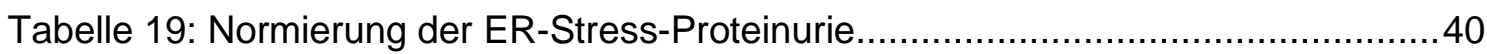

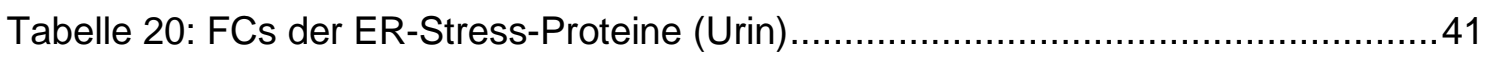

Tabelle 21: FCs der ER-Stress-Proteine (Western Blot-Ergebnisse) ..........................48

Tabelle 22: ER-Stress-Proteine im Serum (ELISA-Ergebnisse) ...............................49

Tabelle 23: FCs der ER-Stress-Proteine (Serum) ............................................ 49

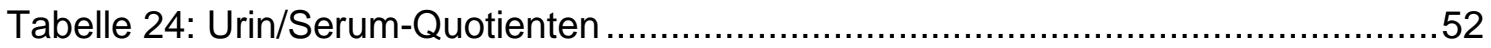




\section{Abkürzungsverzeichnis}

2D-DIGE

ABPM

ACE

APS

AT II

ATF6

BAT

BiP

BMI

BSA

CHAPS

CKD

CKD-EPI

Cnx

Crt

$\mathrm{ddH}_{2} \mathrm{O}$

DEBUT-HT

DM

DTT

ECM-Proteine

ELISA

ER

ER stress

ERAD

ERp57
Zweidimensionale differentielle Gelelektrophorese

Ambulatory blood pressure monitoring

Angiotensin converting enzyme

Ammoniumpersulfat

Angiotensin II

Activating transcription factor 6

Barorezeptoraktivierungstherapie

Immunoglobin heavy chain-binding protein

Body-Mass-Index

Bovines Serumalbumin

3-[(3-Cholamidopropyl) dimethylammonio]-1-Propansulfonat

Chronic kidney disease

Chronic Kidney Disease Epidemiology Collaboration

Calnexin

Calretikulin

Doppelt destilliertes Wasser

Device based therapy in hypertension trial

Diabetes mellitus

Dithiothreitol

Extracellular matrix-Proteine

Enzyme-linked immunosorbent assay

Endoplasmatisches Retikulum

Endoplasmic reticulum stress

ER-associated degradation system

Endoplasmic reticulum protein 57 


\begin{tabular}{|c|c|}
\hline ESC & European Society of Cardiology \\
\hline ESH & European Society of Hypertension \\
\hline EuroKup & European Urine and Kidney Proteomics \\
\hline FC & Fold Change \\
\hline GAPDH & Glycerinaldehyd-3-phosphat-Dehydrogenase \\
\hline GFR & Glomeruläre Filtrationsrate \\
\hline GRP78 & Glucose-regulated protein 78 \\
\hline $\mathrm{HCl}$ & Salzsäure \\
\hline HKUPP & Human Kidney and Urine Proteome Project \\
\hline HMW-Protein & High molecular weight-Proteine \\
\hline HRP & Horseradish peroxidase \\
\hline HSP & Heat shock protein \\
\hline $\lg G$ & Immunglobulin G \\
\hline IPG & Implantierbarer Pulsgenerator \\
\hline IQR & Interquartilsabstand \\
\hline IRE1 & Inositol-requiring enzyme 1 \\
\hline $\mathbf{K}$ & Kontrollkollektiv \\
\hline kDa & Kilodalton \\
\hline KG & Körpergewicht \\
\hline KHK & Koronare Herzkrankheit \\
\hline K-S-Test & Kolmogorov-Smirnov-Test \\
\hline LMW-Proteine & Low molecular weight-Proteine \\
\hline In & Natürlicher Logarithmus \\
\hline MALDI-TOF-MS & $\begin{array}{l}\text { Matrix assisted laser desorption ionization-time of flight- } \\
\text { Massenspektroskopie }\end{array}$ \\
\hline MDRD & Modification of Diet in Renal Disease \\
\hline MWCO & Molecular Weight Cut-off \\
\hline $\mathrm{NaCl}$ & Natriumchlorid \\
\hline
\end{tabular}




\begin{tabular}{ll}
$\mathbf{n m}$ & Nanometer \\
$\mathbf{P}$ & Patienten mit Proteinurie \\
PEI & Protein-Disulfid-Isomerasen \\
$\mathbf{r}$ & PKR-like ER kinase \\
RAAS & Pearson-Korrelationskoeffizient \\
RR & Renin-Angiotensin-Aldosteron-System \\
S1 & Blutdruck nach Riva-Rocci \\
SD & Proteinstandard \\
SDS & Standardabweichung \\
SDS-Page & Sodium dodecyl sulfate \\
TEMED & Sodium dodecyl sulfate polyacrylamide gel electrophoresis \\
TGF- $\beta$ & Tetramethylethylenediamine \\
TMB & Transforming growth factor- $\beta$ \\
TRIS & Tetramethylbenzidin \\
U/min & Tris(hydroxymethyl)-aminomethan \\
UPR & Umdrehungen pro Minute \\
V1/V2 & Unfolded protein response \\
\hline
\end{tabular}




\section{Einleitung}

Etwa 30 bis 45 Prozent der Bevölkerung in den westlichen Industrienationen sind von einer arteriellen Hypertonie betroffen, die somit eine der häufigsten chronischen Erkrankungen darstellt (Leitlinie arterielle Hypertonie 2013). Obwohl es sich bei der arteriellen Hypertonie um einen bedeutenden Risiko- und Progressionsfaktor für kardiovaskuläre Erkrankungen und die chronische Niereninsuffizienz (chronic kidney disease $=\mathrm{CKD}$ ) handelt, liegt der Blutdruck bei lediglich 5 bis 17 Prozent aller Hypertoniker im individuellen Zielbereich (Mahfoud et al. 2011). 20 bis 30 Prozent aller Patienten weisen einen medikamentös nicht einstellbaren Hypertonus im Sinne eines therapieresistenten Hypertonus auf (Bakris et al. 2012). Aufgrund der steigenden Lebenserwartung der Bevölkerung und der Zunahme prädisponierender Faktoren, insbesondere der Adipositas, ist zu vermuten, dass sich das Problem der Therapieresistenz in den nächsten Jahren weiter verstärken wird (Schaller und Wolzt 2006).

In der Einleitung der Dissertation wird die therapieresistente arterielle Hypertonie definiert und insbesondere auf die Bedeutung der sympathischen Überaktivität für ihre Entstehung und die der CKD als hypertensiver Endorganschaden eingegangen. Zudem wird die Barorezeptoraktivierungstherapie (BAT) als neue Behandlungsmethode vorgestellt. Auf zellulärer Ebene ist zum derzeitigen Wissensstand unklar, inwieweit verschiedene Stressmechanismen im Endoplasmatischen Retikulum (ER) an der Manifestation des arteriellen Hypertonus beteiligt sein könnten. Der aktuelle Forschungsstand zum sogenannten endoplasmic reticulum stress (im Folgenden: ER stress) und die Beteiligung speziell der drei ER-Stress-Proteine Calretikulin (Crt), glucose-regulated protein 78 (GRP78) und endoplasmic reticulum protein 57 (ERp57) wird dargestellt und leitet schließlich auf die Fragestellung und Haupthypothese der Arbeit über. Letztere wird mithilfe der Versuchsergebnisse überprüft und anschließend im Diskussionsteil kritisch betrachtet. 


\subsection{Die therapieresistente arterielle Hypertonie}

Eine therapieresistente arterielle Hypertonie wird bei Patienten diagnostiziert, bei denen trotz einer antihypertensiven Dreifachtherapie mit drei verschiedenen Substanzklassen, inklusive eines Diuretikums, keine leitliniengerechte Blutdruckeinstellung möglich ist. Alle Substanzen sollten in maximal tolerabler Dosis eingesetzt werden (Hoppe et al. 2012).

Gemäß der 2013 veröffentlichten Leitlinie der European Society of Hypertension (ESH) und der European Society of Cardiology (ESC) wird bei Hypertonikern mit einem geringen bis moderaten kardiovaskulären Risiko ein Zielblutdruck von unter 140/90 $\mathrm{mmHg}$ empfohlen. Abhängig von den Komorbiditäten des Patienten, wie beispielsweise einer CKD oder einem Diabetes mellitus (DM), ist das kardiovaskuläre Risiko und folglich auch der individuelle Zielblutdruck zu bestimmen. Die Diagnose eines Bluthochdrucks wird in der Regel mithilfe von Praxisblutdruck-Messungen gestellt, wobei leitliniengerecht mindestens zwei Messungen an zwei verschiedenen Tagen durchgeführt werden sollten (Empfehlungsgrad I, Evidenzgrad C). Der gemessene Blutdruck wird anschließend anhand der Tabelle 1 einer Blutdruckkategorie zugeordnet. Definitionsgemäß wird ab einem Blutdruck von 140/90 mmHg die Diagnose einer arteriellen Hypertonie gestellt (Leitlinie arterielle Hypertonie 2013).

\section{Tabelle 1: Klassifikation der arteriellen Hypertonie}

\begin{tabular}{|l|c|c|}
\hline \multirow{2}{*}{ Kategorie } & \multicolumn{2}{|c|}{ Blutdruck (mmHg) $^{\mathbf{1}}$} \\
\cline { 2 - 3 } & systolisch & diastolisch \\
\hline Optimal & $<120$ & $<80$ \\
\hline Normal & $120-129$ & $80-84$ \\
\hline Hoch-normal & $130-139$ & $85-89$ \\
\hline Grad 1-Hypertonie & $140-159$ & $90-99$ \\
\hline Grad 2-Hypertonie & $160-179$ & $100-109$ \\
\hline Grad 3-Hypertonie & $\geq 180$ & $\geq 110$ \\
\hline Isolierte systolische Hypertonie ${ }^{2}$ & $\geq 140$ & $<90$ \\
\hline
\end{tabular}

${ }^{1}$ Der Schweregrad der Hypertonie wird durch den höheren Blutdruckwert (systolisch oder diastolisch) definiert.

2 Eine weitere Einteilung der isolierten systolischen Hypertonie in Grad 1-3 wird empfohlen.

Quelle: Leitlinie arterielle Hypertonie 2013 
Ein therapieresistenter arterieller Hypertonus ist schwer abgrenzbar von einer vermeintlichen Therapieresistenz (Pseudoresistenz), die beispielsweise im Rahmen einer inadäquaten pharmakologischen Therapie, bei mangelnder Adhärenz der Patienten oder einem isoliert vorhandenen Praxishochdruck (Weiß-Kittel-Hypertonie) auftreten kann (Leitlinie arterielle Hypertonie 2013). Vor Diagnosestellung müssen potenziell reversible organische Ursachen, die sekundäre Hypertonieformen verursachen können, ausgeschlossen werden (Schaller und Wolzt 2006). Zudem ist wichtig, eine möglicherweise blutdrucksteigernde Begleitmedikation, wie zum Beispiel nicht-steroidale Antirheumatika oder Glukokortikoide, zu identifizieren (Mahfoud et al. 2011).

\section{2 Überaktivität des sympathischen Nervensystems}

Die Entwicklung einer therapierefraktären arteriellen Hypertonie ist äußerst komplex und von multifaktorieller Genese. Eine Vielzahl verschiedener Faktoren, wie beispielsweise ein hoher Salzverzehr, ein DM, hohes Lebensalter, eine linksventrikuläre Hypertrophie oder eine CKD, können zu ihrer Entstehung beitragen (Mahfoud et al. 2011). Die lange Zeit anerkannte Theorie, dass eine erhöhte Aktivität des Renin-Angiotensin-Aldosteron-Systems (RAAS) sowie eine Hypervolämie infolge einer gesteigerten Wasser- und Natriumresorption die primären Pathomechanismen in der Genese der Hypertonie darstellen, muss heute revidiert werden (Koomans et al. 2004; Schlaich et al. 2009). In verschiedenen experimentellen Studien konnte gezeigt werden, dass eine Überaktivität des sympathischen Nervensystems maßgeblich an der Entstehung und Progression der Hypertonie und der CKD beteiligt ist (Schlaich et al. 2009). Bereits Ende der siebziger Jahre wurden dafür erste Hinweise geliefert: Zum einen zeigte sich, dass Patienten mit CKD im Vergleich zu nierengesunden Patienten erhöhte Plasma-Norepinephrin-Spiegel aufweisen. Des Weiteren wurde bei verschiedenen Formen der Hypertonie mittels neurographischer Untersuchungen eine gesteigerte sympathische Muskelaktivität nachgewiesen (Koomans et al. 2004).

Die Niere stellt mit ihrer dichten sympathischen Innervation ein zentrales Organ für die Regulation des Sympathikotonus dar. Mutmaßlich führen verschiedene Faktoren, wie beispielsweise eine renale Ischämie mit erhöhten Adenosin-Spiegeln, oxidativer Stress, erhöhte Angiotensin II (AT II)-Level oder eine geringe Verfügbarkeit von Stickstoffmonoxid, bereits bei einer minimalen renalen Schädigung reflexartig zu einer Erhöhung des zentralen Sympathikotonus (Schlaich et al. 2009; Park 2012). 
Die in der Niere akkumulierenden Metabolite aktivieren renale Chemo- und Barorezeptoren, deren Signale von der geschädigten Niere über sympathische afferente Nervenfasern in den posterioren Hypothalamus weitergeleitet werden (Sobotka et al. 2011). Dieser Bereich des Hirnstamms ist für die Regulation des Blutdrucks und die Modulierung der zentralen Sympathikusaktivität zuständig. Eine Blutdrucksteigerung ist vereinfachend durch zwei Mechanismen zu erklären: Einerseits führt eine über a1-Adrenozeptoren vermittelte Vasokonstriktion zu einer Zunahme des peripheren Gefäßwiderstands und somit direkt zu einer Blutdruckerhöhung (Park 2012). Andererseits erfolgt eine sympathische Stimulation der Nieren über efferente postganglionäre Nervenfasern, welche die Tubuli, das Gefäßsystem und die juxtaglomerulären Apparate der Niere innervieren (Schlaich et al. 2009). Diese Stimulation führt infolge einer gesteigerten Natriumresorption zu einer vermehrten Wasserretention und zudem durch Renin vermittelt zu einer Aktivierung des RAAS (Schlaich et al. 2009). Dadurch wird sowohl der Blutdruck als auch indirekt über AT II vermittelt, die zentrale sympathische Aktivität erhöht (Schlaich et al. 2009).

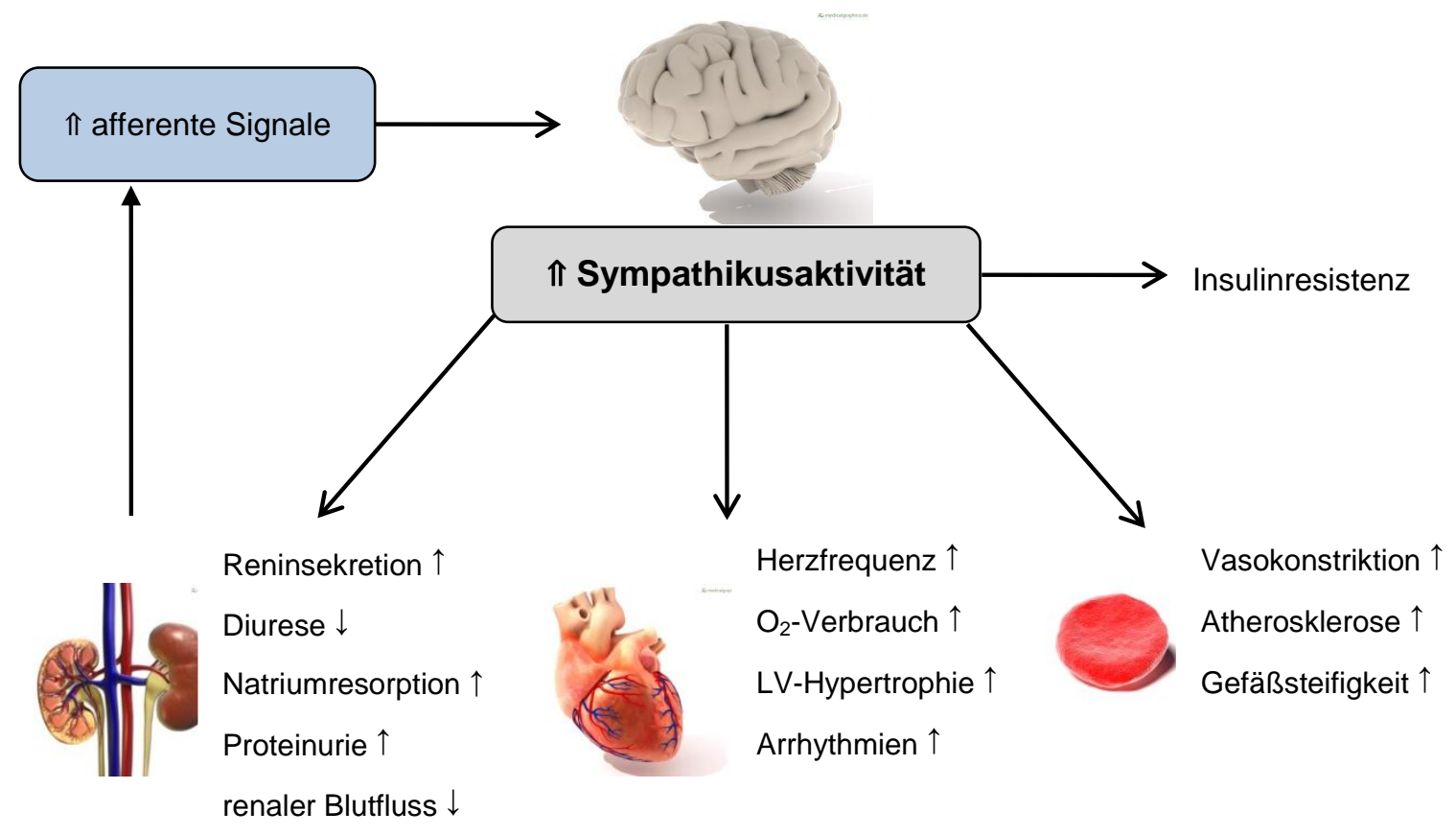

\section{Abbildung 1: Kardiovaskuläre Folgen einer chronisch erhöhten Sympathikus- aktivität}

Bereits eine minimale Nierenschädigung kann über gesteigerte afferente Signale eine Zunahme der zentralen Sympathikusaktivität verursachen. Dies führt unter anderem zu einer erhöhten sympathischen Aktivierung der Nieren, des Herzens und des Gefäßsystems und hat neben einem blutdrucksteigernden auch einen direkten organschädigenden Effekt zur Folge.

Quelle: Modifiziert nach Schlaich et al. 2009, S. 934; Sobotka et al. 2011, S. 1051

Bilder: "Creative commons" von www.MedicalGraphics.de, Lizenz: CC BY-ND 3.0 
Zusätzlich übt eine chronisch erhöhte Sympathikusaktivität blutdruckunabhängig über profibrotische und inflammatorische Prozesse schädigende Effekte auf das gesamte kardiovaskuläre System aus (Park 2012). Im Bereich der Nieren wird die Entstehung einer interstitiellen Fibrose und Glomerulosklerose gefördert und somit die Progression einer Nierenerkrankung begünstigt (Schlaich et al. 2009).

Weitere Effekte auf das kardiovaskuläre System sind in Abbildung 1 dargestellt.

\subsection{Stressreaktion im Endoplasmatischen Retikulum}

Das ER ist ein im Zytoplasma gelegenes Zellorganell, das sowohl für die intrazelluläre Kalziumspeicherung, als auch für die Synthese von Proteinen und Lipiden von Bedeutung ist (Upledger 2003). Im ER-Lumen werden die neu synthetisierten Proteine mit Hilfe von Faltungshelfern, den sogenannten molekularen Chaperonen, in ihre native Struktur gefaltet. Durch Bindung an hydrophobe Sequenzen der Polypeptidketten verhindern die Chaperone eine Aggregation der Proteine (Müller und Graeve 2014). Bestimmte Faktoren wie Hypoxie, Ischämie, Nährstoffmangel, oxidativer Stress oder chemische Substanzen können zu einer Akkumulation von fehl- oder ungefalteten Proteinen im ER-Lumen führen. Dieser Zustand wird als sogenannter ER stress bezeichnet (Kitamura 2008a). Um die Homöostase des ERs aufrechtzuerhalten, wird eine als unfolded protein response (UPR) bezeichnete koordinierte Stressantwort eingeleitet. Dabei wird zwischen dem adaptativen, antiapoptotischen UPR, der ein Überleben der Zelle unter ER stress ermöglicht, und dem proapoptotischen UPR differenziert. Letztgenannter wird erst bei prolongiertem oder sehr intensivem $E R$ stress initiiert und kann über eine Vielzahl verschiedener Mechanismen zu einer Apoptose der Zelle führen (Inagi 2009). ER stress und der UPR sind physiologischerweise auch in Zellen mit einer intensiven Proteinbildung, wie zum Beispiel in Plasmazellen oder Beta-Zellen des Pankreas, zu beobachten (Cybulsky 2010).

Im ER werden drei verschiedene ER-Stress-Sensoren unterschieden: Inositol-requiring enzyme 1 (IRE1), PKR-like ER kinase (PERK) und activating transcription factor 6 (ATF6). GRP78 hält diese Proteine im inaktiven Zustand in der Membran des ERs gebunden. Bei ER stress löst sich diese Bindung, sodass IRE1, PERK und ATF6 aktiviert werden und den adaptativen UPR der Zelle einleiten (Cybulsky 2010). Dieser führt letztendlich zu einer verstärkten Expression verschiedener molekularer Chaperone, welche die Faltungskapazität des ERs erhöhen und zudem die allgemeine Proteinsyntheserate der Zelle verringern. 
Hierzu werden gezielt ER-associated degradation (ERAD)-Faktoren, die für den Abbau fehlgefalteter Proteine von Bedeutung sind, gebildet (Kitamura 2008b). Das sogenannte ERAD-System verhindert eine Proteinakkumulation in der Zelle, sodass eine weitere Steigerung des ER stress verhindert wird (Kitamura 2008b).

In der Literatur wird die Bedeutung des $E R$ stress bereits für die Entstehung einer Vielzahl chronischer Erkrankungen, wie beispielsweise Alzheimer, DM, Arteriosklerose oder Krebserkrankungen, diskutiert (Kitamura 2008b). Der ER stress im Kontext der arteriellen Hypertonie und Nierenerkrankungen ist ein relativ neues Forschungsthema und noch weitestgehend unverstanden (Kitamura 2008b; Cybulsky 2010). Wie Untersuchungen von Cybulsky, Inagi und Dihazi et al. zeigen, trägt der ER stress aller Voraussicht nach zu der Entstehung dieser Erkrankungen bei (Inagi 2009; Cybulsky 2010; Dihazi et al. 2013).

In dieser Arbeit werden speziell die Proteine ERp57, Crt und GRP78 untersucht. Diese sogenannten heat shock proteins (HSP) werden durch Hitze und jegliche Form des ER stress induziert (Benjamin und McMillan 1998), sodass sie im Folgenden als ERStress-Proteine bezeichnet werden.

\subsubsection{Endoplasmic reticulum protein 57}

Ein wichtiger Schritt im Faltungsprozess neu synthetisierter Proteine ist die korrekte Ausbildung von Disulfidbrückenbindungen, welche durch 17 verschiedene Enzyme der Familie der Protein-Disulfid-Isomerasen (PDI) mit jeweils unterschiedlicher Substratspezifität katalysiert wird (Maattanen et al. 2006). Ein bereits intensiv erforschtes Enzym ist die Glykoprotein-spezifische Oxidoreduktase ERp57, die unter einer Vielzahl von Synonymen, wie beispielsweise ER-60, GRP58 oder ERp61, bekannt ist. Die PDIs sind größtenteils im Lumen des ERs lokalisiert, wohingegen für ERp57 zusätzliche Lokalisationen an der Zelloberfläche, im Zytosol und auch im Nukleus der Zelle nachgewiesen wurden. Bis dato ist jedoch ungeklärt, welche Funktion ERp57 dort erfüllt. Im ER ist ERp57 ein Faltungshelfer im Komplex mit Crt und Calnexin (Cnx) und ist somit primär an der Faltung von Glykoproteinen beteiligt (Turano et al. 2002). Es ist aus vier verschiedenen Domänen abb'a' (a/a': Katalytische Domäne, b/b': Nichtkatalytische Domäne) aufgebaut, wobei die Interaktion mit Crt und Cnx über die b'Domäne erfolgt. Die a- und $a^{\prime}$-Domänen enthalten jeweils ein Thioredoxin-ähnliches aktives Zentrum, bestehend aus einer Cystein-Glycin-Histidin-Cystein-Sequenz (Maattanen et al. 2006). 
Durch vorrübergehend ausgebildete Disulfidbindungen zwischen den Cysteinen im aktiven Zentrum von ERp57 und denen der neu synthetisierten Glykoproteine werden Thiolgruppen frei, die ihrerseits neue Disulfidbindungen ausbilden können (Turano et al. 2002).

\subsubsection{Calretikulin}

Crt ist ein im ER-Lumen der Zelle lokalisiertes 60 Kilodalton (kDa) großes Chaperon, das an der korrekten Faltung von neu synthetisierten Glykoproteinen beteiligt ist. Sowohl funktionell, als auch strukturell, besitzt Crt große Ähnlichkeiten mit Cnx. Bei beiden Proteinen handelt es sich um Lektine, die an glykosylierte Eiweiße binden können. Die Glykosylierung der sich bildenden Polypeptidkette erfolgt bereits während der Translation im ER-Lumen (Williams 2006).

Crt und $\mathrm{Cnx}$ binden an die neu entstandenen endständigen Glukosereste der Polypeptidketten und stabilisieren somit bereits kotranslational nicht-native Proteine, die ihre endgültige dreidimensionale Konformation noch nicht erreicht haben. Durch mehrere Zyklen der Dissoziation und erneuten Bindung wird der Transport von ungefalteten Glykoproteinen aus dem ER so lange verzögert, bis ihre native Struktur schließlich erreicht oder ihre Degradation im ERAD-System eingeleitet wird (Williams 2006). Der Faltungsprozess wird dabei durch die Rekrutierung zusätzlicher Chaperone wie ERp57 unterstützt. Eine weitere Funktion von Crt besteht darin, ATP, Kalzium und Zink zu binden, wodurch die Konformation des Proteins verändert und die Kalziumhomöostase im ER beeinflusst wird (Leach und Williams 2003).

\subsubsection{Glucose-regulated protein 78}

GRP78, das unter anderem als immunoglobin heavy chain-binding protein (BiP) bezeichnet wird, ist ein primär im ER vorkommendes Protein der HSP70-Familie mit einem Molekulargewicht von 78 kDa. Es wurde entdeckt, dass die Expression des Proteins primär durch einen Glukosemangel induziert wird (Lee 2005). Neben seiner Funktion als ER-Chaperon und Kalzium-bindendem Protein reguliert GRP78 die Aktivität der Transmembran-Proteine IRE1, PERK und ATF6: GRP78 bindet an diese drei ER-Stress-Sensoren, sodass sie inaktiv bleiben. Die Induktion von $E R$ stress führt zur Freisetzung der Proteine, die im Weiteren den adaptativen UPR einleiten und so ein Überleben der Zelle gewährleisten (Wang et al. 2009). Aktuelle Untersuchungen aus der Krebsforschung zeigen, dass GRP78 an der Pathogenese von Tumorerkrankungen beteiligt zu sein scheint (Lee 2005; Wang et al. 2009). 


\subsection{Chronische Niereninsuffizienz}

Eine arterielle Hypertonie kann lange Zeit klinisch stumm verlaufen oder nur unspezifische Symptome wie Kopfschmerzen, Schwindel oder Sehstörungen verursachen (Schaller und Wolzt 2006). Klassische blutdruckbedingte Organschäden, die einen wichtigen prognostischen Faktor für die kardiovaskuläre Prognose der Patienten darstellen, sind an folgenden Organsystemen zu beobachten: 1) Herz: Herzinsuffizienz, Koronare Herzkrankheit (KHK), Myokardinfarkt, linksventrikuläre Hypertrophie; 2) Gehirn: Apoplex, zerebrale Blutungen; 3) Gefäße: Arteriosklerose; 4) Auge: Retinopathie; 5) Niere: CKD (Leitlinie arterielle Hypertonie 2013; Schmieder 2010).

Die arterielle Hypertonie ist nach dem DM die zweithäufigste Ursache für eine CKD (Schaller und Wolzt 2006), die sich nach 15 bis 20 Jahren als hypertensiver Endorganschaden entwickeln kann (Schmieder 2010). Tuncel et al. beschreiben, dass bei etwa 80 Prozent aller Patienten mit einer CKD eine Hypertonie besteht (Tuncel et al. 2002), wobei die Prävalenz mit abnehmender glomerulärer Filtrationsrate (GFR) zunimmt (Leitlinie CKD 2002). Lediglich 15 Prozent der Patienten erreichen einen systolischen Zielblutdruck von unter $130 \mathrm{mmHg}$ (Mahfoud et al. 2011) und bei etwa einem Viertel bis einem Drittel der Patienten mit hypertensiver Nephropathie liegt eine Therapieresistenz vor (Mettang und Kuhlmann 2003). Die therapierefraktäre Hypertonie stellt zudem einen bedeutenden Risikofaktor für das Auftreten kardiovaskulärer Ereignisse dar (Leitlinie Hypertonie und CKD 2004). 50 Prozent aller Todesfälle bei Patienten mit einer CKD im Stadium 5 sind auf kardiovaskuläre Erkrankungen wie Myokardinfarkt, Herzinsuffizienz, plötzlicher Herztod oder Schlaganfall zurückzuführen (Tuncel et al. 2002). Neben klassischen Risikofaktoren, wie etwa einem DM, Nikotinabusus oder körperlicher Inaktivität, tragen dazu auch speziell mit einer CKD assoziierte Risikofaktoren, wie zum Beispiel eine Proteinurie, renale Anämie oder eine eingeschränkte GFR, bei (Leitlinie CKD 2002).

Um eine CKD frühzeitig zu diagnostizieren, ist die regelmäßige Bestimmung der GFR als wichtiger Parameter zur Beurteilung der Nierenfunktion von Bedeutung. Zur Abschätzung der GFR können verschiedene Formeln, wie beispielsweise die Modification of Diet in Renal Disease (MDRD)-Formel, die Chronic Kidney Disease Epidemiology Collaboration (CKD-EPI)-Formel oder die Cockcroft-Gault-Formel, verwendet werden. 
Mithilfe der Serumkreatinin-Konzentration und weiterer Faktoren wie Gewicht, Geschlecht oder dem Alter des Patienten erfolgt die Berechnung der GFR. Alternativ kann die Messung der endogenen Kreatinin-Clearance aus einem 24-StundenSammelurin erfolgen (Mettang und Kuhlmann 2003).

Die Kreatininausscheidung hängt stark von der individuellen Muskelmasse und der tubulären Kreatininsekretion eines Patienten ab. Zudem führt erst eine über 50 prozentige Abnahme der GFR zu einem Anstieg des Serumkreatinins (Mettang und Kuhlmann 2003), sodass die GFR nicht allein anhand der SerumkreatininKonzentration geschätzt werden sollte (Leitlinie CKD 2002). Die Diagnose einer CKD wird entsprechend der KDOQI-Leitlinie der National Kidney Foundation (KDOQI Clinical Practice Guidelines for Chronic Kidney Disease) bei einem Abfall der GFR auf unter $60 \mathrm{ml} / \mathrm{min} / 1,73 \mathrm{~m}^{2}$ oder bei Nachweis eines über drei Monate persistierenden Nierenschadens gestellt (Leitlinie CKD 2002).

\section{Definition einer CKD:}

1) Nachweis eines Nierenschadens für $\geq 3$ Monate:

- pathologische Veränderungen (Biopsie, bildgebende Verfahren wie zum Beispiel Sonografie, Computertomografie oder Magnetresonanztomografie)

- Marker eines Nierenschadens im Blut und Urin (Proteinurie, Urin-SedimentUntersuchung)

2) GFR $\leq 60 \mathrm{ml} / \mathrm{min} / 1,73 \mathrm{~m}^{2}$ für $\geq 3$ Monate

Quelle: Leitlinie CKD 2002

\section{Tabelle 2: Stadien der CKD}

Per definitionem ist in Stadium 1 und 2 (GFR $\geq 60 \mathrm{ml} / \mathrm{min} / 1,73 \mathrm{~m}^{2}$ ) der Nachweis eines renalen Schadens als diagnostisches Kriterium der CKD ausreichend. In Stadium 3 bis 5 (GFR $\leq 60$ $\mathrm{ml} / \mathrm{min} / 1,73 \mathrm{~m}^{2}$ ) wird unabhängig vom Nachweis eines Nierenschadens die Diagnose einer CKD gestellt.

\begin{tabular}{|c|c|}
\hline Stadium & $\begin{array}{c}\text { GFR } \\
\left(\mathrm{ml} / \mathrm{min} / 1,73 \mathrm{~m}^{2}\right)\end{array}$ \\
\hline 1 & $\geq 90$ \\
\hline 2 & $60-89$ \\
\hline 3 & $30-59$ \\
\hline 4 & $15-29$ \\
\hline 5 & $\leq 15$ \\
\hline
\end{tabular}

Quelle: Leitlinie CKD 2002 
Mithilfe der GFR ist eine Einteilung in eines von fünf CKD-Stadien möglich (Leitlinie CKD 2002). Die Stadien sind in Tabelle 2 aufgeführt.

Da Hypertoniker als Risikopatienten für die Entwicklung einer CKD gelten (Leitlinie Hypertonie und CKD 2004), ist ein regelmäßiges Screening des Urins mithilfe von Urinteststreifen oder Albumin-spezifischen Teststreifen zur Detektion einer Proteinurie indiziert (Leitlinie CKD 2002). Oftmals ist bereits vor dem Auftreten erster Symptome eine pathologische Eiweißausscheidung im Urin von über $300 \mathrm{mg}$ pro Tag nachweisbar (Hoberg et al. 2007; Müller et al. 2007). Eine Proteinurie, die einen direkten nierenschädigenden Effekt ausübt (Dihazi und Müller 2007), steht ebenso wie die Blutdruckhöhe mit einer beschleunigten Abnahme der Nierenfunktion sowie einem erhöhten kardiovaskulären Risiko in Zusammenhang (Leitlinie Hypertonie und CKD 2004).

Bei Patienten mit einem positiven Screening-Ergebnis oder einer bereits manifesten CKD sollte die Proteinausscheidung im 24-Stunden-Sammelurin oder alternativ der Albumin/Kreatinin-Quotient beziehungsweise Protein/Kreatinin-Quotient im Spontanurin bestimmt werden (siehe Tabelle 3).

Tabelle 3: Proteinurie als Leitsymptom der CKD

\begin{tabular}{|c|c|c|}
\hline Stadium & 24-Stunden-Sammelurin & Spontanurin \\
\hline $\begin{array}{c}\text { physiologisch: } \\
\text { 1) Albumin }\end{array}$ & $\begin{array}{c}<30 \mathrm{mg} / 24 \mathrm{~h} \\
<300 \mathrm{mg} / 24 \mathrm{~h}\end{array}$ & $\begin{array}{c}<30 \mathrm{mg} / \mathrm{g} \mathrm{Kreatinin}^{1} \\
<200 \mathrm{mg} / \mathrm{g} \mathrm{Kreatinin}^{2}\end{array}$ \\
\hline 2) Gesamt-Protein & $30-300 \mathrm{mg} / 24 \mathrm{~h}$ & $30-300 \mathrm{mg} / \mathrm{g} \mathrm{Kreatinin}^{1}$ \\
\hline Mikroalbuminurie & $>300 \mathrm{mg} / 24 \mathrm{~h}$ & $>300 \mathrm{mg} / \mathrm{g} \mathrm{Kreatinin}^{1}$ \\
\hline Makroalbuminurie & $>300 \mathrm{mg} / 24 \mathrm{~h}$ & $>200 \mathrm{mg} /$ Kreatinin $^{2}$ \\
\hline Proteinurie & & \\
\hline
\end{tabular}

${ }^{1}$ Angegeben als Albumin/Kreatinin-Quotient

${ }^{2}$ Angegeben als Protein/Kreatinin-Quotient

Quelle: Modifiziert nach Leitlinie CKD 2002 


\subsection{Therapie der arteriellen Hypertonie}

\subsubsection{Medikamentöse Therapie}

Die medikamentöse Therapie der arteriellen Hypertonie orientiert sich an dem in Abbildung 2 gezeigten Stufenschema (Leitlinie Management der arteriellen Hypertonie 2013). Die Behandlung wird bevorzugt mit einer Monotherapie in niedriger Dosierung eingeleitet. Bei Therapieversagen wird entweder die Dosierung des einzelnen Medikamentes erhöht oder gegebenenfalls ein Antihypertensivum einer anderen Substanzklasse verordnet. Bei Patienten mit einem erhöhten kardiovaskulären Risiko oder hohen Ausgangsblutdrücken kann initial bereits eine Zweifach-Kombinationstherapie in Betracht gezogen werden. Die Strategie der Stufentherapie liegt darin, diese so lange zu intensivieren, bis der individuelle Zielblutdruck des Patienten erreicht ist (Leitlinie Management der arteriellen Hypertonie 2013). Wie in Kapitel 1.1 erwähnt wurde, liegt der allgemein empfohlene Zielblutdruck bei unter 140/90 mmHg (Empfehlungsgrad I, Evidenzgrad B). Bei Patienten mit bereits bestehender Proteinurie werden systolische Werte von unter $130 \mathrm{mmHg}$ empfohlen (Empfehlungsgrad Ilb, Evidenzgrad B) (Leitlinie arterielle Hypertonie 2013).

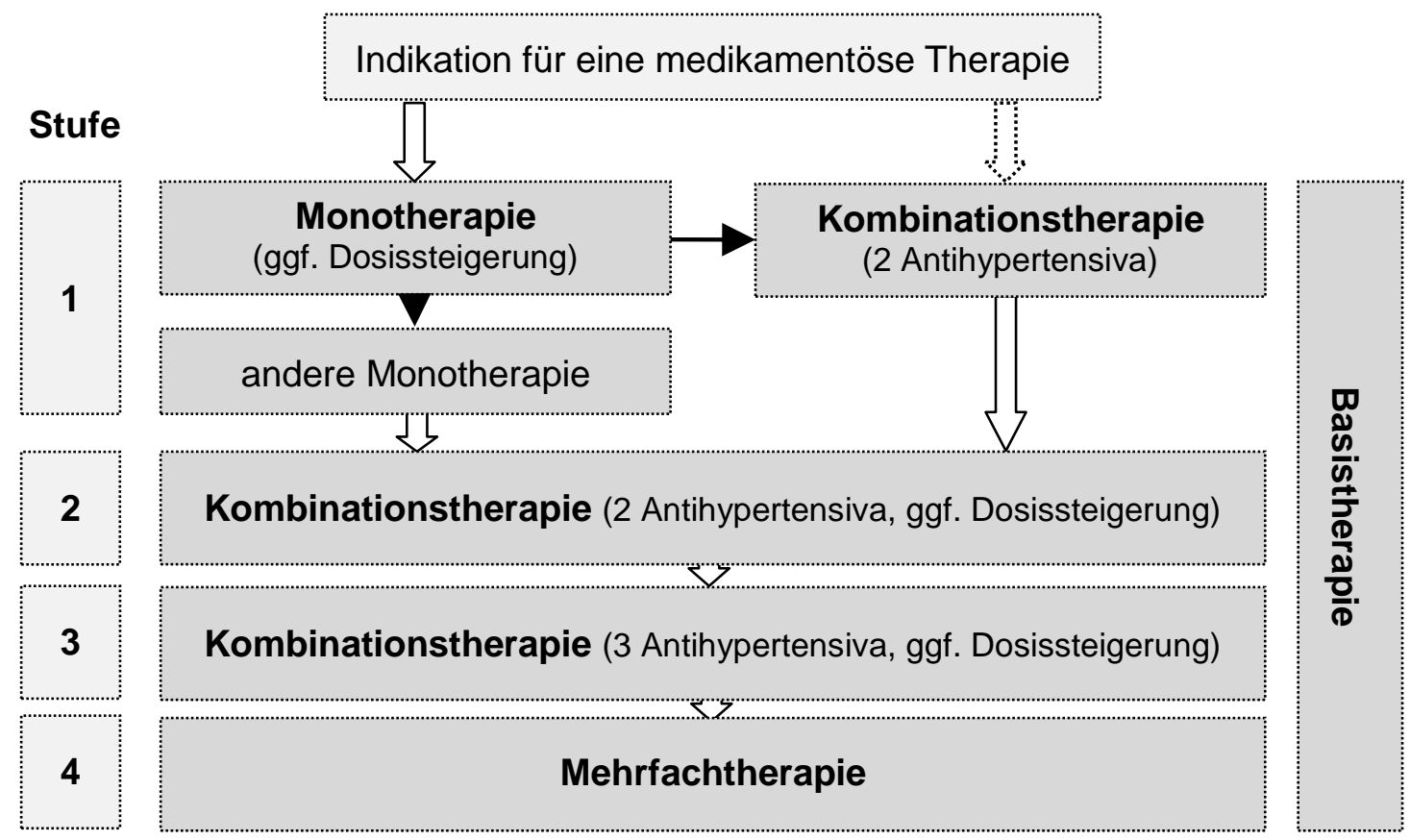

\section{Abbildung 2: Stufenschema zur Therapie der arteriellen Hypertonie}

Quelle: Modifiziert nach Leitlinie Management der arteriellen Hypertonie 2013, S. 32 
Die deutsche Hochdruckliga und Gesellschaft für Kardiologie empfehlen in der Leitlinie zum Management der arteriellen Hypertonie 2013 den Einsatz von $\beta$-Blockern, Diuretika, Kalziumantagonisten, angiotensin converting enzyme (ACE)-Hemmern und RAAS-Inhibitoren zur Behandlung des Hypertonus (Empfehlungsgrad I, Evidenzgrad A). Einige Substanzklassen üben blutdruckunabhängig zusätzlich einen positiven Effekt auf vorhandene kardiovaskuläre Risikofaktoren und hypertensive Endorganschäden aus (Leitlinie Management der arteriellen Hypertonie 2013). Gemäß der ESH/ESC-Leitlinie 2013 wird bei einem therapieresistenten Hypertonus speziell der Einsatz von Doxazosin (a1-Blocker), Amilorid (kaliumsparendes Diuretikum) oder eines Mineralokortikoid-Rezeptor-Antagonisten, wie beispielsweise Spironolacton, empfohlen (Empfehlungsgrad Ila, Evidenzgrad B) (Leitlinie arterielle Hypertonie 2013).

Nach den jüngsten Ergebnissen der PATHWAY-2-Studie $(n=335)$ scheint Spironolacton sowohl Doxazosin als auch Bisoprolol ( $\beta$-Blocker) überlegen zu sein (Williams et al. 2015). Liegt bereits eine CKD vor, ist die Gabe von ACE-Hemmern und Angiotensin-Rezeptor-Antagonisten als Primärtherapie vorzuziehen (Leitlinie Management der arteriellen Hypertonie 2013). Dem aktuellen Forschungsstand zufolge senken diese beiden Substanzklassen über eine Hemmung des RAAS die Aktivität des sympathischen Nervensystems. Es kommt sowohl zu positiven Effekten auf den Blutdruck als auch auf eine eventuell vorhandene Proteinurie. Die genauen Mechanismen sind bis dato nicht bekannt (de Beus et al. 2014).

\subsubsection{Renale Denervation}

Bei Patienten mit therapieresistenter arterieller Hypertonie ist als neue interventionelle Behandlungsmethode die renale Denervation in Betracht zu ziehen (Empfehlungsgrad Ilb, Evidenzgrad C) (Leitlinie arterielle Hypertonie 2013). Mit Hilfe eines Ablationskatheters und Hochfrequenzstrom werden die sympathischen Nervenfasern in der Adventitia renaler Gefäße selektiv verödet (Thomas et al. 2012). Angesichts der unsicheren Datenlage seit Veröffentlichung der Symplicity HTN3-Studie (Bhatt et al. 2014) und der PRAGUE-15-Studie (Rosa et al. 2015) wird die renale Ablation jedoch nicht mehr außerhalb von Studien empfohlen.

\subsubsection{Barorezeptoraktivierungstherapie}

Nach Empfehlungen der ESH/ESC-Leitlinie 2013 sollte bei Therapieresistenz die BAT als weitere Therapieoption erwogen werden (Empfehlungsgrad I, Evidenzgrad C) (Leitlinie arterielle Hypertonie 2013). 
Bereits im 19. Jahrhundert wurde bei hypertensiven Patienten im Rahmen der CarotisSinus-Massage die Bedeutung des Baroreflexes für die physiologische Regulation des Blutdrucks und der Herzfrequenz erkannt (Menne et al. 2013). In den sechziger und siebziger Jahren gewann erstmalig die Carotis-Sinus-Nerv-Stimulation als neue Behandlungsmethode des Hypertonus und der Angina pectoris an Bedeutung (Durand et al. 2009).

Barorezeptoren sind dehnungssensible Mechanorezeptoren, die im Bereich des Sinus caroticus an der Bifurkation der Arteria carotis communis lokalisiert sind. Durch eine Pulswelle und die konsekutive Gefäßwanddehnung werden diese aktiviert. Das Signal wird über Afferenzen des Ramus sinus carotici, eines Astes des Nervus glossopharyngeus, an den Nucleus tractus solitarius in der Medulla oblongata weitergeleitet (Joshi et al. 2009). Bei einem Blutdruckanstieg wird über efferente Fasern im Sinne eines negativen Feedback-Kreislaufes der Sympathikotonus vermindert und der Parasympathikotonus erhöht (Menne et al. 2013). Bei der BAT werden mit Hilfe implantierbarer Elektroden die Barorezeptoren des Sinus caroticus reversibel stimuliert, wodurch ein physiologischer Blutdruckanstieg simuliert wird (Joshi et al. 2009). Das Erstgenerationsgerät Rheos System, bei dem bilateral Stimulationselektroden angebracht wurden, ist von dem Gerät Barostim neo der zweiten Generation abgelöst worden (Menne et al. 2013). Dieser Barorezeptor-Schrittmacher besteht aus einem batteriebetriebenen Impulsgenerator (IPG), der ipsilateral zum stimulierten Karotissinus und infraklavikulär im Subkutangewebe der Pectoralisregion implantiert wird (Hoppe et al. 2012). Der IPG ist über ein transkutanes Kabel mit einer Elektrode, die in der Regel auf der rechten Körperseite in der Gefäßwand des Karotissinus platziert ist, verbunden (Menne et al. 2013).

Der IPG des Zweitgenerationsgerätes ist im Vergleich zu seinem Vorgängermodell kleiner (Menne et al. 2013) und hat mit etwa eineinhalb bis vier Jahren eine längere Batterielaufzeit (CVRx 2013). Darüberhinaus ist die unilaterale Implantation des Schrittmachers weniger invasiv, sodass die 30-Tage-Komplikationsrate auf unter zehn Prozent gesenkt werden konnte (Menne et al. 2013). Als häufigste Komplikationen werden Dysphagie, Dysphonie, lokales Taubheitsgefühl (Bisognano et al. 2011) und Wundkomplikationen, wie beispielsweise Hämatome oder lokale Schmerzen im Implantationsgebiet, beschrieben (Menne et al. 2013). Nach der Implantation des Gerätes wird über ein externes Computer-Programmiersystem der Therapiestatus (Impulsamplitude, Frequenz, Impulsbreite etc.) eingestellt. Per Telemetrie werden die Informationen an den IPG weitergeleitet (CVRx 2013). 


\subsection{Zielsetzung}

Die BAT stellt ein neues effektives Therapieverfahren zur Behandlung der therapieresistenten arteriellen Hypertonie dar. Der blutdrucksenkende Effekt konnte bereits in zahlreichen weltweit durchgeführten Studien nachgewiesen werden. Zu nennen sind vor allem der Rheos Pivotal Trial (Bisognano et al. 2011), der europäische Device Based Therapy in Hypertension Trial (DEBuT-HT) (Menne et al. 2013) und auch die Göttinger BAT-Studie, die Grundlage dieser Arbeit ist und detailliert in Kapitel 2.1 beschrieben wird.

Bislang ist allerdings noch nicht ausreichend belegt, inwieweit die BAT auch organoprotektive Effekte vermitteln kann (Wallbach und Koziolek 2015). Die Haupthypothese dieser Dissertation lautet:

Die sympathikoinhibierende BAT übt bei therapieresistenten Hypertonikern über eine Reduktion des renalen ER stress einen nephroprotektiven Effekt aus.

Zur Überprüfung dieser Hypothese wurden Urin- und Serumproben von 29 Patienten der Göttinger BAT-Studie auf das Vorhandensein der ER-Stress-Proteine ERp57, Crt und GRP78 untersucht. Folgende Aspekte wurden ausgewertet:

$\Rightarrow$ Die Ausscheidung von ER-Stress-Proteinen in den Urin wurde bei hypertensiven Patienten bereits nachgewiesen (siehe Kapitel 4.3).

Anhand der Proteinmuster von ERp57, Crt und GRP78 im Urin vor und nach der sechsmonatigen BAT soll beurteilt werden, inwieweit die BAT zu einer Abnahme des renalen $E R$ stress beigetragen haben könnte.

$\Rightarrow$ Zudem wird untersucht, ob sich die ER-Stress-Proteinurie zwischen einzelnen Subgruppen signifikant unterscheidet. Dies könnte die Frage beantworten, ob einzelne Subgruppen besonders von einer BAT profitieren könnten. Von besonderem Interesse sind Patienten mit einer CKD, die bekanntermaßen eine hohe Sympathikusaktivität aufweisen (Schlaich et al. 2009).

$\Rightarrow$ Als Marker der systemischen Zirkulation werden die ERp57-, Crt- und GRP78Serum-Level der BAT-Patienten vor und nach sechsmonatiger Therapie ausgewertet. Hieraus können möglicherweise Rückschlüsse über den Ursprung der im Urin nachgewiesenen ER-Stress-Proteine gezogen werden. 


\section{Material und Methoden}

Bei der Göttinger BAT-Studie handelt es sich um eine im Juli 2012 begonnene offene, nicht-randomisierte, prospektive Studie, die von den Kliniken Nephrologie und Rheumatologie (Studienleiter: Prof. Dr. med. Koziolek) sowie Kardiologie und Pulmonologie (Studienleiter: Prof. Dr. med. Wachter) des Universitätsklinikums Göttingen durchgeführt wird. Für das Teilprojekt ER stress besteht eine enge Kooperation mit der Arbeitsgruppe von Herrn Prof. Dr. Dihazi aus der Klinik für Nephrologie und Rheumatologie.

In den Kapiteln 2.1 bis 2.3 wird die Studie in ihren wesentlichen Gesichtspunkten zusammengefasst. Als Quelle dient der offizielle Prüfplan der Studie, der freundlicherweise von Herrn Prof. Dr. Koziolek zur Verfügung gestellt wurde und im Folgenden nicht einzeln zitiert wird. In Abbildung 3 ist der zeitliche Ablauf der Studie dargestellt.

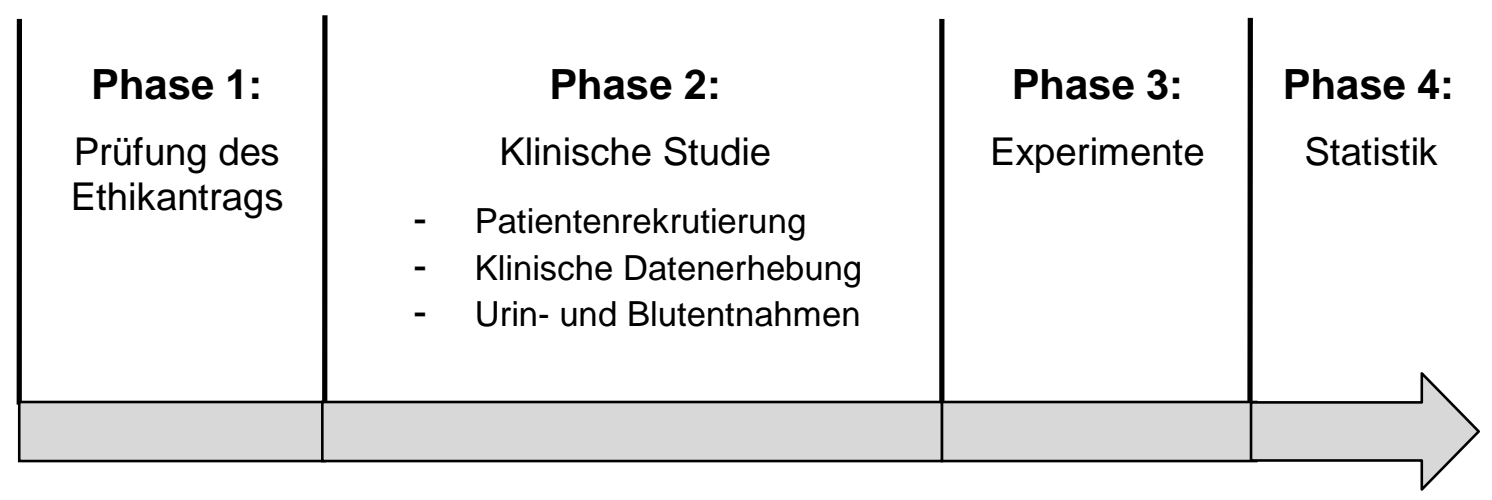

\section{Abbildung 3: Zeitlicher Ablauf der BAT-Studie}

Quelle: Modifiziert nach Koziolek und Wallbach 2013

(Die Verwendung erfolgt mit freundlicher Genehmigung der beiden Autoren.)

\subsection{Ethikvotum (Phase 1)}

Die BAT-Studie wurde mittels eines positiven Ethikvotums (Antragsnummer: 19/9/2011) durch die Ethikkommission der Universitätsmedizin Göttingen genehmigt. Für die Patienten ergab sich durch die Studienteilnahme kein gesundheitlicher Nachteil, da die Serumproben im Rahmen der routinemäßigen Laborkontrollen gesammelt wurden und somit keine zusätzliche Venenpunktion notwendig war. 


\subsection{Klinische Studie (Phase 2)}

\subsubsection{Patientenrekrutierung}

Die Studienteilnehmer wurden im Rahmen eines ambulanten oder stationären Aufenthaltes in den oben genannten Kliniken für die Studie rekrutiert. Die Auswahl der Patienten richtete sich nach den in Tabelle 4 aufgeführten Einschluss- und Ausschlusskriterien.

Tabelle 4: Ein- und Ausschlusskriterien der BAT-Studie

\begin{tabular}{|c|c|c|}
\hline & Einschlusskriterien & Ausschlusskriterien \\
\hline & $\begin{array}{l}\text { Indikation zu einer BAT } \\
\text { Diagnose einer therapieresistenten } \\
\text { arteriellen Hypertonie } \\
\text { Alter } \geq 18 \text { Jahre } \\
\text { Unterschriebene Einverständnis- } \\
\text { erklärung } \\
\text { Einwilligungsfähigkeit des Patienten }\end{array}$ & $\begin{array}{ll}\text { - } & \text { Ablehnung der Studienteilnahme } \\
\text { - } & \text { Alter }<18 \text { Jahre } \\
\text { - } & \text { Sunschangerschaft, Stillzeit, Kinder- } \\
\text { - } & \text { Unbehandelte sekundäre Hypertonie } \\
\text { - } & \text { Teilnahme an anderen klinischen Stu- } \\
\text { - } & \text { dien innerhalb der letzten vier Wochen } \\
\text { Patienten mit Querschnittslähmung, } \\
\text { Gehbehinderung, starker Schwankung } \\
\text { der Blutdruckwerte etc. }\end{array}$ \\
\hline
\end{tabular}

\subsubsection{Klinische Datenerhebung}

Die klinische Untersuchung und die Entnahme der Urin- und Serumproben fand ambulant im Rahmen von zwei Studienvisiten statt. Die erste Visite (V1) wurde bis zu 14 Tage vor der Implantation des Barorezeptor-Schrittmachers und die zweite Visite (V2) schließlich 180 ( \pm 10 ) Tage nach der Implantation durchgeführt. Die Urinproben wurden entsprechend des standardisierten EuroKup/HKUPP-Protokolls für das Sammeln von Urinen (European Urine and Kidney Proteomics = EuroKup, Human Kidney and Urine Proteome Project = HKUPP) aus dem zweiten morgendlichen Mittelstrahlurin gewonnen (EuroKup und HKUPP 2009). Diese wurden anschließend bei 1000 Umdrehungen pro Minute (U/min) für zehn Minuten bei $4^{\circ} \mathrm{C}$ zentrifugiert und die Überstände in Eppendorf-Gefäße aliquotiert (EuroKup und HKUPP 2009). 
Die Aliquots wurden schließlich bei $-80^{\circ} \mathrm{C}$ tiefgefroren (EuroKup und HKUPP 2009). Die Blutproben wurden bei $1500 \mathrm{U} / \mathrm{min}$ für acht Minuten bei $4{ }^{\circ} \mathrm{C}$ zentrifugiert. Anschließend wurde das Serum in Eppendorf-Gefäße pipettiert und bei $-80{ }^{\circ} \mathrm{C}$ tiefgefroren.

\subsubsection{Datenschutz}

Alle gesammelten Daten unterliegen dem Datenschutz. Die namentliche Dokumentation erfolgte lediglich auf der Einverständniserklärung. Die Speicherung und Auswertung der medizinischen und persönlichen Patientendaten war nicht namensbezogen, sondern erfolgte pseudonymisiert mit Hilfe einer fortlaufenden Nummerierung. Lediglich die Prüfärzte der Studie durften eine Zuordnung der personenbezogenen Daten zu den Studiendaten durchführen. Nach Beendigung der Studienteilnahme wurden alle Daten gemäß den Datenschutzbestimmungen aufbewahrt.

\subsubsection{Kontrollkollektiv}

Als Kontrollkollektiv wurden 17 gesunde Blutspender und Blutspenderinnen (im Folgenden als Blutspender bezeichnet) des Blutspendedienstes des Universitätsklinikums Göttingen ausgewählt. Für das Sammeln der Proben wurde ein Amendmentantrag gestellt, der durch die zuständige Ethikkommission genehmigt wurde. Pro Spender wurde jeweils eine Urin- und Serumprobe asserviert. Die Serumprobe wurde im Anschluss an die Blutspende gewonnen, sodass keine zusätzliche Venenpunktion erfolgte. Nach der Aufklärung und Einwilligung der Blutspender wurde das Alter, Geschlecht, Körpergewicht und -größe erfasst und eine Blutdruckmessung durchgeführt. Als Ausschlusskriterien galten folgende Erkrankungen: KHK, periphere arterielle Verschlusskrankheit, CKD, DM, Apoplex und arterielle Hypertonie.

\subsection{Experimente (Phase 3)}

Alle verwendeten Methoden sind in der Arbeitsgruppe von Herrn Prof. Dr. Dihazi etabliert. Es wurde größtenteils auf laborinterne Protokolle zurückgegriffen. 


\subsubsection{Verbrauchsmaterialien und Geräte}

Die Tabellen 5 und 6 geben eine Übersicht über die verwendeten Verbrauchsmaterialien und Geräte.

Tabelle 5: Verbrauchsmaterialien

\begin{tabular}{|c|c|}
\hline Verbrauchsmaterialien & Hersteller \\
\hline Combitip advanced $200 \mu \mathrm{l}$ & Eppendorf, Hamburg, Deutschland \\
\hline DURAN Laborflasche 100/500/1000 ml & $\begin{array}{l}\text { DURAN Group GmbH } \\
\text { Wertheim, Deutschland }\end{array}$ \\
\hline Filterpapier & $\begin{array}{l}\text { Bio-Rad Laboratories GmbH } \\
\text { München, Deutschland }\end{array}$ \\
\hline Gentle Skin Handschuhe & $\begin{array}{l}\text { Meditrade GmbH } \\
\text { Kiefersfelden, Deutschland }\end{array}$ \\
\hline Küvetten (10x4x45 mm) & Sarstedt, Nümbrecht, Deutschland \\
\hline Labortücher (Kimtech Science) & Kimberly-Clark, Koblenz, Deutschland \\
\hline Meliseptol (Schnelldesinfektionsmittel) & Braun, Melsungen, Deutschland \\
\hline $\begin{array}{l}\text { Nitrocellulose Blotting Membran, Amer- } \\
\text { sham Hybond ECL }(0,45 \mu \mathrm{m})\end{array}$ & $\begin{array}{l}\text { GE Healthcare } \\
\text { Little Chalfont, UK }\end{array}$ \\
\hline Pipettenspitzen $10 \mu \mathrm{l}$ & Eppendorf, Hamburg, Deutschland \\
\hline Pipettenspitzen $200 \mu \mathrm{l} / 1000 \mu \mathrm{l}$ & Sarstedt, Nümbrecht, Deutschland \\
\hline Präzisionswischtücher & Kimberly-Clark, Reigate, UK \\
\hline Reaktionsgefäße 0,6 ml/1,5 ml/2 ml & $\begin{array}{l}\text { Biozym Biotech Trading GmbH } \\
\text { Wien, Österreich }\end{array}$ \\
\hline Rührspatel & Sarstedt, Nümbrecht, Deutschland \\
\hline Serologische Pipette $20 \mathrm{ml}$ & Greiner Bio-One, Monroe, USA \\
\hline Serologische Pipette $5 \mathrm{ml} / 10 \mathrm{ml}$ & Sarstedt, Nümbrecht, Deutschland \\
\hline Skalpell (Bard-Parker) & $\begin{array}{l}\text { Aspen Surgical Products } \\
\text { Caledonia, USA }\end{array}$ \\
\hline Urin-Becher $100 \mathrm{ml}$ & Sarstedt, Nümbrecht, Deutschland \\
\hline Vivaspin 4 ml/20 ml (5000 MWCO PES) & $\begin{array}{l}\text { Sartorius Stedim Biotech } \mathrm{GmbH} \\
\text { Göttingen, Deutschland }\end{array}$ \\
\hline Zentrifugenröhrchen $15 \mathrm{ml} / 50 \mathrm{ml}$ & Sarstedt, Nümbrecht, Deutschland \\
\hline
\end{tabular}


Tabelle 6: Geräte

\begin{tabular}{|c|c|}
\hline Geräte & Hersteller \\
\hline $\begin{array}{l}\text { Blottingmodul } \\
\text { (Mini Trans-Blot Module) }\end{array}$ & $\begin{array}{l}\text { Bio-Rad Laboratories GmbH } \\
\text { München, Deutschland }\end{array}$ \\
\hline Electrophoresis Power Supply 2301 & LKB-Produkter AB, Bromma, Schweden \\
\hline Elektronische Feinwaage & Sartorius AG, Göttingen, Deutschland \\
\hline $\begin{array}{l}\text { Elektronische Präzisionswaage } \\
\text { (Universal U4600 P) }\end{array}$ & $\begin{array}{l}\text { Sartorius AG } \\
\text { Göttingen, Deutschland }\end{array}$ \\
\hline $\begin{array}{l}\text { Elektrophoresesystem } \\
\text { (Mini-Protean Tetra Cell) }\end{array}$ & $\begin{array}{l}\text { Bio-Rad Laboratories GmbH } \\
\text { München, Deutschland }\end{array}$ \\
\hline $\begin{array}{l}\text { Eppendorf Pipette Research Plus/ } \\
\text { Research Reference: 0,5-10 } \mu \mathrm{l}, 10-100 \\
\mu \mathrm{l}, 100-1000 \mu \mathrm{l}, 50 / 100 / 200 / 1000 \mu \mathrm{l}\end{array}$ & $\begin{array}{l}\text { Eppendorf } \\
\text { Hamburg, Deutschland }\end{array}$ \\
\hline Eppendorf Thermomixer Comfort & Eppendorf, Hamburg, Deutschland \\
\hline $\begin{array}{l}\text { Flockeneisbereiter } \\
\text { (Scotsman AF80) }\end{array}$ & $\begin{array}{l}\text { Scotsman Europe-Frimont S.p.A. } \\
\text { Pogliano, Italien }\end{array}$ \\
\hline Glass plates & $\begin{array}{l}\text { Bio-Rad Laboratories GmbH } \\
\text { München, Deutschland }\end{array}$ \\
\hline Image Reader FLA 5000 V3.0 & Fujifilm, Düsseldorf, Deutschland \\
\hline $\begin{array}{l}\text { Imaging System } \\
\text { (ChemiDoc MP System) }\end{array}$ & $\begin{array}{l}\text { Bio-Rad Laboratories GmbH } \\
\text { München, Deutschland }\end{array}$ \\
\hline Kurzzeitmesser (Digi-Lock Timer) & Carl Roth GmbH, Karlsruhe, Deutschland \\
\hline Lab-Shaker (Kühner) & $\begin{array}{l}\text { Adolf Kühner AG } \\
\text { Birsfelden, Deutschland }\end{array}$ \\
\hline Magnetrührer (Ikamag RCT) & IKA-Werke GmbH, Staufen, Deutschland \\
\hline Mehrkanalpipette Research & Eppendorf, Hamburg, Deutschland \\
\hline Microliter Syringes (600 series) & $\begin{array}{l}\text { Hamilton Bonaduz AG } \\
\text { Bonaduz, Schweiz }\end{array}$ \\
\hline Mikrozentrifuge 5415D, Rotor 14198 & Eppendorf, Hamburg, Deutschland \\
\hline Mini-Protean Comb & $\begin{array}{l}\text { Bio-Rad Laboratories GmbH } \\
\text { München, Deutschland }\end{array}$ \\
\hline Multipette M4 & Eppendorf, Hamburg, Deutschland \\
\hline Pipettierhilfe (Accu-jet) & Brand GmbH, Wertheim, Deutschland \\
\hline
\end{tabular}




\begin{tabular}{|l|l|}
\hline Pipettierhilfe (Pipetus) & $\begin{array}{l}\text { Hirschmann Laborgeräte GmbH \& Co. } \\
\text { KG, Eberstadt, Deutschland }\end{array}$ \\
\hline $\begin{array}{l}\text { Plattformschüttler } \\
\text { Polymax 2040) }\end{array}$ & $\begin{array}{l}\text { Heidolph Instruments GmbH \& Co. KG } \\
\text { Schwabach, Deutschland }\end{array}$ \\
\hline Sartorius Basic Meter PB-11 & Sartorius AG, Göttingen, Deutschland \\
\hline $\begin{array}{l}\text { Scanner (Fluorescent Image Analyzing } \\
\text { System FLA-5100) }\end{array}$ & $\begin{array}{l}\text { Fujifilm } \\
\text { Düsseldorf, Deutschland }\end{array}$ \\
\hline Schüttelwasserbad (GFL 1083) & $\begin{array}{l}\text { Gesellschaft für Labortechnik (GFL) } \\
\text { Burgwedel, Deutschland }\end{array}$ \\
\hline Spacer plates (1 mm) & $\begin{array}{l}\text { Bio-Rad Laboratories GmbH } \\
\text { München, Deutschland }\end{array}$ \\
\hline Spectrometer (Lambda 25 UV/VIS) & $\begin{array}{l}\text { PerkinElmer LAS GmbH } \\
\text { Rodgau-Jügesheim, Deutschland }\end{array}$ \\
\hline $\begin{array}{l}\text { Tischkühlzentrifuge 1-15PK, Rotor } \\
\text { 12132H }\end{array}$ & $\begin{array}{l}\text { Sigma Laborzentrifugen GmbH } \\
\text { Osterode am Harz, Deutschland }\end{array}$ \\
\hline Tischkühlzentrifuge 3-18K & $\begin{array}{l}\text { Sigma Laborzentrifugen GmbH } \\
\text { Osterode am Harz, Deutschland }\end{array}$ \\
\hline Vortex-Schüttler (Reax 2000) & $\begin{array}{l}\text { Heidolph Instruments GmbH \& Co. KG } \\
\text { Schwabach, Deutschland }\end{array}$ \\
\hline
\end{tabular}

\subsubsection{Chemikalien, Antikörper und Kits}

In Tabelle 7 bis 9 sind alle verwendeten Enzyme-linked immunosorbent assay (ELISA)Kits, Chemikalien und Primär- und Sekundärantikörper aufgelistet.

Tabelle 7: ELISA-Kits

\begin{tabular}{|l|l|}
\hline Kit & Hersteller \\
\hline GRP78/BiP ELISA Kit & $\begin{array}{l}\text { Enzo Life Sciences Inc. } \\
\text { Farmingdale, USA }\end{array}$ \\
\hline Human Calreticulin ELISA Kit & $\begin{array}{l}\text { Aviscera Bioscience Inc. } \\
\text { Santa Clara, USA }\end{array}$ \\
\hline $\begin{array}{l}\text { Human protein disulfide-isomerase A3 } \\
\text { ELISA-Kit (ERp57) }\end{array}$ & $\begin{array}{l}\text { MyBioSource } \\
\text { San Diego, USA }\end{array}$ \\
\hline
\end{tabular}


Tabelle 8: Chemikalien

\begin{tabular}{|c|c|}
\hline Chemikalien & Hersteller \\
\hline 1,4-Dithiothreitol (DTT) & Carl Roth GmbH, Karlsruhe, Deutschland \\
\hline 2-Mercaptoethanol & Sigma-Aldrich, St. Louis, USA \\
\hline $\begin{array}{l}\text { 3-[(3-Cholamidopropyl) } \\
\text { dimethylammonio]-1-Propansulfonat } \\
\text { (CHAPS) }\end{array}$ & $\begin{array}{l}\text { Merck KGaA } \\
\text { Darmstadt, Deutschland }\end{array}$ \\
\hline Aceton & Carl Roth GmbH, Karlsruhe, Deutschland \\
\hline Ammoniumpersulfat (APS) & Serva, Heidelberg, Deutschland \\
\hline Bio-Rad Protein Assay & $\begin{array}{l}\text { Bio-Rad Laboratories GmbH } \\
\text { München, Deutschland }\end{array}$ \\
\hline Bovines Serumalbumin (BSA) & Sigma-Aldrich, Steinheim, Deutschland \\
\hline Butanol & Merck KGaA, Darmstadt, Deutschland \\
\hline Chloroform & Merck KGaA, Darmstadt, Deutschland \\
\hline Essigsäure & Carl Roth GmbH, Karlsruhe, Deutschland \\
\hline Ethanol & Merck KGaA, Darmstadt, Deutschland \\
\hline Glycerin & Merck KGaA, Darmstadt, Deutschland \\
\hline Glycin & Carl Roth GmbH, Karlsruhe, Deutschland \\
\hline LumiGLO Reagent A (20x conc.) & Cell signaling, Danvers, USA \\
\hline Magermilchpulver & Merck KGaA, Darmstadt, Deutschland \\
\hline Methanol & Carl Roth GmbH, Karlsruhe, Deutschland \\
\hline Natriumchlorid (NaCl) & Carl Roth GmbH, Karlsruhe, Deutschland \\
\hline Natriumdodecylsulfat (SDS) & Carl Roth GmbH, Karlsruhe, Deutschland \\
\hline Peroxidase Reagent B (20x conc.) & Cell signaling, Danvers, USA \\
\hline Ponceau S Lösung & Serva, Heidelberg, Deutschland \\
\hline $\begin{array}{l}\text { Precision Plus Protein Kaleidoscope } \\
\text { Standards, Fragmentgrößen: } \\
\text { 250/150/100/75/37/25/15/10 kDa }\end{array}$ & $\begin{array}{l}\text { Bio-Rad Laboratories GmbH } \\
\text { München, Deutschland }\end{array}$ \\
\hline $\begin{array}{l}\text { Rotiphorese Gel } 30 \\
\text { (Acrylamidstamm-Lösung) }\end{array}$ & $\begin{array}{l}\text { Carl Roth } \mathrm{GmbH} \\
\text { Karlsruhe, Deutschland }\end{array}$ \\
\hline Salzsäure (HCl) & Carl Roth GmbH, Karlsruhe, Deutschland \\
\hline Salzsäure $(\mathrm{HCl})$ rauchend $(37 \%)$ & Sarstedt, Nümbrecht, Deutschland \\
\hline Tetramethylethylenediamine (TEMED) & Sigma-Aldrich, Steinheim, Deutschland \\
\hline $\begin{array}{l}\text { Tris(hydroxymethyl)-aminomethan } \\
\text { (TRIS) }\end{array}$ & $\begin{array}{l}\text { Carl Roth GmbH } \\
\text { Karlsruhe, Deutschland }\end{array}$ \\
\hline Tween 20 & Carl Roth GmbH, Karlsruhe, Deutschland \\
\hline
\end{tabular}


Urea

Carl Roth GmbH, Karlsruhe, Deutschland

Tabelle 9: Primär- und Sekundärantikörper

\begin{tabular}{|c|c|c|}
\hline Name & Spezies & Hersteller \\
\hline \multicolumn{3}{|l|}{ Primärantikörper (Verdünnung: 1:1000) } \\
\hline Anti-ERp 57 antibody & Maus & $\begin{array}{l}\text { Enzo Life Sciences GmbH } \\
\text { Lörrach, Deutschland }\end{array}$ \\
\hline Anti-Calreticulin antibody (ab4109) & Ziege & Abcam, Cambridge, UK \\
\hline Anti-GRP 78/BiP antibody & Kaninchen & $\begin{array}{l}\text { Sigma-Aldrich } \\
\text { St. Louis, USA }\end{array}$ \\
\hline \multicolumn{3}{|c|}{ Sekundärantikörper (Verdünnung: 1:2000) } \\
\hline $\begin{array}{l}\text { Anti-mouse IgG (Horseradish Peroxi- } \\
\text { dase-linked) } \\
\text { alternativ: Alexa Fluor 647, goat anti- } \\
\text { mouse IgG antibody }\end{array}$ & $\begin{array}{l}\text { Schaf } \\
\text { Ziege }\end{array}$ & $\begin{array}{l}\text { GE Healthcare } \\
\text { Little Chalfont, UK } \\
\text { Life Technologies } \\
\text { Darmstadt, Deutschland }\end{array}$ \\
\hline $\begin{array}{l}\text { Alexa Fluor 647, donkey anti-goat lgG } \\
\text { antibody }\end{array}$ & Esel & $\begin{array}{l}\text { Life Technologies } \\
\text { Darmstadt, Deutschland }\end{array}$ \\
\hline $\begin{array}{l}\text { Alexa Fluor 647, goat anti-rabbit IgG } \\
\text { antibody }\end{array}$ & Ziege & $\begin{array}{l}\text { Life Technologies } \\
\text { Darmstadt, Deutschland }\end{array}$ \\
\hline
\end{tabular}




\subsubsection{Puffer}

Die Pufferherstellung erfolgte entsprechend den in Tabelle 10 aufgeführten Protokollen.

Tabelle 10: Puffer

\begin{tabular}{|c|c|}
\hline Puffer & Herstellung \\
\hline 1x-Transferpuffer & 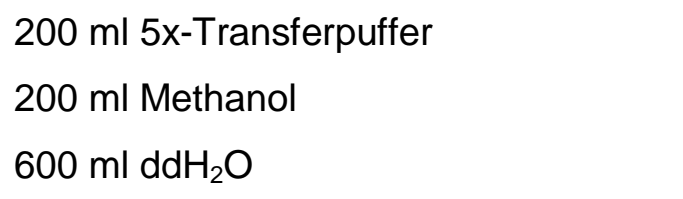 \\
\hline 4x-Lämmli-Puffer & 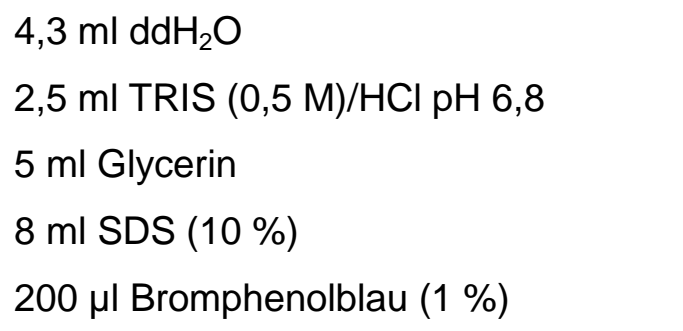 \\
\hline $4 x-$ Probenpuffer & $\begin{array}{l}950 \mu \mathrm{l} \text { 4x-Lämmli-Puffer } \\
50 \mu \mathrm{l} \text { Mercaptoethanol }\end{array}$ \\
\hline 5x-Elektrophoresepuffer & 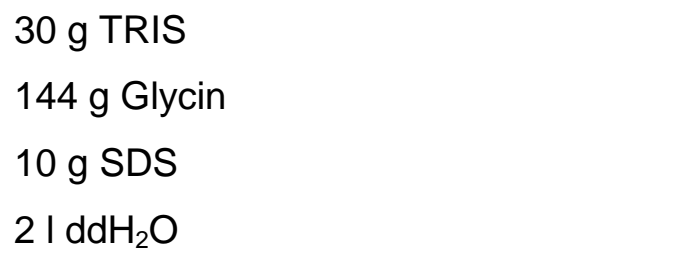 \\
\hline 5x-Transferpuffer & 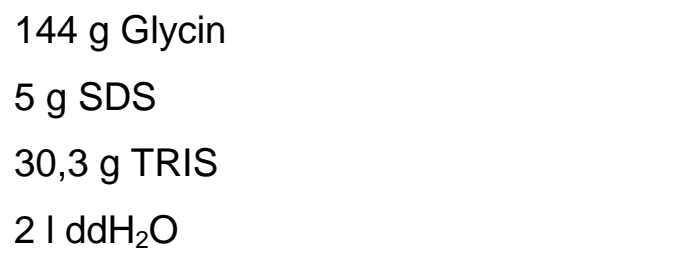 \\
\hline 5x-Waschpuffer & $\begin{array}{l}12,11 \mathrm{~g} \text { TRIS } \\
58,44 \mathrm{~g} \mathrm{NaCl} \\
10 \mathrm{ml} \text { Tween } \\
2 \mathrm{I} \mathrm{ddH} \mathrm{H}_{2} \mathrm{O} \\
\mathrm{HCl} \text { : Einstellung des } \mathrm{pH} \text {-Wertes auf } 7,5\end{array}$ \\
\hline Lysepuffer & 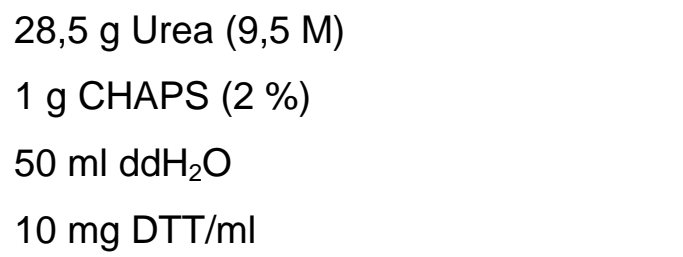 \\
\hline
\end{tabular}




\begin{tabular}{|l|l|}
\hline Magermilchpuffer (5\%) & $\begin{array}{l}5 \mathrm{~g} \text { Magermilchpuffer } \\
100 \mathrm{ml} 1 \mathrm{x} \text {-Waschpuffer }\end{array}$ \\
\hline
\end{tabular}

\subsubsection{Ultrafiltration}

Mit Hilfe von Vivaspin-Zentrifugalkonzentratoren wurden die Proteine der Urinproben konzentriert. Die speziellen Probenbehälter bestehen aus zwei verschiedenen Kompartimenten, die durch eine semipermeable Membran mit einer bestimmten Porengröße voneinander getrennt sind. Die Porengröße ist durch den sogenannten Molecular Weight Cut-off (MWCO) definiert. In dieser Arbeit wurde ein MWCO von 5 kDa gewählt (GE Healthcare Life Sciences). Bis zu $20 \mathrm{ml}$ Urin wurde in den oberen Teil der Probenbehälter gefüllt. Anschließend wurden diese bei $14000 \mathrm{U} / \mathrm{min}$ bei $4{ }^{\circ} \mathrm{C}$ zentrifugiert, sodass der Urin durch die Membran ultrafiltriert und je nach Beschaffenheit der Probe nach bis zu vier Stunden auf 200 bis $300 \mu$ l konzentriert wurde. Im nächsten Schritt wurde der Urin aus dem sogenannten Deadstop-Reservoir, das sich oberhalb der semipermeablen Membran befindet, entnommen und in ein EppendorfGefäß pipettiert. Im Konzentrat befanden sich mit einer über 90-prozentigen Wiederfindungsrate alle Proteine mit einem Molekulargewicht oberhalb des MWCOs von $5 \mathrm{kDa}$ (Sartorius Stedim Biotech $\mathrm{GmbH}$ 2014).

\subsubsection{Chloroform-Methanol-Fällung}

Im Anschluss an die Ultrafiltration wurde die Chloroform-Methanol-Fällung gemäß dem Protokoll von Wessel und Flügge durchgeführt (Wessel und Flügge 1984). Alle Zentrifugationsschritte wurden bei $14000 \mathrm{U} / \mathrm{min}$ bei $4^{\circ} \mathrm{C}$ durchgeführt.

In ein Eppendorf-Gefäß wurden $100 \mu$ l Urin, $400 \mu$ l kaltes Methanol, $100 \mu$ l kaltes Chloroform und $300 \mu \mathrm{l}$ doppelt destilliertes Wasser $\left(\mathrm{ddH}_{2} \mathrm{O}\right)$ pipettiert. Zwischen jeder Zugabe wurde die Probe gründlich vermischt und anschließend für eine Minute zentrifugiert. Es bildeten sich zwei Phasen aus, zwischen denen sich die Proteine in einer weißlichen Schicht befanden. Die obere Phase wurde entfernt, anschließend $400 \mu$ l Methanol zu der Suspension hinzu pipettiert und nach erneutem Vermischen eine zweiminütige Zentrifugation durchgeführt. Infolgedessen bildete sich ein instabiles Pellet am Boden des Gefäßes aus. Nach vorsichtiger Abnahme der wässrigen Phase, einer weiteren Zugabe von $400 \mu \mathrm{l}$ Methanol und gründlichem Vermischen wurde die Probe nochmals für zwei Minuten zentrifugiert. 
Dieser Schritt wurde anschließend ein weiteres Mal wiederholt. Der flüssige Überstand wurde schließlich verworfen und die Probe getrocknet. Auf das getrocknete Pellet wurden 25 bis $100 \mu$ l Lysepuffer pipettiert und die Probe zur Lyse 15 Minuten auf Eis gestellt. Anschließend schloss sich eine 15-minütige Zentrifugation an, um jegliche nicht lysierte Substanzen zu sedimentieren. Der Überstand wurde schließlich in ein Eppendorf-Gefäß pipettiert und stand für die nachfolgende Proteinbestimmung zur Verfügung (Wessel und Flügge 1984).

\subsubsection{Proteinbestimmung nach Bradford}

Die Proteinkonzentrationen der Urinproben wurden mithilfe der photometrischen Bestimmungsmethode nach Bradford ermittelt (Bradford 1976). Zunächst wurde aus

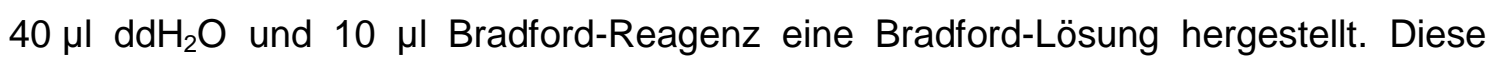
wurde zusammen mit BSA entsprechend des in Tabelle 11 abgebildeten Schemas in Küvetten pipettiert und gründlich mit einem Rührspatel vermischt.

Tabelle 11: Herstellung der Eichlösung

\begin{tabular}{|c|c|c|}
\hline Küvette $^{\mathbf{1}}$ & Bradford-Lösung $(\boldsymbol{\mu l})$ & BSA $(\boldsymbol{\mu l})$ \\
\hline $1^{2}$ & 1000 & 0 \\
\hline 2 & 998 & 2 \\
\hline 3 & 996 & 4 \\
\hline 4 & 994 & 6 \\
\hline 5 & 992 & 8 \\
\hline 6 & 990 & 10 \\
\hline
\end{tabular}

${ }^{1}$ Pro Zeile in Tabelle 11 wurden zwei Küvetten befüllt.

${ }^{2}$ Die Küvette 1 diente als Leerprobe $(0 \mu \mathrm{g}$ Protein $/ \mu \mathrm{l})$.

Vor der Bestimmung der Proteinkonzentrationen war eine Verdünnung der Urinproben mit $\mathrm{dd}_{2} \mathrm{O}$ nötig. Aufgrund unterschiedlich hoher Proteinkonzentrationen variierte die Verdünnung von 1:2 bis 1:30. Bei Proben mit geringer Proteinkonzentration war keine Verdünnung notwendig. Die Bradford-Lösung wurde mit 2 bis $6 \mu$ dieser gegebenenfalls verdünnten Probe in einer Küvette vermischt (Füllmenge stets $1000 \mu \mathrm{l}$ ) und die Absorptionen der Lösungen nach einer 15-minütigen Inkubationszeit bei einer Wellenlänge von 595 Nanometern $(\mathrm{nm})$ bestimmt. 
In Abbildung 4 ist exemplarisch eine Eichgerade dargestellt. Unter Berücksichtigung der Vorverdünnung der Urinproben (1:2 bis 1:30) und der verwendeten Probenvolumina (2 bis $6 \mu \mathrm{l}$ ) wurden die Proteinkonzentrationen der Urinproben errechnet.

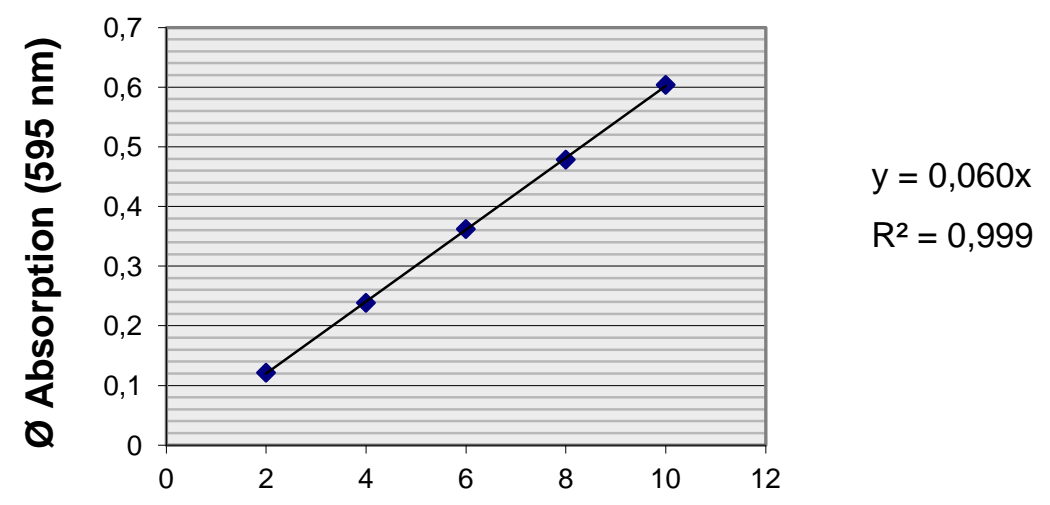

\section{BSA ( $\mu \mathrm{l})$}

\section{Abbildung 4: Eichgerade}

Quelle: Eigene Darstellung (Daten am 03.06.2014 erhoben)

Bei dieser Methode findet der im Bradford-Reagenz enthaltene Farbstoff Coomassie Brilliant-Blau G-250 Verwendung. Je nach pH-Wert des Bradford-Reagenz kann dieser in drei Ladungszuständen mit verschiedenen Absorptionsmaxima vorliegen (siehe Tabelle 12). Vor Hinzugabe der Proben liegt die kationische Form des Farbstoffes vor, die der Lösung eine rot-braune Farbe verleiht. Nach Hinzugabe der Proben kommt es proportional zur Höhe der Proteinkonzentration zu einer Komplexbildung zwischen Farbstoff und Proteinen und somit zu einem Farbwechsel nach blau (Carl Roth 2010).

Tabelle 12: Farbstoff Coomassie Brilliant-Blau G-250

\begin{tabular}{|c|c|c|}
\hline Ladung & Farbe & Absorptionsmaximum (nm) \\
\hline kationisch $(\mathrm{pH} \mathrm{0)}$ & rot/braun & 470 \\
\hline neutral $(\mathrm{pH} 1)$ & grün & 650 \\
\hline anionisch $(\mathrm{pH}>2)$ & blau & 595 \\
\hline
\end{tabular}

Quelle: Modifiziert nach Carl Roth GmbH 2010 


\subsubsection{Western Blotting}

Das Western Blotting ist eine Methode zur Identifikation von Proteinen in einer Probe. Im ersten Schritt werden die Proteine mittels einer Gelelektrophorese gemäß ihren Molekulargewichten in Proteinbanden aufgetrennt. Darauf folgt das sogenannte Blotting, bei dem die aufgetrennten Proteine vom Gel auf eine Nitrocellulose-Membran transferiert werden und somit ein Abbild des Gels entsteht (Mahmood und Yang 2012). Zum Nachweis der ER-Stress-Proteine wurden die Nitrocellulose-Membranen mit den jeweiligen Primärantikörpern inkubiert und die Banden anschließend mit Fluoreszenzoder Chemilumineszenzfärbungen sichtbar gemacht.

\subsubsection{Probenvorbereitung}

Für ein Gelelektrophorese-Gel wurden sechs vorbereitete Urinproben von drei Patienten (jeweils V1 und V2) verwendet. Zur Berechnung des Probenvolumens wurde der Quotient aus der aufzutragenden Proteinmenge $(50 \mu \mathrm{g})$ und der Proteinkonzentration der Probe errechnet. Da das maximale Ladevolumen pro Geltasche bei $30 \mu \mathrm{l} \mathrm{lag}$, wurde bei Proben mit geringer Proteinkonzentration ( $<2 \mu \mathrm{g}$ Protein/ $\mu$ l Urin) lediglich eine Proteinmenge von $20 \mu \mathrm{g}$ pro Geltasche aufgetragen. Die Proteinmengen beider Visiten eines Patienten waren innerhalb eines Gels stets identisch.

Im Anschluss wurde jede Probe mit $\mathrm{dd}_{2} \mathrm{O}$ auf ein Volumen von $10 \mu \mathrm{l}$ aufgefüllt und anschließend $10 \mu \mathrm{l}$ eines Probenpuffers (2x-Lämmli-Puffer) hinzugegeben. Falls das errechnete Probenvolumen bei über $10 \mu \mathrm{l}$ lag, wurde ein $4 \mathrm{x}$ - oder $6 \mathrm{x}$-Lämmli-Puffer verwendet und kein $\mathrm{ddH}_{2} \mathrm{O}$ hinzu pipettiert, sodass der Probenpuffer stets in einfacher Verdünnung vorlag. Im letzten Schritt wurden die Proben bei $96^{\circ} \mathrm{C}$ für zehn Minuten gekocht und anschließend auf Eis abgekühlt.

\subsubsection{Gelelektrophorese}

Die Polyacrylamid-Gele wurden im Voraus entsprechend des in Tabelle 13 gezeigten Schemas angefertigt. 
Tabelle 13: Herstellung der Polyacrylamid-Gele

\begin{tabular}{|c|c|}
\hline Trenngel $12 \%$ & Sammelgel $4 \%$ \\
\hline $7 \mathrm{ml} \mathrm{ddH} \mathrm{H}_{2} \mathrm{O}$ & $15 \mathrm{ml} \mathrm{ddH_{2 }} \mathrm{O}$ \\
\hline $5 \mathrm{ml}$ TRIS-HCl (1,5 M) & 6,3 ml TRIS-HCl (0,5 M) \\
\hline $8 \mathrm{ml}$ Acrylamid/bisacryl (30 \%) & 3,9 ml Acrylamid/bisacryl (30 \%) \\
\hline \multicolumn{2}{|c|}{$\Rightarrow 10$ Minuten im Vakuum entgasen lassen } \\
\hline $200 \mu \mathrm{l}$ SDS (10 \%) & $250 \mu \mathrm{I}$ SDS (10\%) \\
\hline $100 \mu \mathrm{l}$ APS (10\%) & $125 \mu \mathrm{l}$ APS (10\%) \\
\hline $15 \mu \mathrm{l}$ TEMED & $25 \mu \mathrm{I}$ TEMED \\
\hline
\end{tabular}

Vorbereitend wurden Glasplatten mit $\mathrm{ddH}_{2} \mathrm{O}$ und Ethanol gesäubert und in ein Haltesystem eingespannt. Zunächst wurde das 12-prozentige Trenngel zwischen die Platten gegeben und mit Butanol zum Glätten der Geloberfläche bedeckt. Nach der Polymerisierung des Trenngels und der Entfernung des Butanolfilms wurde das 4-prozentige Sammelgel auf das Trenngel gegossen und ein Probenkamm in das obere Gel eingesetzt. Nach einigen Stunden wurde der Probenkamm entfernt. Anschließend wurden die Proteine der Urinproben mittels der Natriumdodecylsulfat-Polyacrylamid-Gelelektrophorese (Sodium Dodecyl Sulfate Polyacrylamide Gel Electrophoresis = SDS-PAGE) nach ihren Molekulargewichten aufgetrennt. Jeweils zwei Polyacrylamid-Gele wurden in einer mit 1x-Elektrophoresepuffer gefüllten Elektrophorese-Kammer platziert. In die erste Geltasche wurden $4 \mu \mathrm{l}$ des Proteinmarkers Precision Plus Protein Standard Kaleidoscope (Größenstandard) und in die zweite Tasche $20 \mu$ l einer Positiv-Kontrolle (TK173-Zellen: Human renal fibroblast cell line) pipettiert (Informationen zu TK173Zellen: Siehe Dihazi et al. 2013). Die Urinproben wurden in die restlichen sechs Taschen gefüllt. Anschließend wurde die Gelelektrophorese bei 200 Volt für etwa 1,5 Stunden durchgeführt.

Bei der Gelelektrophorese denaturiert das im Elektrophoresepuffer und PolyacrylamidGel enthaltene Detergenz SDS die Proteine und bildet mit den Untereinheiten der Proteine negativ geladene SDS-Protein-Komplexe aus. Die Masse des komplexierten SDS ist dabei annähernd proportional zur Proteinmenge. Die SDS-Protein-Komplexe werden im elektrischen Feld entsprechend ihrer Größe aufgetrennt, wobei kleinere Proteinkomplexe schneller durch die Polyacrylamid-Matrix wandern als größere (Abcam). 


\subsubsection{Blotting}

Das Blotting wurde mit Hilfe der sogenannten Tank-Blot-Methode durchgeführt. Hierbei wurden die Proteinbanden im elektrischen Feld vom Polyacrylamid-Gel auf eine Nitrocellulose-Membran übertragen. Vorbereitend wurde Filterpapier und die Membran auf die Größe des Gels zugeschnitten und für einige Minuten in 1x-Transferpuffer getränkt. Das Polyacrylamid-Gel wurde mit Fließ, Filterpapier und der NitrocelluloseMembran in der in Abbildung 5 dargestellten Reihenfolge in einer Blocking-Kassette platziert (Soundy und Harvey 2005).

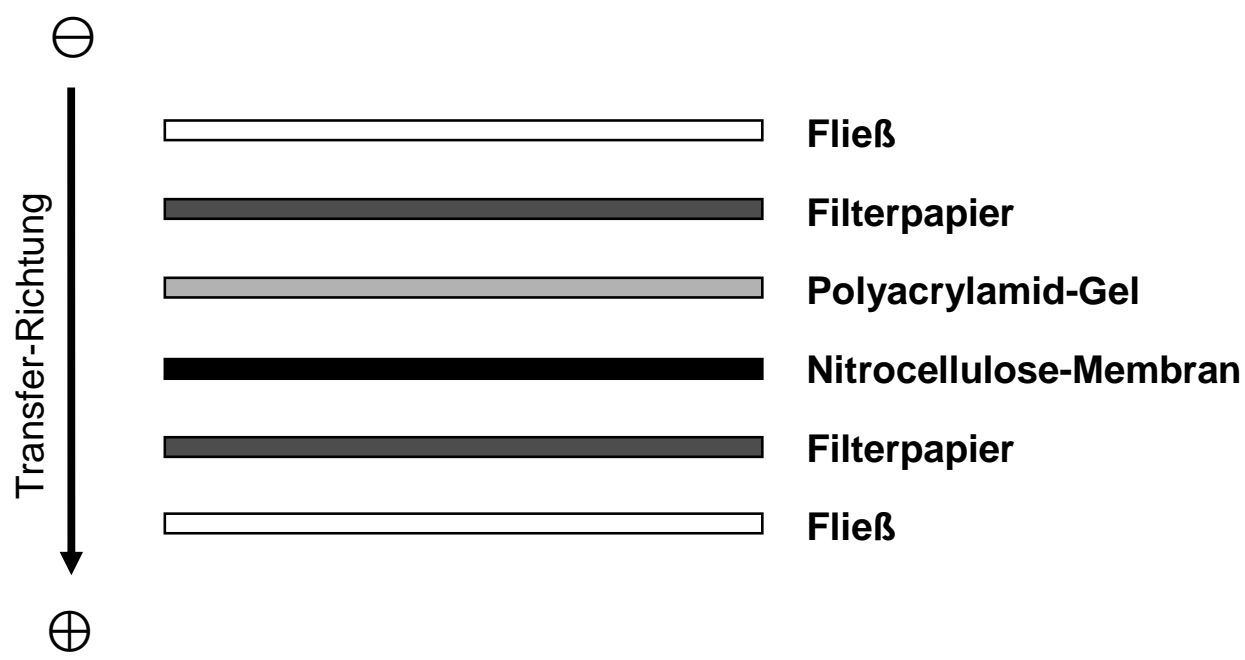

\section{Abbildung 5: Transfereinheit für das Blotting}

Es handelt sich um eine Ansicht von oben auf die Blocking-Kassette. Die Spannung wurde senkrecht zur Laufrichtung der Gele angelegt, sodass die negativ geladenen Proteine in Richtung der positiv geladenen Elektrode wanderten.

Quelle: Modifiziert nach Soundy und Harvey 2005

Jeweils zwei Blocking-Kassetten wurden in ein vertikales Blotting-Modul eingebracht und zusammen mit einem Eisblock in einem mit 1x-Transferpuffer gefüllten Puffertank platziert. Die Membran befand sich dabei zwischen dem Polyacrylamid-Gel und der positiven Elektrode, sodass es durch Anlegen einer elektrischen Spannung (100 Volt für 75 Minuten) zu einem Transfer der negativ geladenen Proteine vom Gel auf die Membran kam. Das ursprüngliche Muster der Proteinbanden blieb dabei erhalten (Soundy und Harvey 2005). Nach dem Blotting wurden die Gele entsorgt und die Nitrocellulose-Membranen getrocknet. Um die Proteinbanden sichtbar zu machen, erfolgte eine Färbung der Membranen mit Ponceau S Solution, eine Fixation mit 5prozentiger Essigsäure und anschließend ein Waschschritt mit 1x-Waschpuffer. 
Anschließend wurden die Membranen für zwei Stunden in Magermilchpuffer bei $37^{\circ} \mathrm{C}$ unter stetigem Schwenken inkubiert, um unspezifische Antikörper-Bindungen an die freien Bindungsstellen der Nitrocellulose-Membran zu verhindern (Mahmood und Yang 2012).

\subsubsection{Immunodetektion}

Mit Hilfe der Immunodetektion wurden die ER-Stress-Proteine auf der Membran identifiziert. Die verwendeten Antikörper sind in Tabelle 9 (Vgl. Kapitel 2.3.2) aufgelistet. Im ersten Schritt wurden mono- oder polyklonale Primärantikörper in einer 1:1000-Verdünnung ( $6 \mu \mathrm{l}$ Antikörper und $6 \mathrm{ml}$ Magermilchpuffer) auf die Membran pipettiert. Dabei kam es zu einer Bindung der Antikörper an die immobilisierten Proteine auf der Nitrocellulose-Membran. Nach einer einstündigen Inkubation der Membran mit dem Primärantikörper bei $37^{\circ} \mathrm{C}$ wurde die Inkubation bei $4{ }^{\circ} \mathrm{C}$ über Nacht fortgesetzt. Am darauffolgenden Tag wurde der Blot insgesamt drei Mal für jeweils zehn Minuten bei $37^{\circ} \mathrm{C}$ unter Schwenken in $1 \mathrm{x}$-Waschpuffer gewaschen. Im zweiten Schritt wurden Sekundärantikörper, die gegen die jeweilige Spezies des primären Antikörpers gerichtet waren, in einer 1:2000-Verdünnung (3 $\mu$ l Antikörper und $6 \mathrm{ml}$ Magermilchpuffer) hinzugegeben und die Membranen für zwei Stunden bei $37{ }^{\circ} \mathrm{C}$ inkubiert. Um eine Signalabschwächung zu vermeiden, wurden die Blots mithilfe von Aluminiumfolie vor Licht geschützt. Die sekundären Antikörper waren entweder mit dem Fluoreszenzfarbstoff Alexa Fluor oder dem Enzym Horseradish peroxidase (HRP) konjugiert. HRP katalysiert nach Hinzugabe einer Substratlösung (LumiGLO Reagent $A$ und Peroxidase Reagent $B$ ) eine enzymatische Farbreaktion. Aufgrund der ähnlichen Molekulargewichte der ER-Stress-Proteine ERp57 (57 kDa) und Crt (48 kDa) wurden zur Detektion mit der Fluoreszenz- und Chemilumineszenzmethode zwei verschiedene Nachweisverfahren verwendet. In Vorversuchen war auffällig, dass bei der Verwendung von lediglich einer Methode keine eindeutige Zuordnung der Banden zu einem der beiden Proteine möglich war.

Nach der zweistündigen Inkubation wurden die Membranen drei Mal mit Waschpuffer gewaschen. Die beschriebenen Schritte wurden pro Blot für alle drei ER-StressProteine durchgeführt. Das Scannen der Membranen erfolgte mit dem Fuji FLA 5100 Scanner (Fluoreszenz) und dem ChemiDoc MP System (Chemilumineszenz). Die mithilfe der Chemilumineszenzmethode erstellten Blots wurden anschließend mit dem Programm Image Lab Software 5.0 (Bio-Rad Laboratories GmbH, Hercules, USA) bearbeitet. 


\subsubsection{ELISA}

Das ELISA wurde als immunologische Methode zur Quantifizierung von Proteinmengen verwendet (Gey 2008). Im Folgenden wird das allgemeine Prinzip dieser Methode erläutert. In dieser Arbeit wurden die in Tabelle 7 (Vgl. Kapitel 2.3.2) aufgeführten ELISA-Kits verwendet. Die Versuchsprotokolle der einzelnen Kits sind auf den Herstellerseiten im Internet zu finden.

Vor der Durchführung eines ELISAs wurden alle benötigten Reagenzien (Waschpuffer, Detektorantikörper, HRP-Konjugate, Protein-Standards) durch Verdünnungsschritte und Vermischungen einzelner Reagenzien vorbereitet. Ausgehend von einem Proteinstandard (S1) mit der höchsten Proteinkonzentration wurde eine Verdünnungsreihe (S1 bis $S 6$ beziehungsweise S7) erstellt. In Abbildung 6 ist dieser Schritt beispielhaft für GRP78 dargestellt.

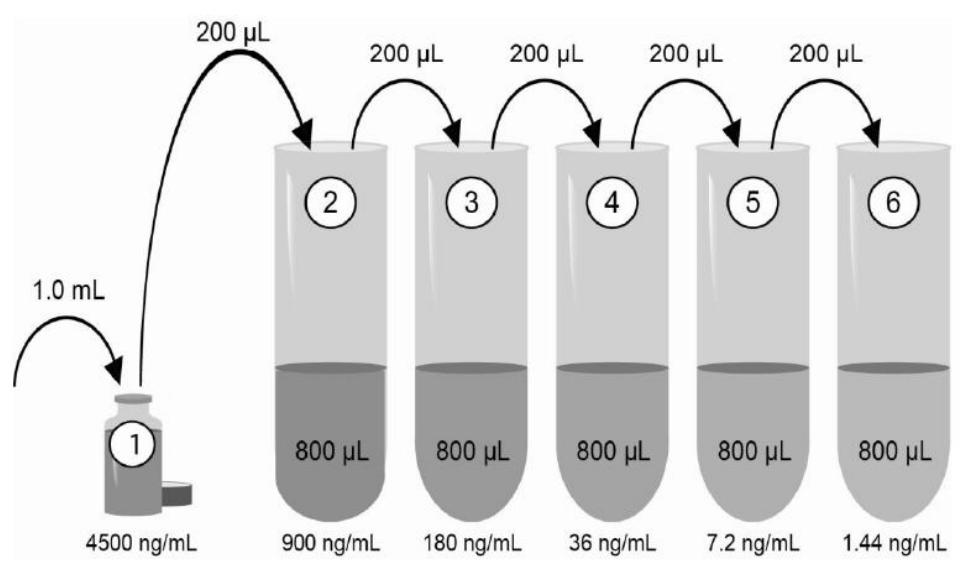

\section{Abbildung 6: Herstellung einer Verdünnungsreihe (GRP78-ELISA-Kit)}

Jeweils $800 \mu$ l eines speziellen Assay-Puffers wurde in durchnummerierte Gefäße (S2 bis S6) pipettiert. Im ersten Eppendorf-Gefäß (S1) befand sich mit $4500 \mathrm{ng} / \mathrm{ml}$ die höchste GRP78Konzentration. Aus diesem Gefäß wurden $200 \mu \mathrm{l}$ in das jeweils darauffolgende Gefäß (S2) überführt usw., sodass sich die GRP78-Konzentration in jedem Schritt um den Faktor fünf reduzierte.

Quelle: Die Verwendung erfolgt mit freundlicher Genehmigung von Enzo Life Sciences 2016.

Jedes Kit enthielt des Weiteren eine 96-well-Mikrotiterplatte (8 x 12 Vertiefungen). Der Assay-Puffer $\left(\mathrm{B}_{0}, 0 \mathrm{ng} / \mathrm{ml}\right)$ und die Proteinstandards (S1 bis S6 bzw. S7) wurden als Doppelbestimmung in insgesamt 14 beziehungsweise 16 Vertiefungen der Platte pipettiert. Zwei Vertiefungen blieben gegebenenfalls als Leerwert frei. 
Die restlichen 80 Vertiefungen wurden für bis zu 20 native Urin- oder Serumproben (jeweils V1 und V2 in Doppelbestimmung) verwendet. Da geringe Proteinkonzentrationen erwartet wurden, war eine Vorverdünnung der Proben nicht notwendig. Je nach benutztem ELISA-Kit wurden im weiteren Verlauf Antikörpersubstrate und -konjugate, Waschpuffer, Substrat- und Stopplösungen in unterschiedlicher Reihenfolge hinzu pipettiert.

Mit dem Sandwich-ELISA (ERp57- und Crt-ELISA-Kit) und dem kompetitiven ELISA (GRP78-ELISA-Kit) wurden zwei unterschiedliche Methoden benutzt: Im SandwichELISA kam es im ersten Schritt zu einer Bindung der ER-Stress-Proteine aus den Proben an die sogenannten Fängerantikörper, die an der Mikrotiterplatte immobilisiert waren (Richter 2003). Bei der Durchführung des Crt-ELISA folgte dann eine Inkubation mit primären, unmarkierten Detektorantikörpern, die an das immobilisierte Crt binden konnten. Das entstandene „Sandwich“ bestand folglich aus dem Fängerantikörper auf der Mikrotiterplatte, Crt und dem Detektorantikörper. Die primären Detektorantikörper wurden im Anschluss mit sekundären HRP-gekoppelten Antikörpern markiert (Aviscera Bioscience). Im ERp57-ELISA wurde ERp57 nach Bindung an die Fängerantikörper durch Biotin-gekoppelte Primärantikörper markiert. Anschließend wurde das Enzym HRP, das an Avidin konjugiert war, hinzugegeben (MyBioSource). Biotin ist ein wasserlösliches Vitamin, das mit hoher Affinität an die Untereinheiten des tetrameren Proteins Avidin bindet (Crowther 2001). Das Avidin-Biotin-System stell somit die Verbindung zwischen dem Sandwich aus Fängerantikörper, ERp57, Biotingekoppeltem Primärantikörper und dem Enzym HRP als Indikatorsystem her (Richter 2003). Im Crt- und ERp57-ELISA wurden die Mikrotiterplatten zwischen den einzelnen Schritten gewaschen, um ungebundene Substanzen zu entfernen. Um eine Quantifizierung der Proteinmengen zu ermöglichen, wurde als Substrat des Enzyms HRP eine Tetramethylbenzidin (TMB)-Substrat-Lösung in alle Vertiefungen der Mikrotiterplatte pipettiert. Durch eine enzymatisch katalysierte Reaktion kam es zu einem Farbwechsel der Proben von gelb nach blau, wobei die Farbintensitäten proportional zur Enzymaktivität beziehungsweise den Proteinkonzentrationen der Proben waren. Nach Hinzugabe einer Stopplösung nahmen die Proben eine gelbe Farbe an. Schließlich wurden die optischen Dichten der Proben mit einem Plattenleser bei einer Wellenlänge von $450 \mathrm{~nm}$ bestimmt (Aviscera Bioscience, MyBioSource).

Beim GRP78-ELISA wurden die Proteinstandards, Patientenproben und die primären GRP78-Antikörper in die Vertiefungen der Mikrotiterplatte pipettiert. Die Platte war mit polyklonalen Anti-Schaf-Antikörpern beschichtet. 
Im Folgenden kam es zu einer Bindung des GRP78s aus den Patientenproben an die Anti-Schaf-Antikörper auf der Mikrotiterplatte sowie an die primären GRP78-Antikörper. Im nächsten Schritt wurden die restlichen freien Bindungsstellen der primären GRP78Antikörper durch die Hinzugabe eines blauen Konjugates, das aus an HRP gekoppeltem GRP78 bestand, besetzt. Nach mehrmaligen Waschvorgängen der Platte mit Waschpuffer wurden nach Hinzugabe einer TMB-Substrat- und Stopplösung die optischen Dichten der Proben bestimmt.

Die Farbintensitäten beziehungsweise optischen Dichten waren im Gegensatz zum Crt- und ERp57-ELISA umgekehrt proportional zu den GRP78-Konzentrationen der Proben (Enzo Life Sciences 2016).

\subsection{Auswertung und Statistik (Phase 4)}

Die Western Blots wurden mit Hilfe des Programms Image $J$ (National Institutes of Health, Bethesda, USA) ausgewertet. Hierbei wurde für jede einzelne Bande die optische Dichte bestimmt und anschließend pro Blot für jedes ER-Stress-Protein das Verhältnis der optischen Dichten von V2 und V1 (V2/V1), der sogenannte Fold Change (FC), gebildet. Da alle Analysen in Doppelbestimmung durchgeführt wurden, konnte pro Patient für jedes ER-Stress-Protein der Mittelwert beider FCs berechnet werden.

Die statistische Auswertung der Daten erfolgte mit dem Programm STATISTICA (StatSoft Europe GmbH, Hamburg, Deutschland) in Kooperation mit dem Institut für medizinische Statistik in Göttingen. Um eine Normalverteilung der Daten zu überprüfen, wurden grafische Verfahren wie Histogramme, Boxplots und QuantilQuantil-Diagramme genutzt, sowie der Kolmogorov-Smirnov-Test angewendet. Dieser wies eine Normalverteilung nach, wenn der berechnete $p$-Wert $\geq 0,05$ betrug. Bei nicht normalverteilten Daten, wie beispielsweise den Proteinkonzentrationen der Patienten (Proteinurie, Albuminurie, ER-Stress-Proteinurie etc.), wurde zunächst der natürliche Logarithmus (In) berechnet, um eine log-Normalverteilung der Daten zu erhalten. Die log-normalverteilten Daten und die nicht transformierten Daten wurden anschließend mit parametrischen Verfahren ausgewertet. Um potenzielle Unterschiede einer Variablen zwischen den Zeitpunkten V1 und V2 zu analysieren, wurde der t-Test für gepaarte Stichproben verwendet. Gruppenunterschiede wurden mit Hilfe des t-Testes für ungepaarte Stichproben nachgewiesen. P-Werte von $\leq 0,05$ wurden hierbei als statistisch signifikant angesehen. 
Die Ergebnisse sind entweder als Mittelwerte und Standardabweichung (Mittelwerte \pm SD), Anzahl und Prozentzahl (n (\%)) oder Median und Interquartilsabstand (Median \pm IQR) dargestellt. Der IQR ist als Differenz zwischen dem 75- und 25-Prozent-Quartil definiert.

Die grafische Darstellung der Ergebnisse erfolgte mithilfe von Streudiagrammen und Box-Whisker-Diagrammen. In den Box-Whisker-Diagrammen sind Mediane, die 25und 75-Prozent-Quartile als Boxen, der Bereich ohne Ausreißer als Antennen (maximal das 1,5-fache des IQRs) und gegebenenfalls Ausreißer und Extremwerte markiert. Ausreißer sind Werte, die zwischen dem 1,5- und 3-fachen des IQRs liegen. Extremwerte liegen im Bereich außerhalb des 3-fachen IQRs. 


\section{Ergebnisse}

\subsection{Patienten- und Kontrollkollektiv}

Die demografischen Daten der BAT-Patienten und des Kontrollkollektivs sind vergleichend in Tabelle 14 aufgeführt.

Tabelle 14: Demografische Daten der BAT-Patienten und des Kontrollkollektivs

\begin{tabular}{|c|c|c|c|}
\hline Merkmal & BAT-Patienten & Kontrollkollektiv & $\mathbf{p}$ \\
\hline Anzahl & 29 & 17 & \\
\hline $\begin{array}{l}\text { Geschlecht } \\
\qquad \begin{array}{r}\text { weiblich } \\
\text { männlich }\end{array}\end{array}$ & $\begin{array}{l}11(38 \%) \\
18(62 \%)\end{array}$ & $\begin{array}{c}5(29 \%) \\
12(71 \%)\end{array}$ & \\
\hline Alter (Jahre) & $56,7 \pm 12,9$ & $38,9 \pm 17,7$ & $<0,0002$ \\
\hline Gewicht (kg) & $98,9 \pm 24,7$ & $76,8 \pm 16$ & $<0,01$ \\
\hline $\mathrm{BMI}\left(\mathrm{kg} / \mathrm{m}^{2}\right)$ & $33,7 \pm 6,9$ & $24 \pm 4,2$ & $<0,00002$ \\
\hline Raucher & $5(17 \%)$ & n.a. ${ }^{2}$ & \\
\hline Ehemalige Raucher & $17(59 \%)$ & n.a. ${ }^{* 2}$ & \\
\hline Z. n. renaler Denervation & $12(41 \%)$ & $0(0 \%)$ & \\
\hline $\begin{array}{l}\text { Nephropathie: } \\
\text { hypertensiv } \\
\text { diabetisch }\end{array}$ & $\begin{array}{c}8(28 \%) \\
2(7 \%)\end{array}$ & $\begin{array}{l}0(0 \%) \\
0(0 \%)\end{array}$ & \\
\hline $\begin{array}{l}\text { Komorbiditäten: } \\
\text { DM } \\
\text { KHK } \\
\text { Herzinsuffizienz } \\
\text { Hyperlipidämie }\end{array}$ & $\begin{array}{c}12(41 \%) \\
10(36 \%) \\
3(11 \%) \\
25(86 \%)\end{array}$ & $\begin{array}{l}0(0 \%) \\
0(0 \%) \\
0(0 \%) \\
0(0 \%)\end{array}$ & \\
\hline $\begin{array}{l}\text { CKD *1 } \\
\text { St. I } \\
\text { St. II } \\
\text { St. III } \\
\text { St. IV } \\
\text { St. V }\end{array}$ & $\begin{array}{c}13(45 \%) \\
0(0 \%) \\
2(15 \%) \\
7(54 \%) \\
2(15 \%) \\
2(15 \%)\end{array}$ & $\begin{array}{l}0(0 \%) \\
0(0 \%) \\
0(0 \%) \\
0(0 \%) \\
0(0 \%) \\
0(0 \%)\end{array}$ & \\
\hline
\end{tabular}

Die Daten sind als Mittelwerte \pm SD oder $n(\%)$ dargestellt.

${ }^{* 1}$ Anwendung der MDRD-Formel. *2 Daten nicht erhoben. 
Die demografischen Daten der BAT-Patienten wurden freundlicherweise von Herrn Prof. Dr. Koziolek zur Verfügung gestellt. Die Daten der Blutspender wurden im Rahmen dieser Dissertation erhoben.

Das Patientenkollektiv bestand aus 11 weiblichen und 18 männlichen Studienteilnehmern, die zu Beginn der BAT im Durchschnitt 56,7 Jahre alt waren. Das Kontrollkollektiv umfasste 12 männliche und 5 weibliche Blutspender, die im Durchschnitt 38,9 Jahre waren. Bei den BAT-Patienten lag mit einem durchschnittlichen Body-MassIndex (BMI) von 33,7 kg/m² gemäß der 2014 von der deutschen AdipositasGesellschaft veröffentlichten Leitlinie zur „Prävention und Therapie der Adipositas“ eine Adipositas Grad I vor (Leitlinie Prävention und Therapie der Adipositas 2014). Die Blutspender waren mit einem durchschnittlichen BMI von $24 \mathrm{~kg} / \mathrm{m}^{2}$ normalgewichtig. Zu Studienbeginn waren 41 Prozent der BAT-Patienten an einem DM und 45 Prozent an einer CKD erkrankt. Diese beiden Subgruppen werden einzeln in Kapitel 3.5 betrachtet. Bei zwölf Patienten war im Vorfeld der Studienteilnahme eine renale Denervierung durchgeführt worden.

In Tabelle 15 wird eine Übersicht über die Blutdruck- und Nüchternglukosewerte sowie die Proteinurie und Albuminurie der Studienteilnehmer gegeben. Es ist sowohl der Praxisblutdruck, als auch der ambulante 24-Stunden-Blutdruck (ambulatory blood pressure monitoring $=\mathrm{ABPM}$ ) angegeben. Letzterer besitzt bezüglich der kardiovaskulären Prognose eine größere Aussagekraft (Niiranen et al. 2014). Zu Studienbeginn lag der durchschnittliche Praxisblutdruck $(171,5 / 89,2 \mathrm{mmHg})$ und auch der ABPM $(148,2 / 81,8 \mathrm{mmHg})$ trotz der Einnahme von im Durchschnitt 6,8 Antihypertensiva oberhalb des empfohlenen Zielblutdrucks von $140 \mathrm{mmHg}$ systolisch. Durch die BAT kam es zu einer signifikanten Reduktion des Praxisblutdrucks, wohingegen sich der Blutdruck im ABPM nicht signifikant veränderte. Neben der signifikanten Reduktion der Nüchternglukosewerte der BAT-Patienten war zudem eine signifikante Abnahme der Proteinurie um 39,5 Prozent und Albuminurie um 29,3 Prozent nachweisbar. Der mediane Protein/Kreatinin-Quotient nahm von 242,3 mg/g Kreatinin um 43,7 Prozent auf $136,5 \mathrm{mg} / \mathrm{g}$ Kreatinin ab $(p=0,24)$. Der mediane Albumin/Kreatinin-Quotient wurde von $101 \mathrm{mg} / \mathrm{g}$ Kreatinin um 40,5 Prozent auf 60,1 $\mathrm{mg} / \mathrm{g}$ Kreatinin reduziert $(\mathrm{p}=0,18)$. Zum Zeitpunkt V1 wiesen 58,6 Prozent der Patienten eine Mikroalbuminurie $(n=9)$ oder Makroalbuminurie $(n=8)$ auf. Zum Zeitpunkt V2 war bei lediglich 15 Patienten eine pathologische Eiweißausscheidung nachweisbar $(51,7 \%, \mathrm{n}=15)$. 
Tabelle 15: Klinische Parameter der BAT-Patienten

\begin{tabular}{|l|c|c|c|}
\hline Parameter & V1 & V2 & p \\
\hline Anzahl der Antihypertensiva & $6,8 \pm 1,5$ & $6,2 \pm 1,7$ & 0,08 \\
\hline $\begin{array}{c}\text { Praxisblutdruck (mmHg) } \\
\text { systolisch } \\
\text { diastolisch }\end{array}$ & $171,5 \pm 26,5$ & $154,4 \pm 28,7$ & $<0,01$ \\
& $89,2 \pm 18,3$ & $82,3 \pm 192$ & $<0,01$ \\
\hline ABPM (mmHg) & & & \\
systolisch & $148,2 \pm 17,1$ & $141,4 \pm 26,5$ & 0,07 \\
diastolisch & $81,8 \pm 13,1$ & $80,9 \pm 18$ & 0,77 \\
\hline Nüchternglukose (mg/dl) & $121,9 \pm 36,2$ & $107,6 \pm 29$ & $<0,002$ \\
\hline Proteinurie (mg/l) & $231(102-818)$ & $139,7(89-335)$ & $<0,01$ \\
Protein/Kreatinin (mg/g Kreatinin) & $242,3(99-598)$ & $136,5(90,7-274,3)$ & 0,24 \\
\hline Albuminurie (mg/l) & $101(44,2-435)$ & $71,4(13,3-171)$ & $<0,01$ \\
Albumin/Kreatinin (mg/g Kreatinin) $* 1$ & $101(33,2-46,5)$ & $60,1(23,3-134,6)$ & 0,18 \\
keine Albuminurie *2 & $11(39 \%)$ & $13(47 \%)$ & \\
Mikroalbuminurie *3 & $9(32 \%)$ & $9(32 \%)$ & \\
Makroalbuminurie *4 & $8(29 \%)$ & $6(21 \%)$ & \\
\hline
\end{tabular}

Die Daten sind als Mittelwerte \pm SD, Mediane (ICR) oder $n(\%)$ dargestellt.

${ }^{* 1} \mathrm{n}=28$ (Daten bei einem Patienten nicht erhoben), ${ }^{* 2}<30 \mathrm{mg} / \mathrm{g}$ Kreatinin

${ }^{* 3} 30-300 \mathrm{mg} / \mathrm{g}$ Kreatinin, ${ }^{* 4}>300 \mathrm{mg} / \mathrm{g}$ Kreatinin

Tabelle 16: Responder und Non-Responder der BAT

\begin{tabular}{|c|c|c|}
\hline & $\begin{array}{c}\text { Praxismessung } \\
\text { Responder }\end{array}$ & $\begin{array}{c}\text { Praxismessung } \\
\text { Non-Responder }\end{array}$ \\
\hline $\begin{array}{c}\text { ABPM } \\
\text { Responder }\end{array}$ & $3(11 \%)$ & $5(17 \%)$ \\
\hline $\begin{array}{c}\text { ABPM } \\
\text { Non-Responder }\end{array}$ & $16(55 \%)$ & $5(17 \%)$ \\
\hline
\end{tabular}

Bei 24 Studienteilnehmern (83 \%) reduzierte sich der systolische Blutdruck entweder um $\geq 10 \mathrm{mmHg}$ in der Praxismessung $(n=16), \mathrm{um} \geq 5 \mathrm{mmHg}$ in der ABPM $(n=5)$ oder in beiden Messungen $(n=3)$ um den jeweiligen Wert. Diese Patienten können als sogenannte responder bezeichnet werden (Mahfoud et al. 2013; Wallbach et al. 2016). Der Begriff wird in der Literatur jedoch nicht einheitlich verwendet (Paivanas et al. 2015). Die Responder- und Non-Responderraten der BAT-Patienten sind in Tabelle 16 dargestellt. 
In Tabelle 17 sind die Korrelationen zwischen dem arteriellen Blutdruck und der Proteinurie beziehungsweise Albuminurie der BAT-Patienten aufgeführt. Es wurde jeweils die Differenz des systolischen und diastolischen Blutdrucks und die Differenz der Gesamt-Proteinurie und Albuminurie zwischen den Zeitpunkten V2 und V1 berechnet und miteinander korreliert (Pearson-Korrelationskoeffizient $=r$ ). Es zeigte sich eine signifikante positive Korrelation zwischen der Reduktion des systolischen und diastolischen Praxisblutdrucks und der Abnahme der Gesamt-Proteinurie. Auch die Abnahme der Albuminurie korrelierte signifikant mit beiden Parametern. Die Blutdruckdifferenz im ABPM korrelierte hingegen nicht signifikant mit der Abnahme der Proteinurie beziehungsweise Albuminurie.

Tabelle 17: Korrelation zwischen arteriellem Blutdruck und Proteinurie

\begin{tabular}{|l|c|c|}
\hline Korrelation & $\mathbf{r}$ & $\mathbf{p}$ \\
\hline Praxisblutdruckmessung: & & \\
$\Delta$ RR systolisch $(\mathrm{mmHg})-\Delta$ Gesamt-Protein $(\mathrm{mg} / \mathrm{l})$ & 0,53 & $<0,01$ \\
$\Delta$ RR diastolisch $(\mathrm{mmHg})-\Delta$ Gesamt-Protein $(\mathrm{mg} / \mathrm{l})$ & 0,52 & $<0,01$ \\
$\Delta$ RR systolisch $(\mathrm{mmHg})-\Delta$ Albumin $(\mathrm{mg} / \mathrm{l})$ & 0,57 & $<0,01$ \\
$\Delta$ RR diastolisch $(\mathrm{mmHg})-\Delta$ Albumin $(\mathrm{mg} / \mathrm{l})$ & 0,55 & $<0,01$ \\
\hline ABPM: & & \\
$\Delta$ RR systolisch $(\mathrm{mmHg})-\Delta$ Gesamt-Protein $(\mathrm{mg} / \mathrm{l})$ & 0,32 & 0,12 \\
$\Delta$ RR diastolisch $(\mathrm{mmHg})-\Delta$ Gesamt-Protein $(\mathrm{mg} / \mathrm{l})$ & 0,28 & 0,18 \\
$\Delta$ RR systolisch $(\mathrm{mmHg})-\Delta$ Albumin $(\mathrm{mg} / \mathrm{l})$ & 0,25 & 0,22 \\
$\Delta$ RR diastolisch $(\mathrm{mmHg})-\Delta$ Albumin $(\mathrm{mg} / \mathrm{l})$ & 0,2 & 0,33 \\
\hline
\end{tabular}

Die beiden Streudiagramme in Abbildung 7 veranschaulichen den Zusammenhang zwischen Praxisblutdruck und der Gesamt-Proteinurie. Je höher die Abnahme des Praxisblutdrucks war, desto stärker wurde die Proteinausscheidung der BAT-Patienten reduziert. 

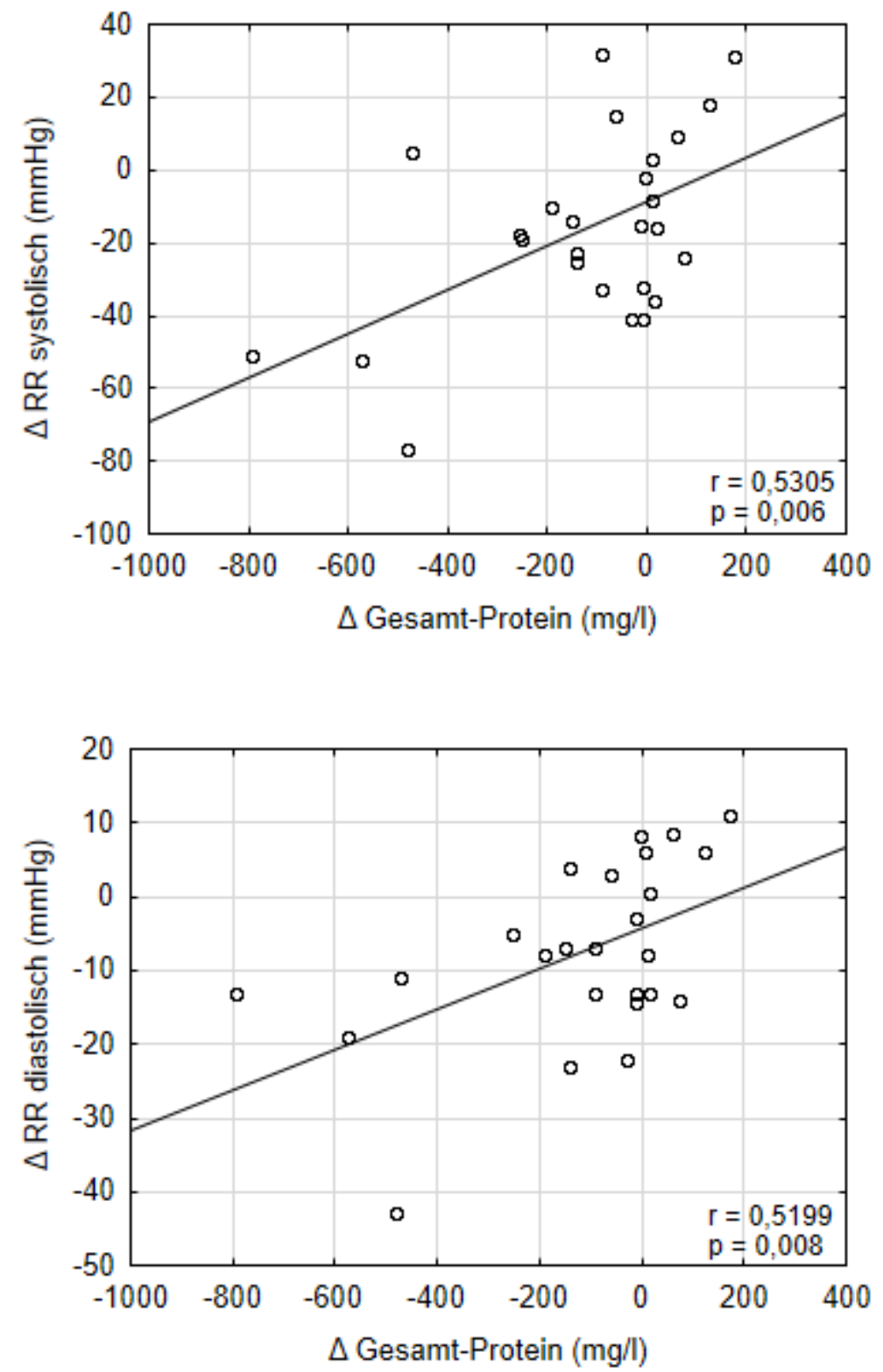

Abbildung 7: Korrelation zwischen $\Delta \mathrm{RR}$ (Praxisblutdruck) und $\Delta$ GesamtProteinurie 


\subsection{ER-Stress-Proteine im Urin}

In Tabelle 18 sind die ER-Stress-Protein-Konzentrationen im Urin der BAT-Patienten und des Kontrollkollektivs vergleichend aufgeführt. Die detaillierte Auswertung der einzelnen ER-Stress-Proteine erfolgt in Kapitel 3.2.1 bis 3.2.3.

Tabelle 18: ER-Stress-Proteinurie (ELISA-Ergebnisse)

\begin{tabular}{|c|c|c|c|c|}
\hline \multirow{2}{*}{$\begin{array}{l}\text { ER-Stress- } \\
\text { Protein * }\end{array}$} & \multicolumn{3}{|c|}{ BAT-Patienten $(n=29)$} & \multirow{2}{*}{$\begin{array}{l}\text { Kontrollkollektiv } \\
\qquad(n=17)\end{array}$} \\
\hline & V1 & V2 & p & \\
\hline ERp57 & $0,01(0,0-0,38)$ & $0,0(0,0-0,28)$ & 0,21 & $0,18(0-1,43)$ \\
\hline Crt & $0,47(0,01-6,17)$ & $0,68(0,04-3,9)$ & 0,53 & $16,55(11,6-30,27)$ \\
\hline GRP78 & $0,94(0,21-5,36)$ & $0,36(0,11-2,58)$ & 0,44 & $0,94(0,07-28,05)$ \\
\hline
\end{tabular}

Die Daten sind als Mediane (IQR) dargestellt.

* Einheit der ER-Stress-Proteine: $\mathrm{ng} / \mathrm{ml}$

Tabelle 19 gibt eine Übersicht über die ER-Stress-Proteinurie in Bezug auf die Proteinbeziehungsweise Kreatininausscheidung der BAT-Patienten.

Tabelle 19: Normierung der ER-Stress-Proteinurie

\begin{tabular}{|l|cc|c|}
\hline ER-Stress-Protein * & \multicolumn{1}{|c|}{ V1 } & V2 & p \\
\hline ERp57/Protein & $0,03(0,0-1,55)$ & $0,0(0,0-4,06)$ & 0,05 \\
\hline ERp57/Kreatinin & $0,01(0,0-0,53)$ & $0,0(0,0-0,57)$ & 0,12 \\
\hline Crt/Protein & $1,22(0,04-3,9)$ & $2,99(0,17-17,3)$ & 0,06 \\
\hline Crt/Kreatinin & $0,58(0,01-4,56)$ & $1,2(0,03-4,92)$ & 0,33 \\
\hline GRP78/Protein & $1,74(0,47-12,22)$ & $3,18(0,33-23,99)$ & 0,48 \\
\hline GRP78/Kreatinin & $0,97(0,28-2,65)$ & $0,7(0,17-2,16)$ & 0,99 \\
\hline
\end{tabular}

Die Daten sind als Mediane (IQR) dargestellt.

* Einheiten: ER-Stress-Protein/Protein: $\mu \mathrm{g} / \mathrm{g}$ Protein

ER-Stress-Protein/Kreatinin: $\mu g / g$ Kreatinin 
Durch die sechsmonatige BAT kam es zu keiner signifikanten Veränderung der ERStress-Protein-Konzentrationen beziehungsweise der auf die Protein- und Kreatininexkretion normierten ER-Stress-Protein-Level. Beim Kontrollkollektiv war mit einer medianen Crt-Konzentration von $16,55 \mathrm{ng} / \mathrm{ml}$ das höchste ER-Stress-Protein-Level im Urin aller untersuchten Personen nachweisbar. Dieses unterschied sich signifikant von den medianen Crt-Konzentrationen der BAT-Patienten ( $\left.\mathrm{p}_{\mathrm{v} 1 / 2}:<0,00005\right)$.

Die medianen ERp57- und GRP78-Konzentrationen des Kontrollkollektivs unterschieden sich teilweise signifikant von denen der BAT-Patienten (ERp57: $p_{V_{1}}=0,04$; $p_{\mathrm{V} 2}=0,15$; GRP78: $\left.p_{\mathrm{V} 1}=0,12, p_{\mathrm{V} 2}=0,04\right)$. Beim Vergleich mit den Serum-Ergebnissen (Vergleich Kapitel 3.3) war eine geringere mediane ERp57-Konzentration (V1 ${ }_{\text {Serum: }}$ 4,37 $\mathrm{ng} / \mathrm{ml}$, V2 ${ }_{\text {Serum }}: 8,64 \mathrm{ng} / \mathrm{ml}$ ) und vor allem GRP78-Konzentration (V1 ${ }_{\text {Serum }}$ : 1119,86 $\mathrm{ng} / \mathrm{ml}$, V2 ${ }_{\text {Serum: }}$ 1432,97 ng/ml) im Urin der BAT-Patienten auffällig.

In Tabelle 20 sind die FCs der untersuchten ER-Stress-Proteine aufgelistet. Zur Berechnung der FCs wurden die medianen ER-Stress-Protein-Konzentrationen zum Zeitpunkt V1 und V2 verwendet. Die mediane ERp57-Ausscheidung veränderte sich unter der BAT nicht $(F C=1)$, Crt wurde um etwa das 1,4-Fache heraufreguliert ( $F C=$ $1,44)$ und GRP78 um etwa 60 Prozent herabreguliert $(F C=0,38)$.

Tabelle 20: FCs der ER-Stress-Proteine (Urin)

\begin{tabular}{|l|c|}
\hline ER-Stress-Proteine & FC * \\
\hline ERp57 & 1 \\
ERp57/Protein & 1 \\
ERp57/Kreatinin & 1 \\
\hline Crt & 1,44 \\
Crt/Protein & 2,45 \\
Crt/Kreatinin & 2,09 \\
\hline GRP78 & 0,38 \\
GRP78/Protein & 1,82 \\
GRP78/Kreatinin & 0,72 \\
\hline
\end{tabular}

${ }^{*} \mathrm{FC}=\mathrm{V} 2 / \mathrm{V} 1$

$\Rightarrow F C>1$ : Heraufregulation des jeweiligen Proteins

$\Rightarrow F C<1$ : Herabregulation des jeweiligen Proteins 


\subsubsection{ERp57 im Urin}

In Abbildung 8 sind die im Urin gemessenen ERp57-Konzentrationen der BATPatienten und des Kontrollkollektivs dargestellt. Das Kontrollkollektiv ist in den folgenden Abbildungen mit „K“ gekennzeichnet. Abbildung 9 und 10 veranschaulichen die ERp57/Protein- und ERp57/Kreatinin-Quotienten der BAT-Patienten.

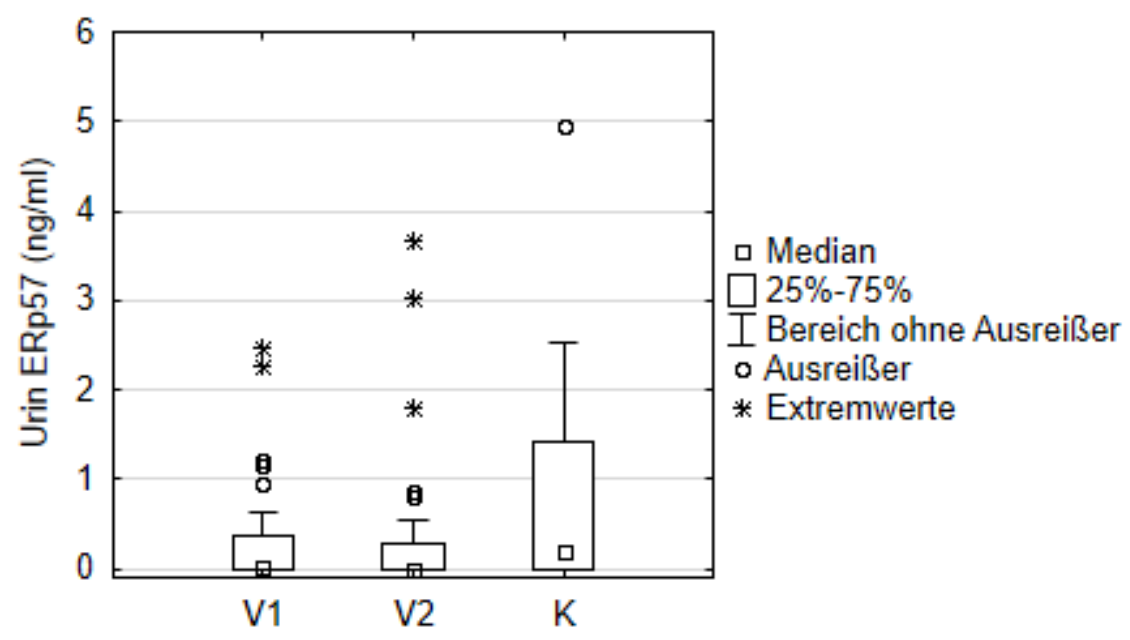

Abbildung 8: ERp57-Konzentrationen im Urin

Bei über 50 Prozent der Studienteilnehmer war im Urin kein ERp57 messbar. Die durschnittlichen ERp57-Level waren mit 0,42 ng/ml (V1 und V2) höher als die medianen ERp57-Level (V1: 0,01 ng/ml, V2: $0 \mathrm{ng} / \mathrm{ml}$ ), beeinflusst von zahlreichen Ausreißern und Extremwerten. Die höchsten ERp57-Konzentrationen der BAT-Patienten wurden bei Patient 15 nachgewiesen ( $\mathrm{V} 1_{\max }: 2,46 \mathrm{ng} / \mathrm{ml}, \mathrm{V} 2_{\max }: 3,65 \mathrm{ng} / \mathrm{ml}$ ). Diese Werte lagen noch unterhalb der maximalen Crt-Level (V1 $\max : 12,14 \mathrm{ng} / \mathrm{ml}, \mathrm{V} 2_{\max }$ : 94,64 $\mathrm{ng} / \mathrm{ml}$ ) und GRP78-Level (V1 $1_{\text {max }}: 22,85 \mathrm{ng} / \mathrm{ml}, \mathrm{V} 2_{\max }: 25,41 \mathrm{ng} / \mathrm{ml}$ ). Bei den Blutspendern betrug die mediane ERp57-Konzentration $0,18 \mathrm{ng} / \mathrm{ml}$, die somit geringfügig höher als die der BAT-Patienten war. Die maximale ERp57-Konzentration ( $\mathrm{V}_{\text {max }}$ : 4,9 $\mathrm{ng} / \mathrm{ml}$ ) wurde bei einer Person des Kontrollkollektivs gemessen. 


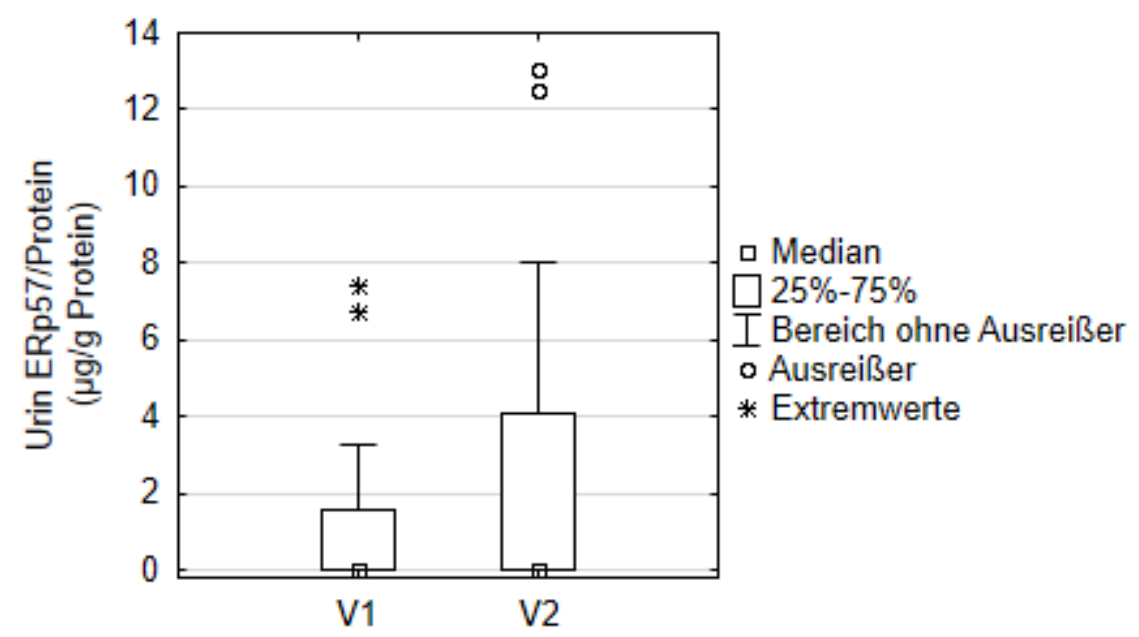

Abbildung 9: ERp57/Protein-Quotienten

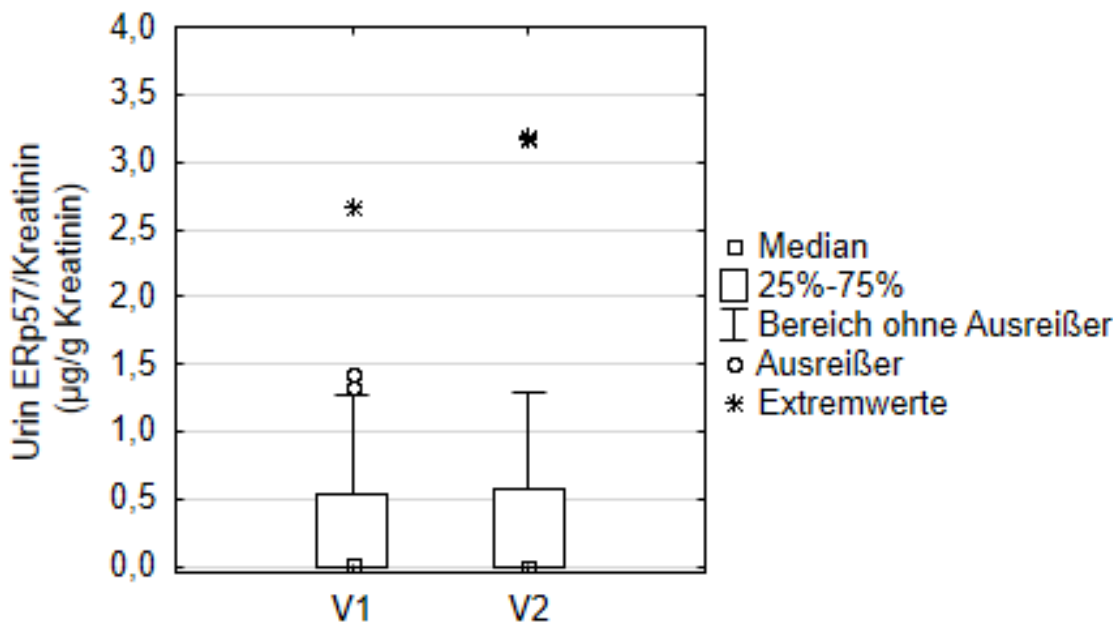

Abbildung 10: ERp57/Kreatinin-Quotienten

Die medianen ERp57/Protein- und ERp57/Kreatinin-Quotienten der BAT-Patienten veränderten sich unter der BAT nicht signifikant. Der durchschnittliche ERp57/ProteinQuotient stieg um fast 90 Prozent (V1: $1,57 \mathrm{ng} / \mathrm{ml}$, V2: 2,95 ng/ml) und der ERp57/Kreatinin-Quotient um 72 Prozent (V1: 0,35 ng/ml, V2: 0,6 ng/ml) an. 


\subsubsection{Crt im Urin}

In den Box-Whisker-Diagrammen in Abbildung 11 bis 13 sind die im Urin gemessenen Crt-Level der BAT-Patienten und des Kontrollkollektivs sowie die Crt/Protein- und Crt/Kreatinin-Quotienten der BAT-Patienten dargestellt.

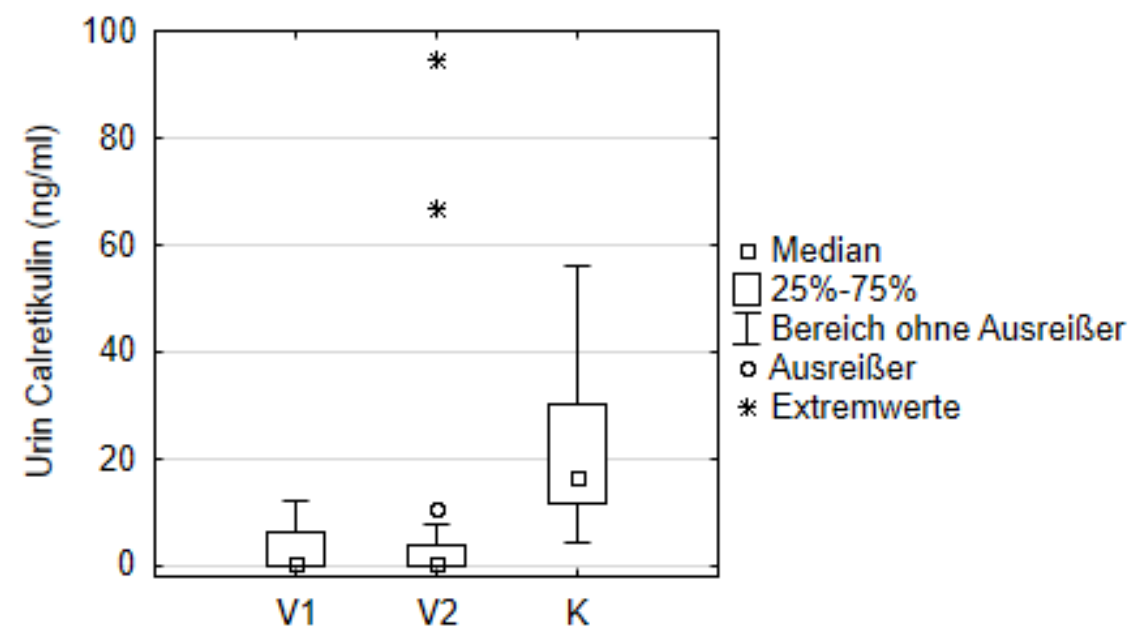

Abbildung 11: Crt-Konzentrationen im Urin

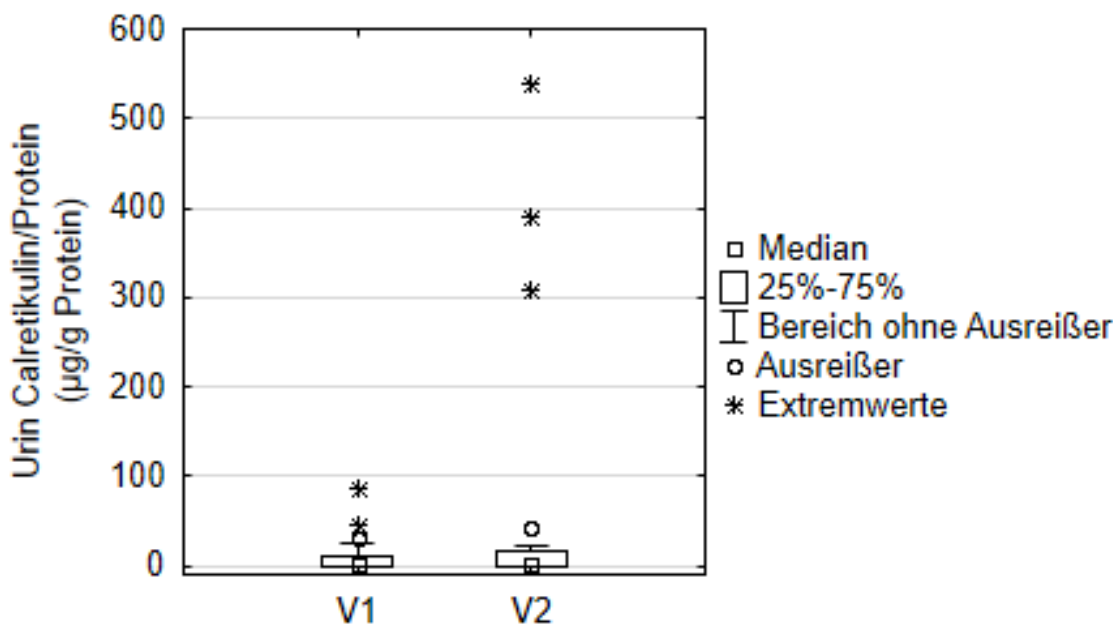

Abbildung 12: Crt/Protein-Quotienten 


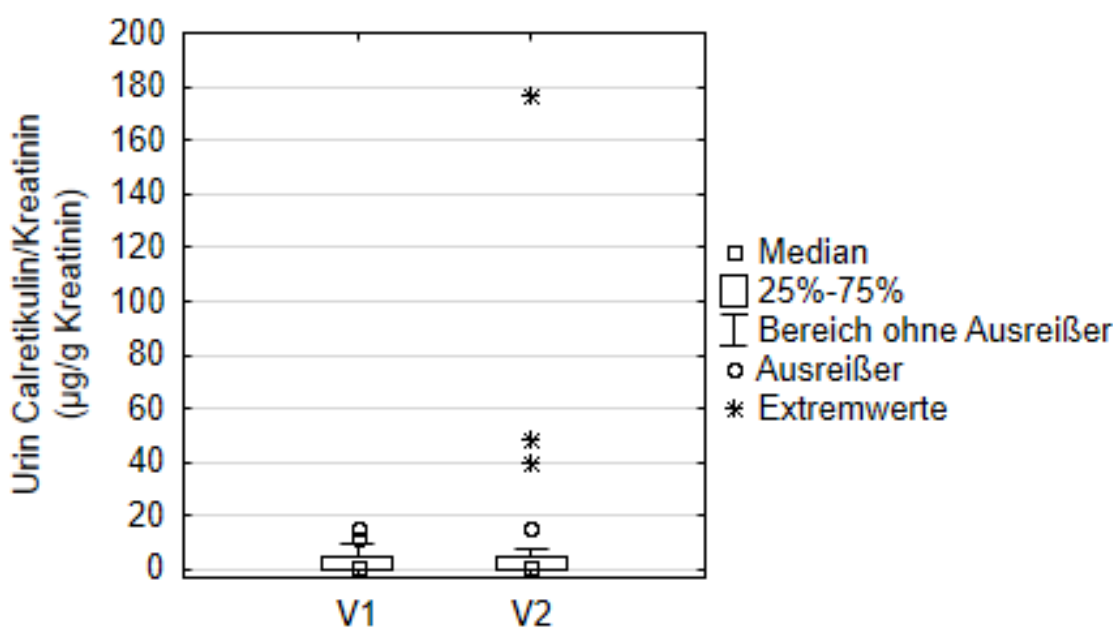

Abbildung 13: Crt/Kreatinin-Quotienten

Die mediane Crt-Konzentration der Studienteilnehmer ist von $0,47 \mathrm{ng} / \mathrm{ml}$ um etwa 40 Prozent auf $0,68 \mathrm{ng} / \mathrm{ml}$ angestiegen $(\mathrm{p}=0,53$ ). Maximalwerte waren bei Patient 12 (V1 $\left.1_{\text {max }}: 12,14 \mathrm{ng} / \mathrm{ml}\right)$ und Patient 13 (V2 $\left.{ }_{\text {max }}: 94,64 \mathrm{ng} / \mathrm{ml}\right)$ nachweisbar. Beim Kontrollkollektiv gab es, wie auch die Größe der Box anzeigt, eine stärkere Streuung der CrtLevel. Die mediane Crt-Konzentration des Kontrollkollektivs $(16,55 \mathrm{ng} / \mathrm{ml})$ war um etwa das 35-Fache (V1) beziehungsweise 24-Fache (V2) höher als die der BAT-Patienten. Die medianen Crt/Protein- und Crt/Kreatinin-Quotienten sind unter der BAT auf etwa das Doppelte angestiegen (Crt/Protein-Quotient: $p=0,06$; Crt/Kreatinin-Quotient: $p=$ $0,33)$. 


\subsubsection{GRP78 im Urin}

Die im Urin gemessenen GRP78-Konzentrationen der Studienteilnehmer und des Kontrollkollektivs sowie die GRP78/Protein- und GRP78/Kreatinin-Quotienten der BATPatienten sind in Abbildung 14 bis 16 veranschaulicht.

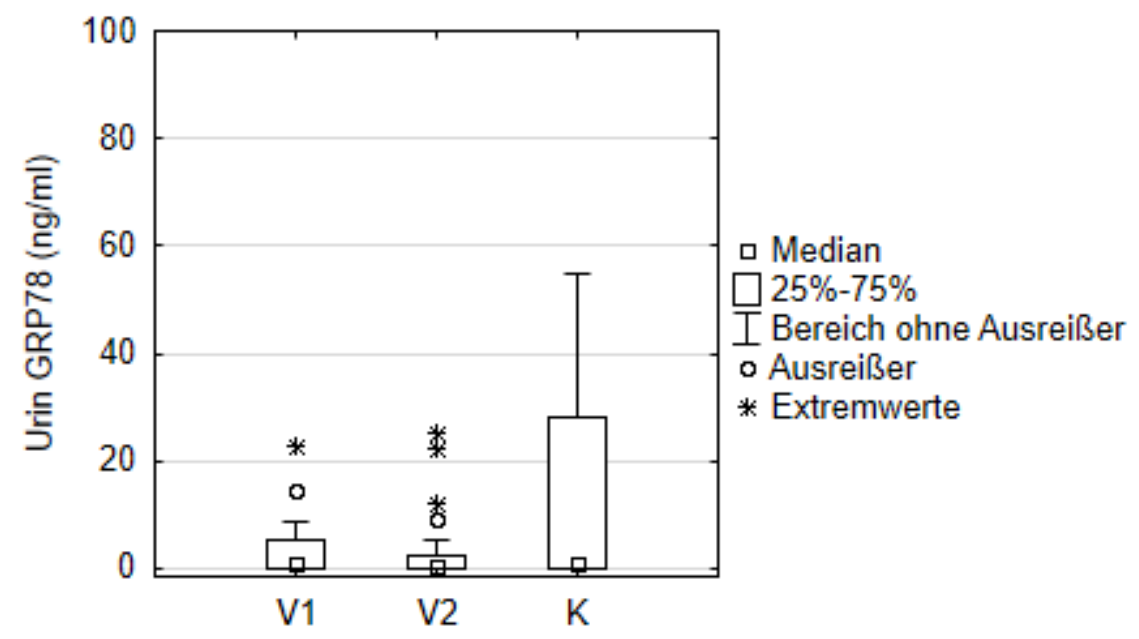

\section{Abbildung 14: GRP78-Konzentrationen im Urin}

Es zeigte sich eine Verringerung der medianen GRP78-Konzentration der BATPatienten von $0,94 \mathrm{ng} / \mathrm{ml}$ um etwa 62 Prozent auf $0,36 \mathrm{ng} / \mathrm{ml}(\mathrm{p}=0,44)$. Die durchschnittlichen GRP78-Level blieben hingegen konstant (V1: 3,12 ng/ml, V2: 3,2 ng/ml). Wie in Abbildung 14 erkennbar ist, gibt es zahlreiche Ausreißer und Extremwerte, die alle verschiedenen Patienten zuzuordnen sind. Die maximale GRP78-Exkretion wurde bei Patient 26 (V1 max: 22,85 ng/ml) und bei Patient 3 (V2 $2_{\text {max }}$ 25,41 ng/ml) gemessen. Bei den Blutspendern zeigte sich insgesamt eine größere Streuung der Werte. Die mediane GRP78-Konzentration des Kontrollkollektivs $(0,94 \mathrm{ng} / \mathrm{ml})$ war identisch mit dem medianen GRP78-Level der BAT-Patienten zum Zeitpunkt V1.

Der mediane GRP78/Protein-Quotient ist unter der BAT von 1,74 $\mu \mathrm{g} / \mathrm{g}$ Protein (V1) auf $3,18 \mu \mathrm{g} / \mathrm{g}$ Protein (V2) um etwa 80 Prozent angestiegen, wohingegen sich der mediane GRP78/Kreatinin-Quotient um den Faktor 0,7 reduzierte. Die maximalen GRP78/Protein-Quotienten lagen bei 149,53 $\mu \mathrm{g} / \mathrm{g}$ Protein (V1, Patient 26) und $239,04 \mu \mathrm{g} / \mathrm{g}$ Protein (V2, Patient 28) und waren somit um ein Vielfaches höher als die maximalen ERp57- und Crt/Protein-Quotienten (siehe: Kapitel 3.2.1, Abbildung 9 und Kapitel 3.2.2, Abbildung 12). 


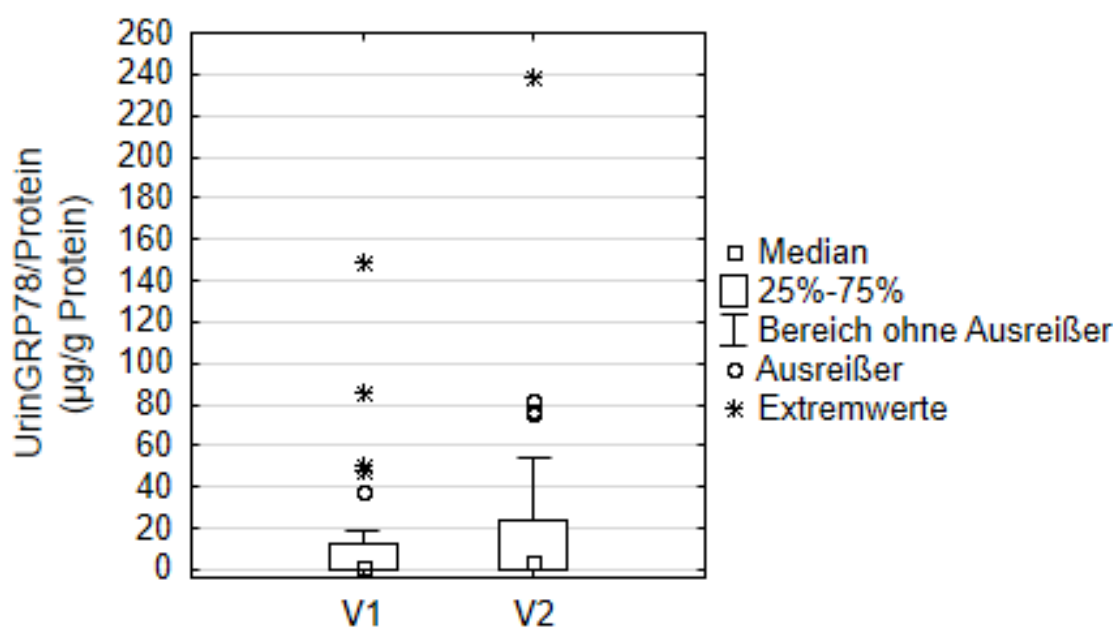

Abbildung 15: GRP78/Protein-Quotienten

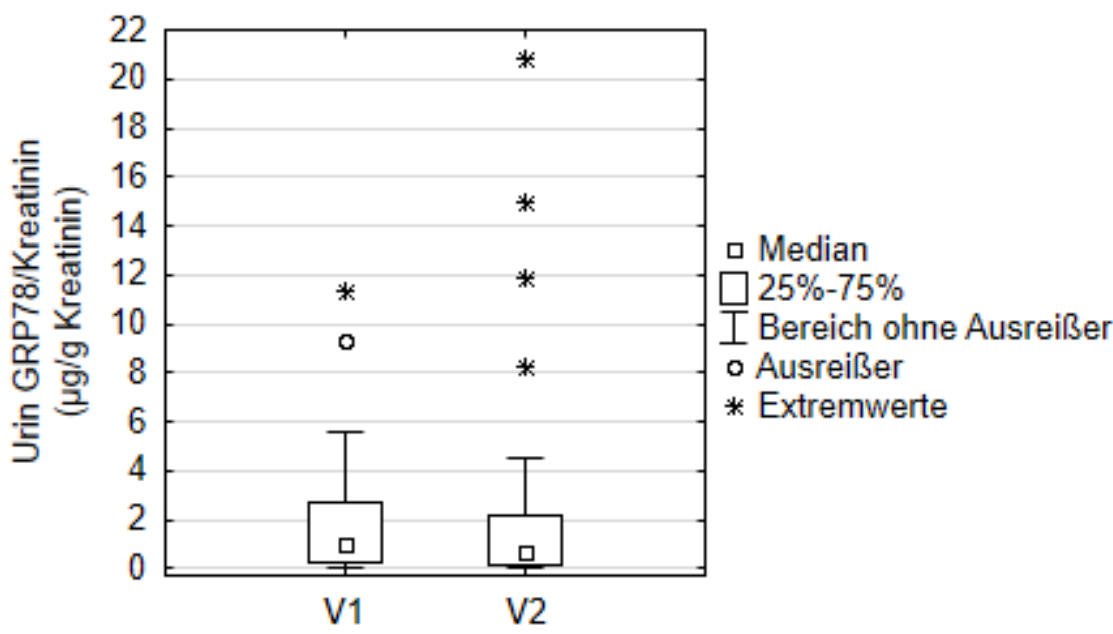

Abbildung 16: GRP78/Kreatinin-Quotienten

\subsubsection{Western Blot-Ergebnisse}

In Abbildung 17 sind exemplarisch Western Blot-Ausschnitte aller drei ER-StressProteine abgebildet. Pro Geltasche wurde optimalerweise eine Proteinmenge von $50 \mu \mathrm{g}$ aufgetragen (siehe Abbildung 17B Blot 1). Bei Patienten mit geringen UrinProteinkonzentrationen wurde alternativ eine Proteinmenge von $20 \mu \mathrm{g}$ verwendet (siehe Abbildung 17A, 17B Blot 2 und 14C). Die ERp57-Banden wurden mit der Chemilumineszenzfärbung, die Crt- und GRP78-Banden mit der Fluoreszenzfärbung sichtbar gemacht. 


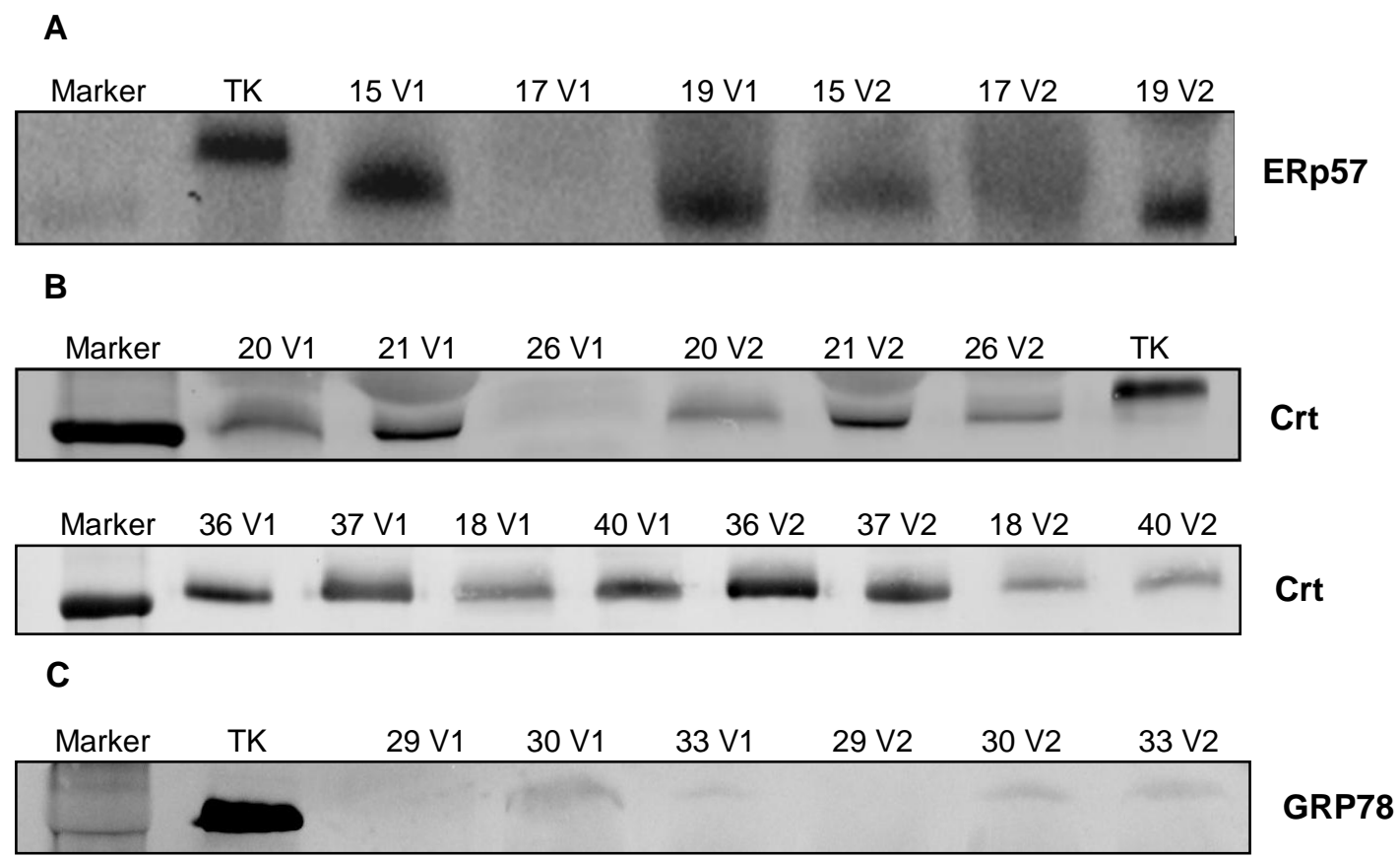

\section{Abbildung 17: Western Blot-Ausschnitte}

Oberhalb der Western Blot-Ausschnitte ist markiert, in welcher Reihenfolge der Größenstandard („Marker"), die Positivkontrolle (TK173-Zellen = „TK“) und Urinproben („Patient, V1/V2“) auf dem Gel aufgetragen wurden.

Quelle: Eigene Darstellungen (Abbildung 17A: 10.07.2014, Abbildung 17B: 06.06.2014 und 26.11.2014, Abbildung 17C: 04.07.2016)

Die Western Blots wurden densitometrisch mit dem Programm ImageJ ausgewertet. Anschließend wurde pro Patient und Western Blot für jedes ER-Stress-Protein der FC berechnet. Da jeder Western Blot zwei Mal erstellt wurde, konnte der Mittelwert der beiden ermittelten FCs errechnet werden. Anschließend wurden die mittleren und medianen FCs aller BAT-Patienten errechnet. Diese sind in Tabelle 21 aufgelistet.

Tabelle 21: FCs der ER-Stress-Proteine (Western Blot-Ergebnisse)

\begin{tabular}{|l|c|c|}
\hline ER-Stress-Protein & \multicolumn{2}{|c|}{ FC } \\
\hline & Mittelwert & Median \\
\hline ERp57 & 2,03 & 0,82 \\
\hline Crt & 4,59 & 1,09 \\
\hline GRP78 & 0,22 & 0 \\
\hline
\end{tabular}




\subsection{ER-Stress-Proteine im Serum}

Tabelle 22 gibt eine Übersicht über die im Serum gemessenen ER-Stress-ProteinKonzentrationen der BAT-Patienten und des Kontrollkollektivs. Die ER-Stress-Proteine werden einzeln in Kapitel 3.3.1 bis 3.3.3 ausgewertet.

Die medianen ERp57- und Crt-Konzentrationen der Studienteilnehmer veränderten sich unter der Therapie nicht signifikant (ERp57: $p=0,19$; Crt: $p=0,49$ ). Auffällig waren hohe mediane GRP78-Konzentrationen, die unter der BAT signifikant um etwa 28 Prozent anstiegen $(p<0,0002)$. Bei keinem Blutspender war ERp57 im Serum nachweisbar. Crt wurde in einer verhältnismäßig niedrigen und GRP78 in einer hohen Konzentration gemessen. Die ER-Stress-Protein-Konzentrationen im Serum des Kontrollkollektivs unterschieden sich signifikant von den Ergebnissen der BATPatienten (alle $p<0,0001$ ).

Tabelle 22: ER-Stress-Proteine im Serum (ELISA-Ergebnisse)

\begin{tabular}{|c|cc|c|c|}
\hline $\begin{array}{c}\text { ER-Stress- } \\
\text { Protein * }\end{array}$ & \multicolumn{3}{|c|}{ BAT-Patienten $(\mathbf{n}=\mathbf{2 9})$} & Vontrollkollektiv \\
V1 & \multicolumn{2}{|c|}{ V2 } & p & 17) \\
\hline ERp57 & $4,37(2,12-8,85)$ & $8,64(1,73-12,7)$ & 0,19 & $0(0-0)$ \\
\hline Calretikulin & $0,0(0,0-0,17)$ & $0,01(0,0-0,11)$ & 0,49 & $1,69(1,18-25,43)$ \\
\hline GRP78 & $\begin{array}{c}1119,86 \\
(878,72-1877,62)\end{array}$ & $\begin{array}{c}1432,97 \\
(1107,6-3180,27)\end{array}$ & $<0,0002$ & $\begin{array}{c}14678,02 \\
(13365,18-17422,8)\end{array}$ \\
\hline
\end{tabular}

Die Daten sind als Mediane (IQR) dargestellt.

* Einheit der ER-Stress-Proteine: $\mathrm{ng} / \mathrm{ml}$

In Tabelle 23 sind die FCs der medianen ER-Stress-Protein-Konzentrationen aufgeführt.

Tabelle 23: FCs der ER-Stress-Proteine (Serum)

\begin{tabular}{|l|c|}
\hline ER-Stress-Proteine & FC \\
\hline ERp57 & 1,98 \\
\hline Crt & 0 \\
\hline GRP78 & 1,28 \\
\hline
\end{tabular}




\subsubsection{ERp57 im Serum}

Abbildung 18 veranschaulicht die ERp57-Serum-Konzentrationen der BAT-Patienten und des Kontrollkollektivs. Das mediane ERp57-Level wurde auf fast das Doppelte gesteigert (V1: $4,37 \mathrm{ng} / \mathrm{ml}$, V2: 8,58 ng/ml). Auch die durchschnittliche ERp57Konzentration stieg um etwa 33 Prozent an (V1: 6,43 ng/ml, V2: 8,58 ng/ml). Die maximalen ERp57-Level, die in Abbildung 18 als Ausreißer markiert sind, wurden bei Patient 14 (V1 $1_{\text {max }}:$ 24,65 ng/ml, V2 $2_{\text {max }}: 31,07 \mathrm{ng} / \mathrm{ml}$ ) nachgewiesen. Insgesamt waren die ERp57-Level im Serum höher als die im Urin gemessenen Level (siehe Kapitel 3.2, Tabelle 18). Die maximalen ERp57-Konzentrationen im Urin ( $\mathrm{V} 1_{\max }: 2,46 \mathrm{ng} / \mathrm{ml}, \mathrm{V} 2_{\text {max }}$ : $3,65 \mathrm{ng} / \mathrm{ml}$ ) lagen beispielsweise im Bereich der 25-Prozent-Quartile der Serumwerte. Bei den Blutspendern war kein ERp57 nachweisbar.

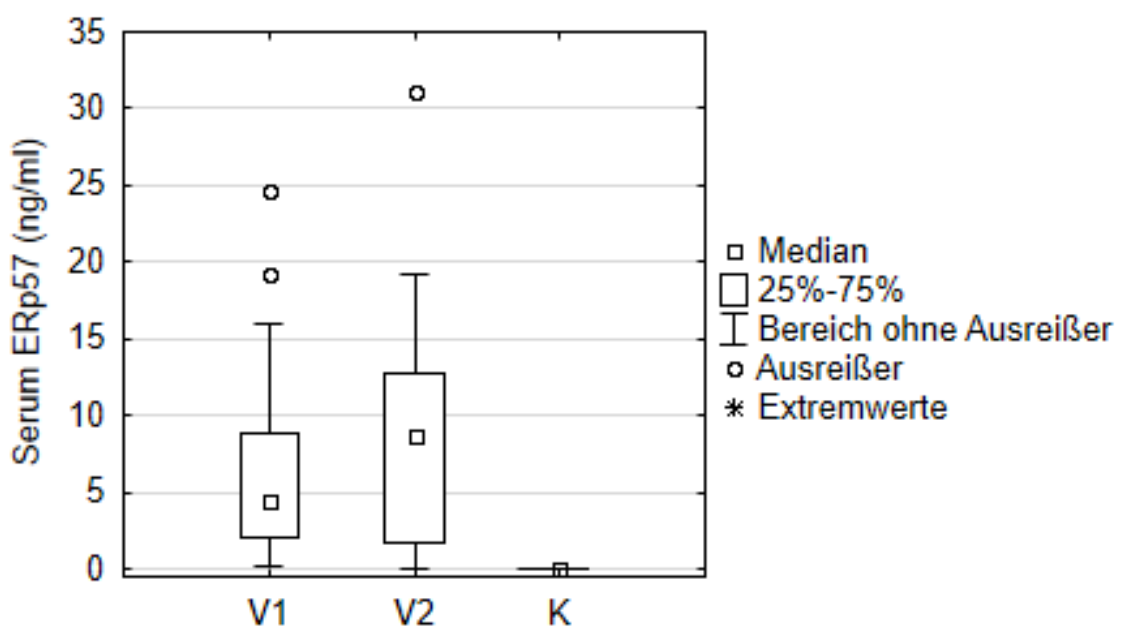

Abbildung 18: ERp57-Konzentrationen im Serum

\subsubsection{Crt im Serum}

Die Crt-Konzentrationen im Serum der Studienteilnehmer und des Kontrollkollektivs sind in Abbildung 19 dargestellt. Verglichen mit den ERp57- und GRP78-Serum-Leveln waren die Crt-Level der BAT-Patienten insgesamt gering. Zu den Zeitpunkten V1 und V2 war bei 15 beziehungsweise 12 Personen kein Crt im Serum nachweisbar. Des Weiteren waren die maximalen Crt-Konzentrationen im Serum ( $\mathrm{V} 1_{\max }: 4,64 \mathrm{ng} / \mathrm{ml}$, Patient 23; V2 $2_{\max }: 2,14 \mathrm{ng} / \mathrm{ml}$, Patient 4) wesentlich geringer als die maximalen CrtKonzentrationen im Urin (siehe Kapitel 3.2.2, Abbildung 11). 
Beim Kontrollkollektiv zeigte sich eine starke Streuung der Werte (Median: 1,69 ng/ml, Mittelwert: 27,23 ng/ml, SD: 56,12). Die beiden höchsten Crt-Konzentrationen der Blutspender (193,3 $\mathrm{ng} / \mathrm{ml}$ und 151,71 ng/ml) sind im Box-Whisker-Diagramm nicht dargestellt.

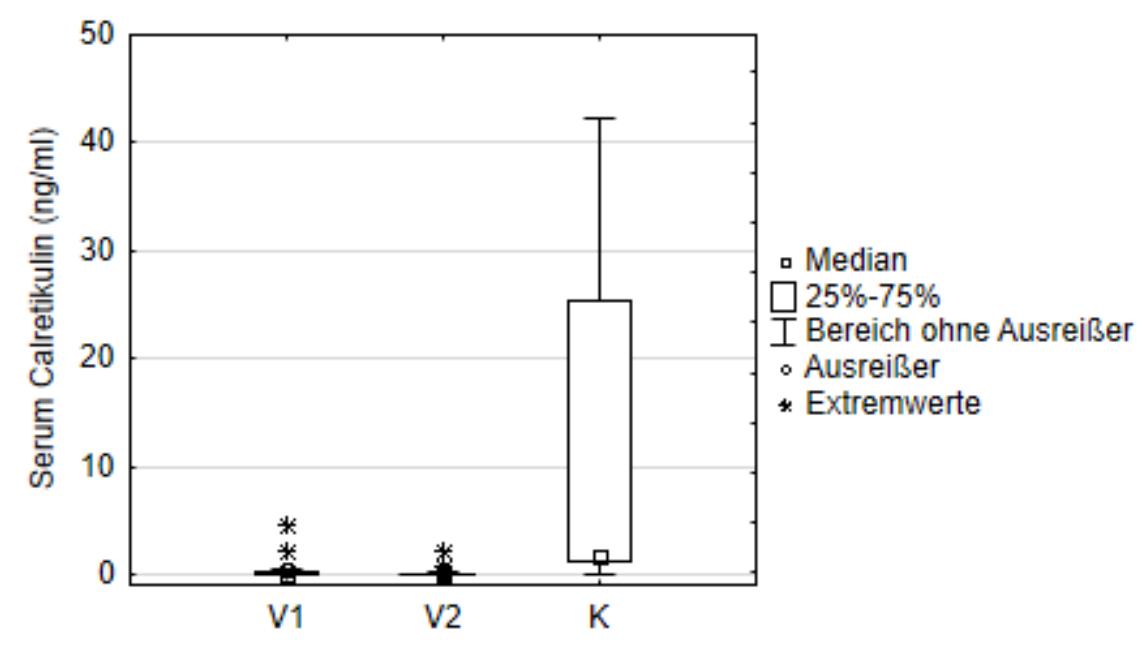

Abbildung 19: Crt-Konzentrationen im Serum

\subsubsection{GRP78 im Serum}

Die Serum-GRP78-Konzentrationen der BAT-Patienten und des Kontrollkollektivs sind in Abbildung 20 dargestellt. Es wurden hohe mediane GRP78-Konzentrationen gemessen (V1: 1119,86 ng/ml, V2: 1432,97 ng/ml), die durch die BAT signifikant um etwa 28 Prozent heraufreguliert wurden $(p<0,0002)$. Trotz dieser verhältnismäßig hohen Konzentrationen wurden die GRP78-Ergebnisse für eine bessere Vergleichbarkeit der Box-Whisker-Diagramme untereinander in der Einheit „ng/ml“ aufgetragen.

Auch die durchschnittliche GRP78-Konzentration wurde von 1512,33 ng/ml auf 2273 $\mathrm{ng} / \mathrm{ml}$ um etwa 50 Prozent gesteigert. Die minimalen GRP78-Serum-Level (V1 $\min$ : 388,11 ng/ml, Patient 7; V2 ${ }_{\min }$ : 607,47 ng/ml, Patient 7) lagen oberhalb aller im Serum und Urin gemessenen Maximalkonzentrationen der ER-Stress-Proteine.

Beim Kontrollkollektiv war sowohl die höchste mediane (14678,02 ng/ml), als auch die maximale GRP78-Konzentration ( $\mathrm{K}_{\max }: 21414,78 \mathrm{ng} / \mathrm{ml}$ ) zu finden. Wie Abbildung 20 zeigt, lagen die maximalen GRP78-Level der BAT-Patienten (V1 max: 4190,47 ng/ml, Patient 27; V2 ${ }_{\max }: 6793,31 \mathrm{ng} / \mathrm{ml}$, Patient 28) noch unterhalb der 25-Prozent-Quartile des Kontrollkollektivs. 


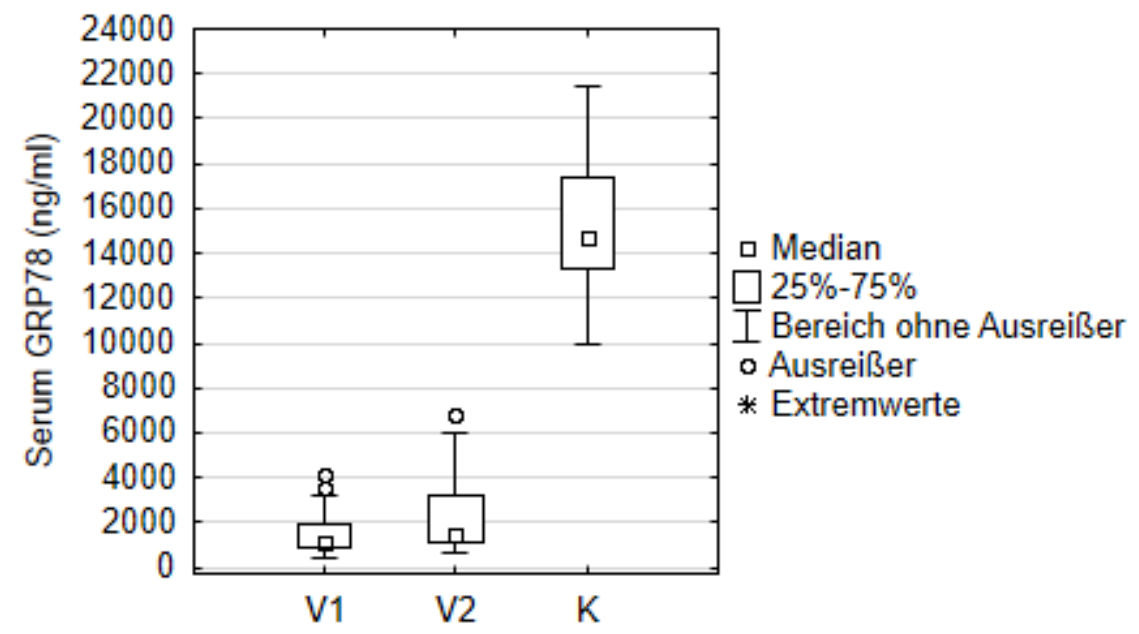

Abbildung 20: GRP78-Konzentrationen im Serum

\subsection{Urin/Serum-Quotienten}

Pro BAT-Patient und Blutspender wurde für jedes ER-Stress-Protein der Urin/SerumQuotient der jeweiligen ER-Stress-Protein-Konzentration gebildet. Anschließend wurden die durchschnittlichen Urin/Serum-Quotienten für ERp57, Crt und GRP78 berechnet. Diese sind in Tabelle 24 aufgelistet.

Tabelle 24: Urin/Serum-Quotienten

\begin{tabular}{|c|c|c|c|c|}
\hline \multirow{3}{*}{$\begin{array}{c}\text { Urin/Serum- } \\
\text { Quotienten } \\
\text { ERp57 }\end{array}$} & \multicolumn{3}{|c|}{$\begin{array}{ll}\text { V1 } & \text { V2 }\end{array}$} & \multirow{3}{*}{$\begin{array}{c}\text { Kontroll- } \\
\text { kollektiv } \\
\text { Mittelwerte } \\
0\end{array}$} \\
\hline & \multicolumn{2}{|c|}{ Mittelwerte } & $p$ & \\
\hline & 46,74 & 48,31 & 0,77 & \\
\hline Crt & 5,64 & 0,32 & 0,32 & 12,94 \\
\hline GRP78 & 38661,46 & 22885,64 & 0,89 & 0,01 \\
\hline
\end{tabular}




\subsection{Subgruppen-Analysen}

In Abbildung 21 und 22 sind die Urin- und Serum-Konzentrationen der ER-StressProteine ausgewählter Subgruppen vergleichend dargestellt. Folgende Legende gilt für alle Diagramme:

口 Median

$25 \%-75 \%$

I Bereich ohne Ausreißer

o Ausreißer

* Extremwerte

In den Crt-Diagrammen sind keine Extremwerte markiert.

\subsubsection{Subgruppen-Analysen im Urin}

Wie in Abbildung $21 \mathrm{zu}$ sehen ist, fielen die medianen ER-Stress-ProteinKonzentrationen bei fast allen Subgruppen ab. Lediglich die medianen ERp57- und CrtKonzentrationen der responder stiegen unter der BAT an. Die einzige signifikante Veränderung wurde bei Patienten mit einer CKD verzeichnet. Bei ihnen reduzierte sich die GRP78-Konzentration signifikant um etwa 69 Prozent $(p<0,03)$.

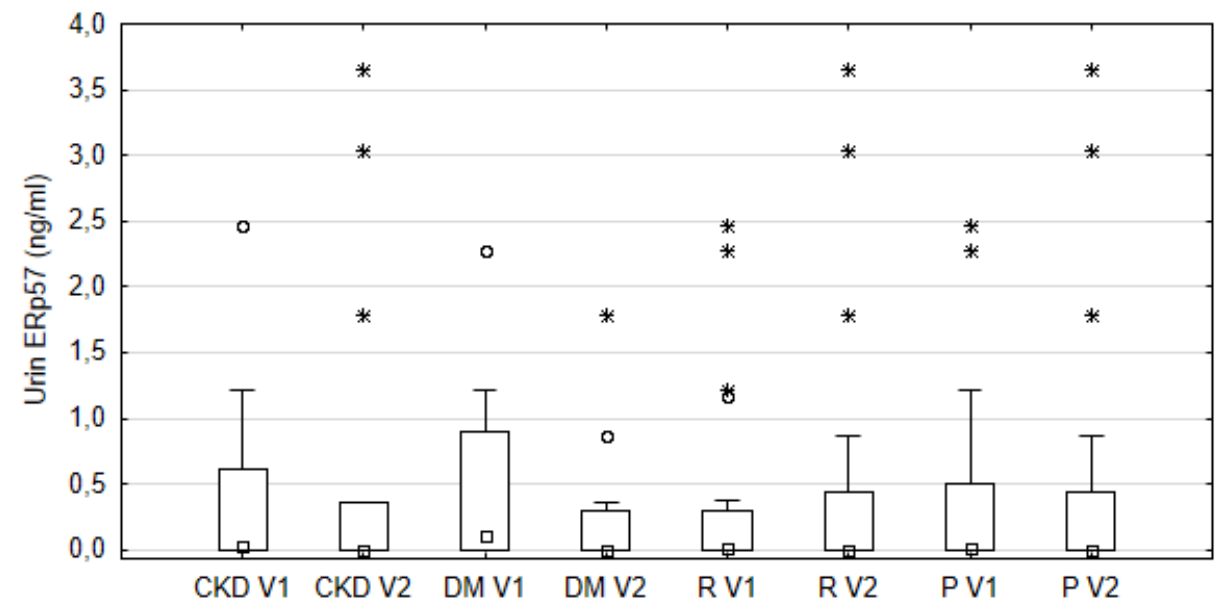



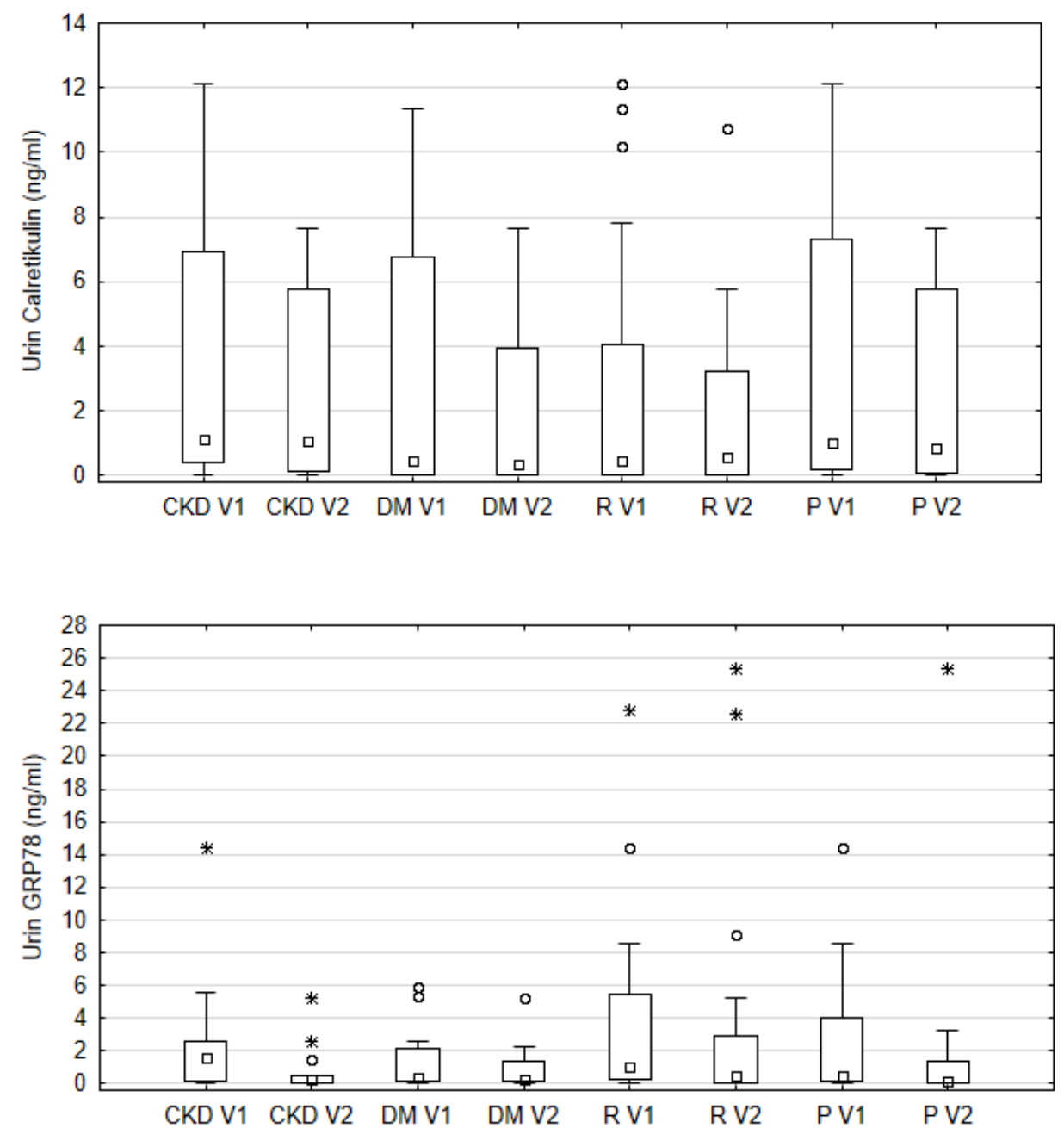

\section{Abbildung 21: Subgruppen-Vergleich im Urin}

Abkürzungen: Chronische Niereninsuffizienz $=$ CKD, Diabetes mellitus $=\mathrm{DM}$, responder $=\mathrm{R}$, Patienten mit Proteinurie $=\mathrm{P}$

\subsubsection{Subgruppen-Analysen im Serum}

Bei allen Subgruppen war ein Anstieg der medianen ER-Stress-ProteinKonzentrationen im Serum nachweisbar. Die ERp57- und GRP78-Konzentrationen der Patienten mit Proteinurie, sowie die GRP78-Konzentration der responder wurden unter der BAT signifikant heraufreguliert (Patienten mit Proteinurie: ERp57: $p<0,01$, GRP78: $p<0,03$; responder: GRP78: $p<0,001)$. 

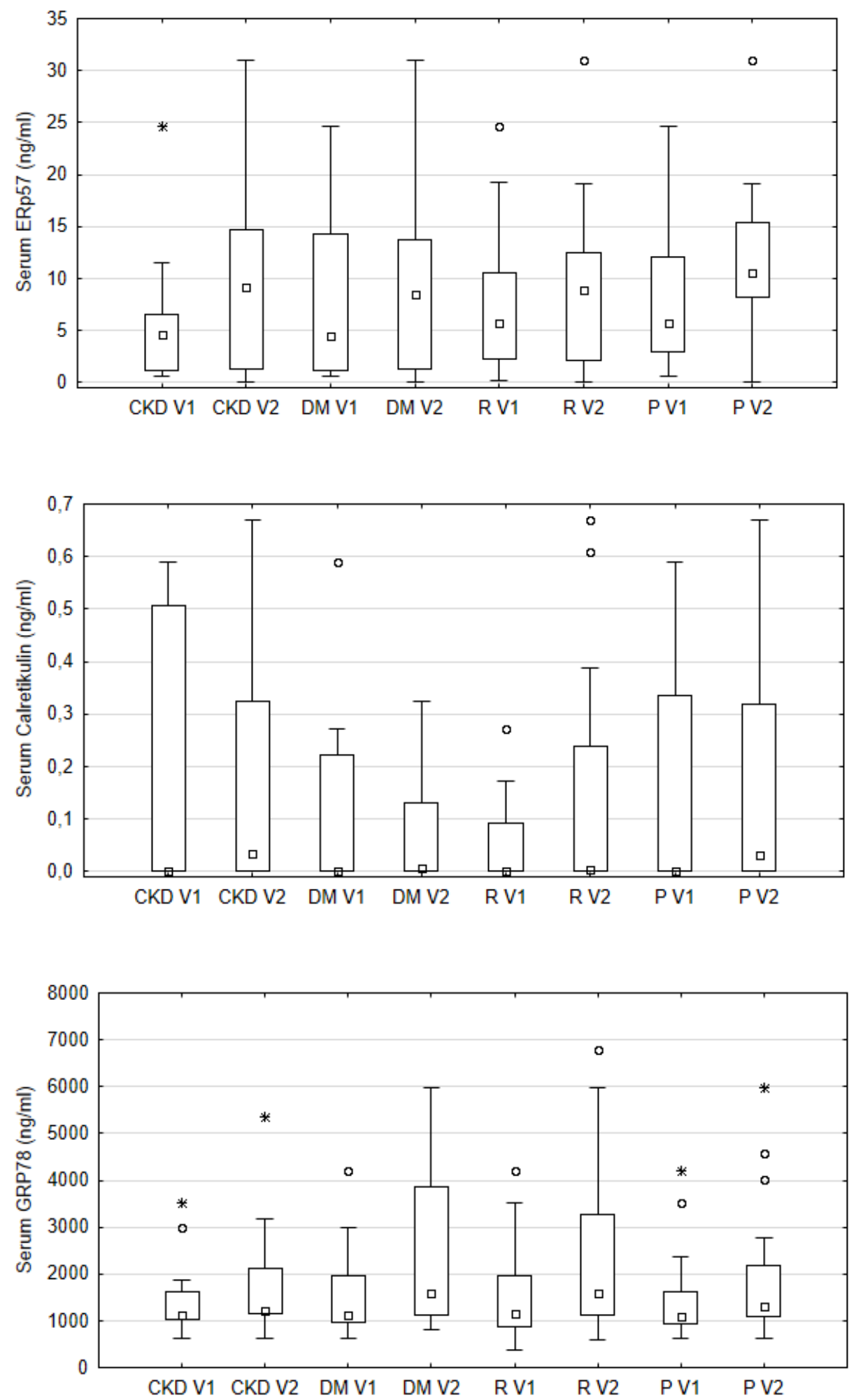

\section{Abbildung 22: Subgruppen-Vergleich im Serum}

Abkürzungen: Chronische Niereninsuffizienz $=\mathrm{CKD}$, Diabetes mellitus $=\mathrm{DM}$, responder $=\mathrm{R}$, Patienten mit Proteinurie $=\mathrm{P}$ 


\section{Diskussion}

Im Diskussionsteil wird anfänglich zum besseren Verständnis das Urinproteom erläutert und die Bedeutung der ausgeprägten Proteinurie der BAT-Patienten diskutiert. Anschließend werden die ER-Stress-Proteinmuster im Urin und Serum kritisch analysiert.

\subsection{Das Urinproteom}

Der menschliche Primärharn entsteht durch Ultrafiltration des Plasmas im Bereich der Nierenglomeruli. Durch Rückresorption vor allem im Bereich des proximalen Tubulus wird lediglich ein Prozent des Ultrafiltrates als Urin ausgeschieden (Adachi et al. 2006). Da Urin nicht invasiv (Dihazi und Müller 2007) und nahezu unbegrenzt gewonnen werden kann, spielt die Urindiagnostik bei Patienten mit therapieresistenter Hypertonie eine wichtige Rolle, um die Funktion der Nieren und ableitenden Harnwege zu beurteilen und noch vor dem Auftreten erster Symptome einen Nierenschaden zu detektieren (Leitlinie Hypertonie und CKD 2004).

Ab 1975 gewinnt die Analyse des Proteinmusters im Urin, des sogenannten Urinproteoms, in der klinischen Proteomik an Bedeutung. Das Urinproteom umfasst zum derzeitigen Wissensstand etwa 2000 Proteine (Kalantari et al. 2015), von denen 1823 durch Marimuthu et al. identifiziert wurden (Marimuthu et al. 2011). Der Urin ist in punkto Proteinvielfalt verglichen mit dem Blutplasma mit insgesamt 10000 Proteinen weniger komplex (Kalantari et al. 2015). Die Urinproteine stammen zu 70 Prozent aus der Niere selbst oder aus den ableitenden Harnwegen. Sie werden als lösliche Proteine im Bereich der Nierentubuli und in Form von Exosomen sezerniert oder gelangen infolge von Zelluntergang in den Urin. Die restlichen 30 Prozent umfassen Plasmaproteine (Dihazi und Müller 2007), die im Glomerulum in den Urin filtriert werden.

Der glomeruläre Filter besteht aus drei Barrieren (von innen nach außen): 1) Fenestriertes Kapillarendothel, 2) Basalmembran, 3) Podozyten mit Filtrationsschlitzen (D'Amico und Bazzi 2003). Abhängig von ihrer elektrischen Ladung, ihrem Molekulargewicht und ihrer Konfiguration passieren die Plasmaproteine die Filtrationsbarriere in unterschiedlichem Ausmaß. 
Kleinmolekulare Plasmaproteine mit einem Molekulargewicht von unter $45 \mathrm{kDa}$ (low molecular weight-Proteine $=$ LMW-Proteine) können die Filtrationsbarriere in der Regel frei passieren (D'Amico und Bazzi 2003; Jia et al. 2009). Sie werden jedoch größtenteils im Bereich des proximalen Tubulus rückresorbiert (D'Amico und Bazzi 2003). Großmolekulare Proteine mit einem Molekulargewicht von über 60 kDa (high molecular weight -Proteine $=$ HMW-Proteine), wie ERp57 (57 kDa), Crt (60 kDa), GRP78 (78 kDa) und auch Albumin (67 kDa), werden bei intaktem glomerulären Filter normalerweise nicht in den Urin filtriert (Jia et al. 2009; Regeniter et al. 2009).

Das Urinproteom darf nicht als isoliertes, statisches System betrachtet werden, da es von vielen Faktoren, wie beispielsweise der Temperatur oder dem Zellzyklus, abhängig ist (Dihazi 2009). Es unterliegt nicht nur zirkadianen Schwankungen, sondern unterscheidet sich auch zwischen einzelnen Patienten und interessanterweise auch zwischen Männern und Frauen (Kalantari et al. 2015). Da 30 Prozent der Proteine nicht renalen Ursprungs sind (Dihazi 2009), wird das Proteinmuster im Urin auch von der Zusammensetzung des Plasmaproteoms beeinflusst (Jia et al. 2009). Dieser Aspekt wurde in dieser Dissertation insofern berücksichtigt, als die ER-Stress-Proteine im Urin und auch im Serum analysiert wurden.

\subsection{Proteinurie der BAT-Patienten}

Drei verschiedene Formen der Proteinurie können unterschieden werden (Hofmann et al. 2001):

1) Prärenale Proteinurie („Überlaufproteinurie“)

2) Renale Proteinurie (glomerulär, tubulär, gemischt glomerulär-tubulär)

3) Postrenale Proteinurie

Da die prä- und postrenale Proteinurie bei hypertensiven Patienten nicht von spezieller Relevanz sind, wird auf diese Formen nicht näher eingegangen. Die renale Proteinurie kann sich durch einen erhöhten Verlust von Plasmaproteinen als glomeruläre, tubuläre oder gemischt glomerulär-tubuläre Proteinurie präsentieren (Hofmann et al. 2001). Physiologischerweise wird der renale Blutfluss bei mittleren arteriellen Blutdruckwerten zwischen 80 und $160 \mathrm{mg}$ mit Hilfe eines Autoregulationsmechanismus konstant gehalten (Ravera et al. 2006). Ein Blutdruckanstieg führt zu einer Vasokonstriktion der Vasa afferentia, sodass letztendlich der effektive Filtrationsdruck und die GFR keinen ausgeprägten Schwankungen unterliegen (Bidani und Griffin 2004). 
Bei Patienten mit einer chronischen Hypertonie, wie den BAT-Patienten, wird der Autoregulationsbereich in Richtung höherer Blutdruckwerte verschoben (Ravera et al. 2006). Wird der obere Grenzwert im Rahmen eines akut auftretenden Blutdruckanstiegs überschritten oder versagt die Autoregulation, kann der hohe intraglomeruläre Blutdruck über eine Dehnung der glomerulären Kapillaren zu einer Schädigung des Kapillarendothels führen. Es kommt somit zu einer vermehrten Filtration von Plasmaproteinen (Bidani und Griffin 2004; Ravera et al. 2006).

Initial wird ein Verlust der Ladungsselektivität des glomerulären Filters beobachtet, sodass insbesondere negativ geladene Proteine, wie Albumin und eine kleine Menge von HMW-Proteinen, in das Tubuluslumen filtriert werden (D'Amico und Bazzi 2003). Im Verlauf geht schließlich die Größenselektivität der Filtrationsbarriere verloren, sodass diese zunehmend permeabel für HMW-Proteine, wie beispielsweise Immunglobulin G (IgG: 150 kDa), wird (Hofmann et al. 2001; D'Amico und Bazzi 2003). Die HMW-Proteine und die physiologischerweise in das Tubuluslumen filtrierten LMWProteine konkurrieren um die Resorption in die Tubulusepithelzellen. Sobald die Resorptionsmechanismen ausgeschöpft sind, werden vor allem die HMW-Proteine und eine geringe Menge der LMW-Proteine in den Urin ausgeschieden (D'Amico und Bazzi 2003). Es resultiert initial eine „selektiv glomeruläre Proteinurie“ (Markerprotein: Albumin), die in eine „unselektiv glomeruläre Proteinurie“ (Markerprotein: Albumin und IgG) übergehen kann (Hofmann et al. 2001).

Eine persistierende Proteinurie in Folge einer chronischen glomerulären Schädigung kann zu morphologischen Veränderungen der Tubulusepithelzellen und wahrscheinlich auch zu direkten toxischen Effekten führen. Hierdurch kann es zu einer drastischen Verschlechterung der Resorptionsfunktion des proximalen Tubulus kommen. Proteine aller Molekulargewichtsklassen, vor allem die LMW-Proteine, gelangen in den Urin (D'Amico und Bazzi 2003). Dies wird als tubuläre Proteinurie (Markerprotein: $\alpha_{1}$ Mikroglobulin (33 kDa)) bezeichnet (Hofmann et al. 2001). Weiterhin kann eine Proteinurie durch einen abnormen Verlust an renalen Proteinen, die durch einen Tubulusschaden freigesetzt werden, entstehen (Leitlinie Evaluation und Management der CKD 2012).

Wie in Tabelle 15 (siehe Kapitel 3.1) zu sehen ist, zeigte sich bei den BAT-Patienten eine etwa 10-prozentige Reduktion des systolischen Praxisblutdrucks (V1: 171,5 $\mathrm{mmHg}, \mathrm{V} 2: 154,4 \mathrm{mmHg}$ ) und eine etwa 8-prozentige Abnahme des diastolischen Praxisblutdrucks (V1: 89,2 mmHg, V2: 82,3 mmHg). Durch die Abnahme des systemischen Blutdrucks und folglich auch des intraglomerulären Drucks wird der glomeruläre Filter vor weiteren vaskulären Schädigungen geschützt (Lea et al. 2005). 
Der daraus resultierende antiproteinurische Effekt trägt wesentlich zur Nephroprotektion der BAT-Patienten bei (Ravera et al. 2006).

Wie in Kapitel 3.1 beschrieben wurde, fiel bei den BAT-Patienten sowohl die mediane Gesamt-Proteinkonzentration signifikant um fast 40 Prozent (V1: $231 \mathrm{mg} / \mathrm{l}, \mathrm{V} 2:$ 139,7 $\mathrm{mg} / \mathrm{l}$ ), als auch die mediane Albumin-Konzentration (V1: $101 \mathrm{mg} / \mathrm{l}, \mathrm{V} 2: 71,4 \mathrm{mg} / \mathrm{l}$ ) signifikant um 30 Prozent ab. Eine Gesamt-Proteinurie von über $150 \mathrm{mg} / \mathrm{l}$ oder eine Albuminausscheidung von über $30 \mathrm{mg} / \mathrm{l}$ gilt als pathologisch (Hofmann et al. 2001). Interessanterweise korrelierte der Abfall des systolischen und diastolischen Praxisblutdrucks mit dem Abfall der Gesamt-Protein- und Albuminausscheidung (siehe Kapitel 3.1, Tabelle 17). Wie verschiedene Studien zeigen, ist das Ausmaß einer Proteinexkretion vor Beginn einer antihypertensiven Therapie und die Veränderung der Proteinurie im Verlauf ein wichtiger Prognosefaktor für das renale Outcome der Patienten (Peterson et al. 1995; Lea et al. 2005).

Bei der Analyse der Proteinkonzentrationen ist kritisch zu bedenken, dass die Konzentrationen im Spontanurin sowohl von der Menge der filtrierten Proteine, als auch vom Urinvolumen und somit dem Hydrierungszustand der Patienten abhängig sind (Leitlinie Hypertonie und CKD 2014). Die Proteinkonzentrationen geben bereits einen ersten Hinweis für das Ausmaß der Proteinurie. Als Goldstandard zur Quantifizierung der Proteinurie wird hingegen der 24-Stunden-Sammelurin verwendet (Price et al. 2005). Bei dieser zeitaufwändigen und oftmals fehlerbehafteten Methode werden die Proteinkonzentration und das Urinvolumen eines Patienten in 24 Stunden bestimmt und anschließend die Proteinausscheidung berechnet (ClinLab 2013).

In dieser Dissertation wurden als alternative Methode die Albumin- und Proteinkonzentrationen im Urin in Bezug zur Kreatininkonzentration im Urin gesetzt (siehe Kapitel 3.1, Tabelle 15). In zahlreichen Studien wurde eine positive Korrelation zwischen beiden Parametern und der Proteinexkretion im 24-Stunden-Sammelurin nachgewiesen (Xin et al. 2004; Price et al. 2005; Siu et al. 2011). Da die Proteine und das Kreatinin im Urin gleichermaßen verdünnt werden (Leitlinie CKD 2002), ist der Albumin/Kreatinin- und Protein/Kreatinin-Quotient im Spontanurin unabhängig vom Urinvolumen eines Patienten. Die Kreatininausscheidung ist bei einem einzelnen Patienten innerhalb eines Tages und auch zwischen verschiedenen Patienten relativ konstant (Leitlinie CKD 2002). Sie beträgt bei Frauen $15 \mathrm{mg} / \mathrm{kg}$ Körpergewicht (KG) und bei Männern $20 \mathrm{mg} / \mathrm{kg} \mathrm{KG}$, sodass insgesamt 1 bis $1,5 \mathrm{~g}$ Kreatinin täglich ausgeschieden werden (ClinLab 2013). Die physiologische Albuminausscheidung kann bis zu 30 mg pro Tag, die Gesamt-Proteinurie bis zu 300 mg pro Tag betragen. 
Je nach Quelle ist somit ein Albumin/Kreatinin-Quotient von unter $30 \mathrm{mg} / \mathrm{g}$ und ein Protein/Kreatinin-Quotient von unter 200 mg/g normal (Leitlinie CKD 2002) (siehe Kapitel 1.4, Tabelle 3).

Wie in Tabelle 15 veranschaulicht ist (siehe Kapitel 3.1), zeigte sich unter der BAT ein Abfall des medianen Albumin/Kreatinin-Quotienten von fast 60 Prozent (V1: $101 \mathrm{mg} / \mathrm{g}$ Kreatinin, V2: 60,1 mg/g Kreatinin, $p=0,18)$ und eine Reduktion des Protein/KreatininQuotienten von etwa 56 Prozent (V1: 242,3 mg/g Kreatinin, V2: 136,5 mg/g Kreatinin, $p=0,24)$.

\subsection{ER-Stress-Proteinurie}

Wie zahlreiche Untersuchungen belegen, scheint der ER-Stress pathophysiologisch an der Entwicklung der arteriellen Hypertonie, sowie glomerulärer beziehungsweise tubulärer Nierenerkrankungen beteiligt zu sein (Kitamura 2008b; Inagi 2009). In dieser Arbeit wurden gezielt die ER-Stress-Proteine ERp57, Crt und GRP78 analysiert. Die Idee resultiert aus Ergebnissen eines Teilprojektes der Göttinger BAT-Studie. In diesem Projekt wurde das Urinproteom von zwei verschiedenen Patientengruppen vor und nach der sechsmonatigen BAT untersucht (Lehnig 2016):

- Gruppe 1: Patienten mit therapieresistenter Hypertonie und diabetischer Nephropathie $(n=6)$

- Gruppe 2: Patienten mit therapieresistenter Hypertonie und hypertensiver Nephropathie $(n=6)$

Als Methoden wurde die zweidimensionale differentielle Gelelektrophorese (twodimensional gel electrophoresis $=2 \mathrm{D}-\mathrm{DIGE})$, bei der die Proteine nach ihrem $\mathrm{pH}$ (1. Dimension: isoelektrische Fokussierung) und ihrem Molekulargewicht (2. Dimension: SDS-PAGE) aufgetrennt wurden (Lilley und Friedman 2004), sowie die Massenspektroskopie (matrix assisted laser desorption ionization-time of flight Massenspektroskopie = MALDI-TOF-MS) genutzt. Interessanterweise wurden im Urin der diabetischen Patienten unter anderem ERp57 und GRP78 identifiziert und diese sogar signifikant unter der BAT herabreguliert (Lehnig 2016). Dies ließ die Vermutung zu, dass der ER-Stress pathogenetisch an den durch die arterielle Hypertonie vermittelten Schäden beteiligt sein könnte. Womöglich scheinen besonders Diabetiker mit einem bekanntermaßen hohen Sympathikotonus von der sympathikoinhibierenden BAT zu profitieren (Nesto 2004). Typischerweise müssen die Versuchsergebnisse durch eine weitere Methode validiert werden (Taylor und Posch 2014). 
Das Western Blotting und ELISA stellen in dieser Dissertation somit einen Validierungsschritt in der Identifikation der potenziellen Urin-Biomarker ERp57, Crt und GRP78 dar.

Wie Thongboonkerd und Malasit bereits 2005 beschrieben haben, ist die Interpretation von Ergebnissen in der Urinproteomik in vielerlei Hinsicht eine große Herausforderung (Thongboonkerd und Malasit 2005). Zum besseren Verständnis wird die sogenannte Black Box-Methode von Jia et al. vorgestellt (Jia et al. 2009).

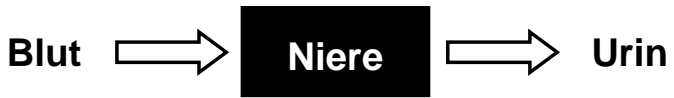

\author{
Abbildung 23: Black Box-Methode \\ Quelle: Modifiziert nach Jia et al. 2009
}

Das Plasmaproteom stellt vereinfachend den Input und das Urinproteom den Output der Niere dar. Wie experimentelle Daten zeigen, können drei Gruppen unterschieden werden (Jia et al. 2009):

1) Blut-Subproteom:

a) Proteine, die nicht gefiltert werden, oder

b) Proteine, die gefiltert und in der Niere rückresorbiert werden

2) Blut- und Urin-Subproteom: Glomerulär filtrierte und/oder sezernierte Proteine

3) Urin-Subproteom: Proteine, die durch Sekretion oder Zelluntergang in den Urin gelangen

In dieser Arbeit wurde die Ausscheidung der ER-Stress-Proteine als Teil des In- und Outputproteoms im Blut und Urin vergleichend untersucht. Auf Grundlage der Ergebnisse können lediglich Vermutungen angestellt werden, über welche Mechanismen die ER-Stress-Proteine in den Urin der BAT-Patienten gelangt sein könnten. Die Niere der BAT-Patienten kann in dieser Arbeit, genau wie im Modell von Jia et al., in gewisser Weise als black box betrachtet werden. Folgende Überlegungen helfen bei der Interpretation der Urin-Ergebnisse weiter:

1) Anstieg der ER-Stress-Proteinurie: Dieser kann durch eine erhöhte Produktion des jeweiligen ER-Stress-Proteins in der Niere und folglich erhöhten Sekretion in den Urin verursacht werden (Thongboonkerd und Malasit 2005). Zudem ist denkbar, dass die ER-Stress-Proteine aufgrund des chronisch erhöhten Blutdrucks durch den defekten glomerulären Filter vermehrt in den Urin filtriert werden. 
Physiologischerweise passieren ERp57, Crt und GRP78 die Blut-Harn-Schranke aufgrund ihres Molekulargewichtes von über 60 kDa nicht.

2) Reduktion der ER-Stress-Proteinurie: Eine Abnahme der ER-Stress-Proteinurie kann durch eine verminderte Filtration des jeweiligen Proteins bedingt sein (Thongboonkerd und Malasit 2005), eventuell aufgrund einer vermehrten Bindung an Blutbestandteile. Des Weiteren könnte bei intaktem glomerulärem Filter möglicherweise die Rückresorption des jeweiligen Proteins im proximalen Tubulus, eventuell zur Nutzung in der Zelle, erhöht worden sein (Thongboonkerd und Malasit 2005). Weiterhin könnte die BAT durch die Blutdruckreduktion auch zu einer Reduktion des renalen ERStresses und somit verminderten ER-Stress-Proteinurie beigetragen haben. Auf dieser Idee basiert die Haupthypothese dieser Dissertation (siehe Kapitel 1.6).

\subsubsection{ERp57}

Die ERp57-Konzentrationen im Urin und die ERp57/Kreatinin- beziehungsweise ERp57/Protein-Quotienten der BAT-Patienten waren verglichen mit den Crt- und GRP78-Urin-Leveln sehr gering und wurden durch die BAT wider Erwarten nicht signifikant verändert (siehe Kapitel 3.2, Tabelle 18).

Um die folgende Diskussion besser nachvollziehen zu können, wird initial der Zusammenhang zwischen der arteriellen Hypertonie, der renalen Fibrose und der Induktion von ER-Stress-Proteinen näher erläutert: Wie verschiedene Experimente belegen, führt eine Aktivierung des RAAS durch AT II vermittelt zu einer verstärkten Sekretion des transforming growth factor-beta (TGF- $\beta$ ) (Border und Noble 1998). Neben weiteren profibrotischen Zytokinen wie dem platelet-derived growth factor und Angiotensinogen führt TGF- $\beta$ über eine Steigerung der Synthese- und Verringerung der Abbaurate extrazellulärer Matrixproteine (extracellular matrix-Proteine = ECMProteine) zu einer Ablagerung dieser Proteine im Tubulointerstitium. Es kommt zur Entstehung einer interstitiellen Fibrose (Border und Noble 1998; Dihazi et al. 2013). Dihazi et al. wiesen in Zellkultur- und Mausexperimenten nach, dass die Überladung des ERs mit ECM-Proteinen den UPR als ER-Stress-Antwort aktiviert. Bei mit TGF- $\beta$ behandelten renalen Fibroblasten waren im Gegensatz zu unbehandelten Zellen, die als Kontrollgruppe fungierten, folgende Proteingruppen nachweisbar:

1) Proteine, die an der Fibrogenese beteiligt sind, wie beispielsweise Desmin und Vimentin;

2) ER-Stress-Marker, wie zum Beispiel ERp57, Crt und GRP78. 
Wie tierexperimentelle Ergebnisse verdeutlichen, besteht eine direkte Korrelation zwischen dem ERp57-Level im Urin und dem Ausmaß der renalen Fibrose (Dihazi et al. 2013). Da ERp57 bereits in frühen Stadien eines Nierenschadens ausgeschieden wird, betrachten Dihazi et al. ERp57 als potenziellen Biomarker zur frühzeitigen Erkennung einer renalen Fibrose (Dihazi et al. 2013). Die BAT-Patienten wiesen interessanterweise niedrigere ERp57-Konzentrationen als die Blutspender auf. Ausgehend von oben genannter Hypothese hieße dies, dass bei ihnen zum Zeitpunkt V1 und V2 weniger Fibrose als bei den normotensiven Blutspendern vorhanden sein müsste. Da bei 45 Prozent der BAT-Patienten vor Therapiebeginn eine CKD manifest war, ist dieser Rückschluss sicherlich nicht korrekt.

Dass der Einsatz von ACE-Hemmern und $\mathrm{AT}_{1}$-Rezeptor-Antagonisten die Wirkung von AT II inhibiert, ist allgemein bekannt. In zahlreichen älteren Publikationen wird berichtet, dass im Tiermodell durch den Einsatz dieser beiden Medikamente eine Abnahme der TGF- $\beta$-Sekretion verzeichnet und antifibrotische Effekte vermittelt werden (RuizOrtega et al. 1995; Pimentel et al. 1995; Zoja et al. 1997). Eine interessante Hypothese, die sich aus dem zuvor Genannten ableiten lässt, lautet wie folgt: Durch die BAT kommt es zu einer Inhibierung des RAAS (1) und folglich zu einer Reduktion des profibrotischen TGF- $\beta$ (2), welches mit einer Abnahme der ER-Stress-Proteinurie (3) einhergeht. Diese Hypothese ist grundsätzlich für alle drei ER-Stress-Proteine überprüfbar.

(1) Für den ersten Teilaspekt gibt es ausreichend Hinweise in der Literatur. Die sympathikoinhibierende BAT führt mutmaßlich über eine verminderte sympathische Nervenaktivität der Nieren zu einer Abnahme der Reninexkretion und somit auch der redu-zierten Aktivität des RAAS (Georgakopoulos et al. 2011; Hart et al. 2015). Dies könnte ein Mechanismus sein, wie die BAT zur langfristigen Blutdruckkontrolle beiträgt (Hart et al. 2015).

(2) Der zweite Punkt bleibt in dieser Dissertation unbeantwortet, da keine TGF- $\beta$ Analysen durchgeführt wurden. Wie Ergebnisse von Lehnig zeigen, kam es bei 31 untersuchten BAT-Patienten nach sechsmonatiger Therapie zu einem Abfall des TGF$\beta$-Spiegels $(p=0,1)$ (Lehnig 2016).

(3) Da überraschenderweise keine Abnahme der ERp57-Level im Urin nachweisbar war, lässt sich der dritte Teilaspekt für ERp57 nicht bestätigen. Obwohl mutmaßlich ein Teil der BAT-Patienten eine Nierenfibrose aufwies, waren die ERp57-UrinKonzentrationen sehr gering. 
Dies widerspricht der Hypothese von Dihazi et al., dass ERp57 in diesem Patientenkollektiv als Marker der renalen Fibrose fungieren könnte (Dihazi et al. 2013).

Eine mögliche Erklärung wäre, dass die ER-Stress-Proteine bei den CKD-Patienten bereits vor Beginn der BAT heraufreguliert wurden und Adaptionsvorgänge zu einer Normalisierung der ERp57-Spiegel geführt haben könnten. Hinweise dafür liefern die Untersuchungen von Dihazi et al. mit TGF- $\beta$-behandelten Fibroblasten. Lediglich in der ersten Behandlungswoche wurde eine Heraufregulation der ER-Stress-Proteine beobachtet. Danach normalisierten sich die ERp57-Konzentrationen, wohingegen die Level der Fibrosemarker (zum Beispiel Desmin und Vimentin) weiterhin erhöht blieben. Des Weiteren wurde in Mausexperimenten nachgewiesen, dass lediglich innerhalb der ersten sieben Wochen eine Korrelation zwischen dem ERp57-Level und dem Ausmaß der Fibrose bestand. Danach wurde ein Abfall der ERp57-Ausscheidung im Urin beobachtet. Ob diese Erkenntnisse auch für den menschlichen Organismus gelten, ist ungeklärt (Dihazi et al. 2013).

Ein weiterer auffälliger Aspekt ist die im Vergleich zum Urin hohe mediane ERp57Serum-Konzentration bei den BAT-Patienten, die unter der BAT auf fast das Doppelte angestiegen ist. Da ERp57 bei keinem Blutspender im Serum messbar war, ist das Vorhandensein von ERp57 im Serum mutmaßlich als pathologisch zu werten. Die Fragestellung, welche Bedeutung der Nachweis von ERp57 im Serum von hypertensiven Patienten haben könnte, wird in der Literatur nicht adressiert und ist Gegenstand weiterer Untersuchungen.

\subsubsection{Calretikulin}

Unter der BAT änderten sich die mediane Crt-Urin-Konzentration und die Crt/Proteinund Crt/Kreatinin-Quotienten nicht signifikant (siehe Kapitel 3.2, Tabelle 18 und 19). Die medianen Crt-Konzentrationen im Urin waren mit unter $1 \mathrm{ng} / \mathrm{ml}$ im Vergleich zum Kontrollkollektiv verhältnismäßig gering. Da im Serum zum Zeitpunkt V1 und V2 kaum Crt messbar war, scheint der Mechanismus der glomerulären Filtration wahrscheinlich nicht wesentlich zur Crt-Ausscheidung beigetragen zu haben. Mutmaßlich wurde Crt direkt aus der Niere in den Urin sezerniert. Inwieweit der Nachweis von Crt im Urin als Ausdruck renalen Stresses zu werten ist, kann nicht sicher beurteilt werden.

Die Forschung konzentriert sich primär auf die Funktion von Crt im ER, wo es hauptsächlich lokalisiert zu sein scheint (Johnson et al. 2001). Es fungiert dort als molekulares Chaperon an der Faltung von Glykoproteinen und ist maßgeblich an der Aufrechterhaltung der Kalziumhomöostase beteiligt (siehe Kapitel 1.3.2) 
In den letzten Jahren wurde Crt auch außerhalb des ERs in extrazellulären Kompartimenten, auf der Zelloberfläche von zum Beispiel Fibroblasten und Endothelzellen und auch im systemischen Kreislauf nachgewiesen. Es ist jedoch umstritten, wie das Crt aus dem ER über die subzellulären Kompartimente an die Zelloberfläche transportiert und schließlich sezerniert wird. Dies würde der anerkannten Theorie, dass Crt über die sogenannte „KDEL-Sequenz“ im ER-Lumen festgehalten wird, widersprechen (Gold et al. 2010). Zwei Mechanismen werden in der Literatur diskutiert:

1) Aktive Sekretion: Einerseits wurde der vesikuläre Transport und die anschließende Exozytose von Crt nach extrazellulär nachgewiesen (Michalak et al. 2009). Andererseits wird vermutet, dass eine Protease die KDEL-Sequenz abspalten und so einen Transport des Chaperons über den Golgi-Apparat ermöglichen könnte (Michalak et al. 2009; Ní Fhlathartaigh et al. 2013).

2) Nekrose: Eine Zellschädigung könnte die Freisetzung von Crt aus dem ER bedingen (Gold et al. 2010). Dieser Mechanismus ist insbesondere für die BAT-Patienten zu diskutieren: Infolge der ausgeprägten Proteinurie könnte es zu einer Schädigung der Tubulusepithelzellen mit anschließender Crt-Freisetzung gekommen sein (Ravera et al. 2006). Wie Abbildungen 11 und 19 (siehe Kapitel 3.2.2 und 3.3.2) verdeutlichen, wurden bei den Blutspendern allerdings höhere mediane Crt-Konzentration im Urin und Serum als bei den BAT-Patienten nachgewiesen. Da ein renaler Schaden bei den gesunden Blutspendern unwahrscheinlich ist, widerspricht dies der Theorie.

Die Crt-Ergebnisse des Kontrollkollektivs implizieren also, dass die Ausscheidung von Crt in den Urin nicht zwangsläufig als krankhaft zu werten ist. Wie Gold et al. beschreiben, scheint Crt einerseits an physiologischen Prozessen, wie beispielsweise der Wundheilung oder Differenzierung von Stammzellen, beteiligt zu sein. Andererseits spielt Crt auch bei pathologischen Prozessen, wie zum Beispiel der Entstehung von Autoimmunerkrankungen, eine Rolle (Gold et al. 2010; Wang et al. 2017). Welche Bedeutung der Nachweis von Crt im Urin oder Serum hat, ist noch nicht ausreichend verstanden. Crt wurde im Serum bereits bei Patienten mit Blasenkarzinom (Kageyama et al. 2004), rheumatoider Arthritis (Holoshitz et al. 2010) und systemischem Lupus erythematodes (Eggleton und Llewellyn 1999) in erhöhten Konzentrationen gegenüber Gesunden nachgewiesen. Die Frage, warum das Crt-Level im Urin der BAT-Patienten niedriger als das der Blutspender war, kann in dieser Arbeit nicht abschließend geklärt werden. 


\subsubsection{GRP78}

Die Bedeutung von GRP78 an der Entstehung der arteriellen Hypertonie ist heutzutage noch unklar. Es existieren zahlreiche Publikationen, in denen die große Bedeutung von GRP78 für die Krebsentstehung und -progression, Metastasierung und Ausbildung einer Chemotherapieresistenz betont wird (Wang et al. 2009). Dies trifft zum Beispiel auf das Mamma-, Prostata-, Blasen- und Lungenkarzinom zu, um einige wenige zu nennen (Lee 2007; Wang et al. 2009). Hypoxie und niedrige Glukoselevel in der Umgebung eines Tumors induzieren ER-Stress, wodurch der adaptative UPR aktiviert und die Expression von GRP78 in der Tumorzelle gesteigert wird (Wang et al. 2009). GRP78 wirkt zudem über die Inaktivierung proapoptotischer Faktoren, wie beispielsweise Caspase, antiapoptotisch. Hohe GRP78-Level sind somit essenziell für das Überleben der Tumorzellen (Lee 2007).

In Anbetracht dieser Ergebnisse sind die hohen medianen GRP78-SerumKonzentrationen der BAT-Patienten (V1: 1119,86 ng/ml; V2: 1432,97 ng/ml) und des Kontrollkollektivs (14678,02 ng/ml) auf den ersten Blick überraschend. Zum derzeitigen Wissensstand ist die Bedeutung des frei im Blut zirkulierenden GRP78s noch unklar. Delpino und Castelli mutmaßen, dass GRP7 aktiv ins Blut sezerniert werden könnte, um dort eine physiologische, derzeit noch unbekannte Funktion, auszuüben (Delpino und Castelli 2002). Da bei den Blutspendern wesentlich höhere GRP78-SerumKonzentrationen als bei den BAT-Patienten messbar waren, ist diese Überlegung durchaus plausibel. Alternativ wäre die Freisetzung des normalerweise intrazellulär lokalisierten GRP78s aus geschädigten Zellen ins Blut denkbar. Da eine Zellschädigung bei den gesunden Blutspendern eher unwahrscheinlich ist, scheint dieser Mechanismus vermutlich eine untergeordnete Rolle zu spielen.

Der Nachweis von GRP78 im Blut gesunder Individuen wird interessanterweise in zahlreichen Publikationen beschrieben. Delpino und Castelli wiesen GRP78 und GRP78-Antikörper mit Hilfe des Western Blots und ELISA im Serum von sieben gesunden Personen nach (Delpino und Castelli 2002). In einer Arbeit von Pockley et al. mit insgesamt 92 gesunden Personen wurde GRP78 bei 85 Prozent der Männer $(\mathrm{n}=40)$ und 98 Prozent der Frauen $(\mathrm{n}=44)$ im Serum nachgewiesen. Die GRP78Level unterschieden sich dabei sehr stark zwischen den einzelnen Individuen, wobei maximale Konzentrationen von $18550 \mathrm{ng} / \mathrm{ml}$ beschrieben wurden (Pockley et al. 1998). In dieser Dissertation zeigen sich ähnliche Ergebnisse: Zum einen war GRP78 bei jedem Blutspender nachweisbar. Zum anderen variierten die GRP78-SerumKonzentrationen zwischen $10000 \mathrm{ng} / \mathrm{ml}$ und fast $22000 \mathrm{ng} / \mathrm{ml}$ sehr stark. 
Ungeklärt bleibt, warum die GRP78-Serum-Konzentrationen der BAT-Patienten niedriger waren als die der Blutspender und wie der signifikante Anstieg der medianen GRP78-Konzentration im Serum der BAT-Patienten zu erklären ist.

Im Urin der BAT-Patienten zeigte sich keine signifikante Veränderung der GRP78Exkretion. Zudem waren die Urin-Konzentrationen verglichen mit den SerumKonzentrationen sehr gering. Die glomeruläre Schranke könnte möglicherweise noch soweit intakt gewesen sein, als dass GRP78 nur in sehr geringem Ausmaß in den Urin filtriert wurde. Wie Abbildung 14 verdeutlicht (siehe Kapitel 3.2.3), waren beim Kontrollkollektiv höhere GRP78-Urin-Konzentrationen als bei den BAT-Patienten messbar. Da ein glomerulärer Schaden bei normotensiven Personen unwahrscheinlich ist, könnte GRP78 aktiv in den Urin sezerniert worden sein.

\subsubsection{ER-Stress-Proteinurie (Subgruppenanalysen)}

Im Urin fielen die medianen ER-Stress-Protein-Konzentrationen und insbesondere die 75-Prozent-Quartile der drei ER-Stress-Proteine bei fast allen Subgruppen ab. Im Serum zeigte sich interessanterweise ein Anstieg aller medianen ER-Stress-ProteinLevel. Die meisten Ergebnisse waren jedoch nicht signifikant (siehe Kapitel 3.5).

In dieser Arbeit sind besonders Patienten mit einer CKD, die einen Anteil von 45 Prozent der Studienteilnehmer ausmachen, von Interesse. Bei ihnen kann der therapieresistente arterielle Hypertonus sowohl Ursache, als auch Folge der CKD sein (Ravera et al. 2006). Wie in tierexperimentellen Studien bewiesen wurde, ist der Autoregulationsmechanismus bei Patienten mit einer CKD verschlechtert. Bereits ein geringer Blutdruckanstieg kann einen glomerulären Schaden (Bidani und Griffin 2004; Bidani et al. 2012) und in Folge eine Proteinurie verursachen (Ravera et al. 2006).

Insbesondere die begleitende Proteinurie scheint langfristig an der Entstehung eines dialysepflichtigen Nierenversagens beteiligt zu sein (Bidani und Griffin 2004). Wie in Kapitel 1.2 erläutert wird, scheint die Überaktivität des sympathischen Nervensystems maßgeblich zur CKD-assoziierten Hypertonie beizutragen. Die Hypothese, dass es durch die Sympathikoinhibition zu einer signifikanten Abnahme der ER-StressProteinurie bei CKD-Patienten kommen könnte, ließ sich in dieser Dissertation nicht bestätigen. 


\subsection{Methodendiskussion}

Die Anzahl der Teilnehmer der BAT-Studie ist verglichen mit beispielsweise der multizentrischen, doppel-verblindeten Rheos Pivotal-Studie $(n=265$, Studiendauer: 20072009) gering (Bisognano et al. 2011). Aufgrund von experimentellen Vorarbeiten waren die Urin- und Serumproben der BAT-Patienten limitiert, sodass in dieser Dissertation die Proben von lediglich einem Teil der Patienten ausgewertet wurden $(n=29)$. Eine weitere Limitierung der Göttinger BAT-Studie ist der kurze Beobachtungszeitraum von insgesamt sechs Monaten. Sowohl in der Rheos Pivotal-Studie (Bisognano et al. 2011) als auch in der europäischen nicht-randomisierten DEBUT-HT-Studie ( $n=45$, Studiendauer: 2003-2011) (Menne et al. 2013) wurden die Patienten für mindestens zwei Jahre nachverfolgt (Paivanas et al. 2015). Es ist denkbar, dass sich ein nephroprotektiver Effekt womöglich erst nach mehreren Monaten durch die BAT einstellt.

Wie Dihazi hervorhebt, ist die standardisierte Sammlung, Vorbereitung und Analyse der Urine in der klinischen Proteomik von großer Bedeutung (Dihazi 2009). Um dies zu gewährleisten, wurde im Rahmen der BAT-Studie der zweite morgendliche Mittelstrahlurin entsprechend des standardisierten EuroKup/HKUPP-Protokolls gesammelt (EuroKup und HKUPP 2009). Dieser weist aufgrund einer kürzeren Verweildauer in der Harnblase verglichen mit dem ersten morgendlichen Mittelstrahlurin und 24-Stunden-Sammelurin eine geringere Proteindegradation auf (Dihazi und Müller 2007). Wie Untersuchungen von Lee et al. interessanterweise zeigen, ist das Urinproteom relativ stabil gegenüber einem bis zu fünfmaligen Auftauund Einfrierprozess sowie einer bis zu 24-stündigen Lagerung bei Raumtemperatur (Lee et al. 2008). Da in dieser Arbeit zwischen der Probengewinnung und der experimentellen Analyse teilweise mehrere Monaten lagen, ist trotz einer Lagerung der Proben bei $-80{ }^{\circ} \mathrm{C}$ eine negative Beeinflussung der Urinqualität, beispielsweise durch Zelldegradation oder Zelllyse, nicht 100-prozentig auszuschließen (Dihazi und Müller 2007).

In dieser Arbeit wurden mit dem Western Blotting und ELISA zwei verschiedene Methoden verwendet. Das ELISA wird als Goldstandard in der Validierung von Biomarker-Kandidaten angesehen (Köhler und Seitz 2012). Die Durchführung in dieser Arbeit war ohne Schwierigkeiten möglich. 
Vor der Durchführung der Western Blots wurden die Urinproben mittels Ultrafiltration und der Chloroform-Methanol-Fällung vorbereitet (siehe Kapitel 2.3.4 und 2.3.5). Empfehlungen von Thongboonkerd et al. zur Folge ist die Kombination mehrerer Methoden dem Einsatz einer einzelnen Methode stark überlegen (Thongboonkerd et al. 2005). Das Ziel bestand darin, Proben mit einem geringen Proteingehalt zu konzentrieren und störende Substanzen, wie beispielsweise Salze oder Lipide, die zu einer Verunreinigung der Elektrophorese-Gele führen könnten, zu entfernen (Dihazi und Müller 2007).

Kritisch anzumerken ist, dass aufgrund zum Teil geringer Proteinkonzentrationen $(<2$ $\mu \mathrm{g}$ Protein/ $\mu$ U Urin) keine konstante Proteinmenge von jeweils $50 \mu \mathrm{g}$ in die Geltaschen pipettiert werden konnte. Um eine Auswertung der optischen Dichten der Banden gewährleisten zu können, wurde pro Patient innerhalb eines Gels (V1 und V2) stets die gleiche Proteinmenge (entweder 20 oder $50 \mu \mathrm{g}$ ) aufgetragen.

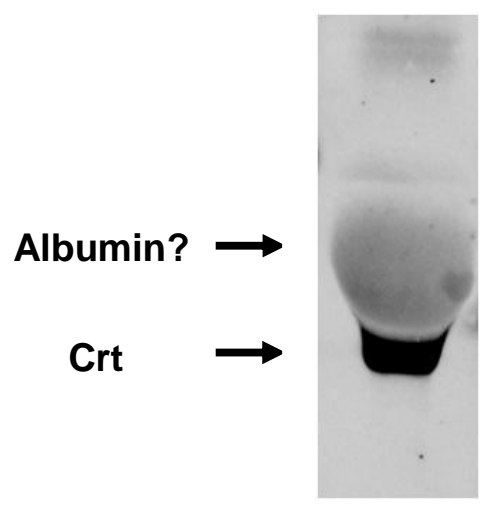

\section{Abbildung 24: Unspezifische Bande im Bereich von 50 bis 70 kDa}

Quelle: Ausschnitt eines Western Blots vom 20.06.2014 (Patient 21, V1)

In Abbildung 24 ist exemplarisch ein Western Blot-Ausschnitt nach Inkubation mit dem Antikörper Anti-Crt dargestellt. Nach der Färbung der Nitrocellulose-Membranen mit Ponceau S Solution beziehungsweise nach der Zugabe der Antikörper waren auf zahlreichen Membranen breite, ausladende Banden im Bereich von 50 bis $70 \mathrm{kDa}$ erkennbar. Diese befanden sich direkt oberhalb der Crt-Banden. Probehalber wurde die Antikörperkonzentration reduziert, wodurch jedoch keine Abnahme der Bandenbreite beobachtet werden konnte. Identisch aussehende Banden werden in der Literatur als Albuminbanden beschrieben (Chen et al. 2005; Kushnir et al. 2009). Zum einen liegt das Molekulargewicht von Albumin bei 67 kDa (Regeniter et al. 2009) und somit im Größenbereich der beobachteten Banden. 
Zum anderen wird Albumin bei hypertensiven Patienten typischerweise als Ausdruck des glomerulären Schadens in den Urin ausgeschieden (Fornara und Fischer 2007). Bei den BAT-Patienten lag der Albuminanteil an der Gesamt-Proteinurie bei etwa 48 Prozent. Es ist zu mutmaßen, dass die Banden durch eine unspezifische Interaktion zwischen den verwendeten Antikörpern und dem Albumin in der Patientenprobe entstanden sind (Rauch et al. 2005). Die Problematik, dass in hohen Konzentrationen vorkommende Plasmaproteine die Identifikation von niedrig konzentrierten Proteinen im Serum oder Urin erschweren können, wird in der Literatur intensiv diskutiert (Chen et al. 2005; Kushnir et al. 2009; Anderson et al. 2011; Kalantari et al. 2015). Wie Dihazi et al. hervorhebt, kommen potenzielle Urin-Biomarker größtenteils in niedrigen Konzentrationen vor (Dihazi und Müller 2007). Eine vielversprechende Strategie liegt darin, die am höchsten konzentrierten Proteine aus der Urinprobe zu entfernen. Bis dato sind kommerzielle Kits lediglich für die Depletion von Proteinen aus Serumproben etabliert (Kushnir et al. 2009).

In dieser Arbeit wurde mit diesen Serum-spezifischen Kits versuchsweise getestet, ob auch die Albumin-Konzentration in den Urinproben verringert werden kann. Die Idee basierte auf einer Arbeit von Kushnir et al., in der untersucht wurde, inwieweit das für Serum entwickelte multiple affinity removal column system bei proteinurischen Patienten die sechs am höchsten konzentrierten Urin-Proteine (Albumin, Transferrin, Haptoglobin, IgG, IgA, alpha-1 Antitrypsin) reduzieren kann. Abgesehen von einer Abnahme der Proteinkonzentration konnten nach der Depletion etwa 2,5-mal so viele Proteine im Urin identifiziert werden wie vor der Depletion (vor der Depletion: 60 Proteine, nach der Depletion: 142 Proteine) (Kushnir et al. 2009). Da in dieser Arbeit nach dem Depletionsversuch weiterhin ausladende Banden sichtbar waren, wurde die Albumindepletion nicht weiter fortgeführt. Zudem ist unklar, inwieweit es durch die Depletion von Albumin, welches als wichtiges Trägerprotein fungiert (Kragh-Hansen 1990), auch zu einem Verlust der ER-Stress-Proteine kommen könnte (Holewinski et al. 2013).

Die Auswertung der Western Blots erfolgte wie in Kapitel 2.4 beschrieben. Es ist zu bedenken, dass das Western Blotting eine semiquantitative Methode ist (Mahmood und Yang 2012). Das heißt, dass im Gegensatz zum ELISA keine absoluten Proteinkonzentrationen ermittelt werden. Problematisch ist, dass innerhalb eines Gels sowohl die Proteinmenge, die in die Geltaschen pipettiert wird, als auch der Transfer der Proteine vom Gel auf die Membran unterschiedlich sein kann (Johnson 2012; Taylor et al. 2013). 
Bei der Arbeit mit Zellkulturen stehen dafür Ladekontrollen, wie beispielsweise BetaAktin oder Glycerinaldehyd-3-phosphat-Dehydrogenase (GAPDH), zur Verfügung (Li und Shen 2013). Diese sogenannten housekeeping-Proteine werden durch die dazugehörigen housekeeping-Gene in verschiedenen Gewebearten konstant exprimiert und können durch entsprechende Antikörper sichtbar gemacht werden (She et al. 2009; Taylor und Posch 2014). Eine konstante Bandengröße der housekeepingProteine innerhalb einer Membran spiegelt somit den gleichmäßigen Transfer der zu untersuchenden Proteine auf die Membran wider.

\subsection{ERp57, Crt und GRP78- neue renale Biomarker?}

Gemäß des National Institutes of Health ist ein biologischer Marker ein objektiv messbarer Parameter, der Ausdruck eines physio- oder pathologischen Prozesses im Körper ist (Biomarkers Definition Working Group 2001). In den letzten Jahren wurden in zahlreichen Studien neue Urin-Biomarker-Kandidaten für renale Erkrankungen, wie zum Beispiel die diabetische Nephropathie und das akute Nierenversagen, aber auch Erkrankungen anderer Organsysteme, wie beispielsweise das Blasen- und Prostatakarzinom, identifiziert (Marimuthu et al. 2011). Das Ziel besteht darin, neue renalen Biomarker zu detektieren, die:

1) eine frühe Diagnosestellung zulassen (Dihazi 2009)

2) eine Klassifikation einer Erkrankung in verschiedene Schweregrade ermöglichen (Hewitt et al. 2004)

3) zur Beurteilung eines Therapieeffektes geeignet sind (Bonomini et al. 2012).

Der Prozess von der Entdeckung eines potenziellen Biomarkers bis hin zur Etablierung in den klinischen Alltag ist ein komplexer Prozess. Der Großteil der Studien befindet sich noch in der ersten Phase, der sogenannten discovery phase (Hewitt et al. 2004), so auch die in Göttingen durchgeführte BAT-Studie. Die Haupthypothese, dass die BAT über eine Reduktion des renalen ER-Stresses einen nephroprotektiven Effekt ausübt, wird durch die Versuchsergebnisse in dieser Dissertation nicht bestätigt. Da bei den Blutspendern teilweise höhere ER-Stress-Protein-Konzentrationen als bei den BAT-Patienten gemessen wurden, wird die Frage aufgeworfen, ob hohe ER-StressProtein-Level im Urin und Serum zwangsläufig als Ausdruck renalen ER-Stresses zu werten sind.

In den meisten Studien und auch in dieser Dissertation wurden Expressionsanalysen durchgeführt, was bedeutet, dass das Proteinmuster zwischen verschiedenen Patientengruppen analysiert wird (Thongboonkerd 2010). 


\section{$5 \quad$ Zusammenfassung}

Die arterielle Hypertonie stellt in der Bevölkerung mit einer Prävalenz von 30 bis 45 Prozent einen wichtigen Risikofaktor für die Entstehung kardiovaskulärer Erkrankungen dar. Umso überraschender erscheint die Tatsache, dass bei etwa einem Fünftel der Bluthochdruckpatienten ein therapieresistenter arterieller Hypertonus vorliegt. Seit einigen Jahren steht die sympathikoinhibierende BAT bei diesem Patientenkollektiv als neue Behandlungsmethode zur Verfügung. Bis dato ist unklar, ob die BAT neben der Blutdruckreduktion auch organoprotektive Effekte vermittelt.

Das Ziel dieser Dissertation bestand darin, das Proteinmuster speziell der ER-StressProteine ERp57, Crt und GRP78 im Urin und Serum bei 29 Teilnehmern der in Göttingen durchgeführten BAT-Studie zu analysieren. Als Methoden wurden das Western Blotting und ELISA-Verfahren verwendet. Die Ergebnisse zeigen, dass sowohl die Gesamt-Proteinurie als auch Albuminurie signifikant unter der BAT abgesunken sind. Überraschenderweise wurde lediglich die Expression von GRP78 im Serum signifikant unter der BAT verändert (heraufreguliert). Die Haupthypothese dieser Arbeit, dass die BAT bei therapieresistenten Hypertonikern über eine Reduktion des renalen ER stress eine Nephroprotektion bewirken könnte, konnte somit nicht bestätigt werden.

Kritisch zu bedenken ist, dass die Funktion der ER-Stress-Proteine, welche maßgeblich zum pathophysiologischen Verständnis des ER stress und der arteriellen Hypertonie beitragen könnte, noch unklar ist. Weitere histologische und molekularbiologische Untersuchungen sind notwendig, um die Eignung der ER-StressProteine als Biomarker zu verifizieren. Ein in ferner Zukunft liegendes Ziel liegt sicherlich darin, neue nephroprotektive Medikamente zu entwickeln, die über eine Modulation des ER stress eine Nephroprotektion bewirken könnten. 


\section{$6 \quad$ Anhang}

Die Ergebnisse wurden auf folgendem Kongress im Rahmen eines Vortrages präsentiert:

\section{Jahrestagung der Deutschen Gesellschaft für Nephrologie:}

12.-15. September 2015 in Berlin

Titel: „Proteomische Urinanalysen unter Barorezeptoraktivierungstherapie“

Autoren: M. Wallbach, K. Schierke, H. Dihazi, L.-Y. Lehnig, G. A. Müller, R. Wachter, M. Koziolek 


\section{$7 \quad$ Literaturverzeichnis}

$($ Abcam $)=$

Abcam: Western Blotting- A Beginner's Guide. o. J.

URL: http://wolfson.huji.ac.il/purification/PDF/PAGE_SDS/Western/ABCAM_WB_Begin nerGuide.pdf (Zugriff am 02.08.2016)

(Adachi et al. 2006) $=$

Adachi J, Kumar C, Zhang Y, Olsen JV, Mann M (2006): The human urinary proteome contains more than 1500 proteins, including a large proportion of membrane proteins. Genome Biol $\underline{7}(9)$

(Anderson et al. 2011) $=$

Anderson H, Maust M, Boyce G, Powell MJ (2011): A new technology for highly efficient and reproducible albumin depletion from whole serum. J Biomol Tech 22, 56

(Aviscera Bioscience) $=$

Aviscera Bioscience: Human Calreticulin ELISA Kit. o. J.

URL: http://www.aviscerabioscience.com/Product_Systems/calreticulin/SK00016-

01.pdf (Zugriff am 08.08.2016)

(Bakris et al. 2012) $=$

Bakris GL, Nadim MK, Haller H, Lovett EG, Schafer JE, Bisognano JD (2012): Baroreflex activation therapy provides durable benefit in patients with resistant hypertension: Results of long-term follow-up in the Rheos Pivotal Trial. J Am Soc Hypertens $\underline{6}$ (2), 152-158

\section{(Benjamin und McMillan 1998) $=$}

Benjamin IJ, McMillan DR (1998): Stress (heat shock) proteins- Molecular chaperones in cardiovascular biology and disease. Circ Res $\underline{83}$ (2), 117-132

(Bhatt et al. 2014) =

Bhatt DL, Kandzari DE, O'Neill WW, D'Agostino R, Flack JM, Katzen BT, Leon MB, Liu M, Mauri L, Negoita M (2014): A controlled trial of renal denervation for resistant hypertension. N Engl J Med $\underline{370}$ (15), 1393-1401

(Bidani und Griffin 2004) =

Bidani AK, Griffin KA (2004): Pathophysiology of hypertensive renal damage: Implications for therapy. Hypertension $\underline{44}$ (5), 595-601

(Bidani et al. 2012) $=$

Bidani AK, Griffin KA, Epstein M (2012): Hypertension and chronic kidney disease progression: Why the suboptimal outcomes?. Am J Med $\underline{125}$ (11), 1057-1062 
(Biomarkers Definition Working Group 2001) =

Biomarkers Definition Working Group (2001): Biomarkers and surrogate endpoints: Preferred definitions and conceptual framework. Clin Pharmacol Ther $\underline{69}$ (3), 89-95

(Bisognano et al. 2011) =

Bisognano JD, Bakris G, Nadim MK, Sanchez L, Kroon AA, Schafer J, de Leeuw PW, Sica DA (2011): Baroreflex activation therapy lowers blood pressure in patients with resistant hypertension: Results from the double-blind, randomized, placebo-controlled rheos pivotal trial. J Am Coll Cardio $\underline{58}$ (7), 765-773

(Bonomini et al. 2012) $=$

Bonomini M, Sirolli V, Magni F, Urbani A (2012): Proteomics and nephrology. J Nephrol $\underline{25}$ (6), 865-871

\section{(Border und Noble 1998) $=$}

Border WA, Noble NA (1998): Interactions of transforming growth factor- $\beta$ and angiotensin II in renal fibrosis. Hypertension 31 (1), 181-188

$($ Bradford 1976) $=$

Bradford MM (1976): A rapid and sensitive method for the quantitation of microgram quantities of protein utilizing the principle of protein-dye binding. Anal Biochem $\underline{72}, 248-$ 254

(Carl Roth GmbH 2010) =

Carl Roth $\mathrm{GmbH}$ (2010): Coomassie Brilliant Blue and mechanisms of protein staining and Bradford-Assay. o. Verf.

URL: http://solioz-scientific.ch/knowledge/Coomassie_blue_info.pdf

(Zugriff am 26.07.2016)

(Chen et al. 2005) $=$

Chen YY, Lin SY, Yeh YY, Hsiao HH, Wu CY, Chen ST, Wang AH (2005): A modified protein precipitation procedure for efficient removal of albumin from serum. Electrophoresis $\underline{26}$ (11), 2117-2127

$($ ClinLab 2013) $=$

ClinLab (2013): Protein urine quantitative. o. Verf.

URL: www.clinlabnavigator.com/protein-urine-quantitative.html (Zugriff am 25.07.2017)

(Crowther 2001) =

Crowther JR (Hrsg.): The ELISA Guidebook, Vol. 149: Methods in molecular Biology. Humana Press, Totowa 2001 
$(C V R x$ 2013) $=$

CVRx (2013): Systemreferenzhandbuch Barostim neoTM. o. Verf.

URL: http://www.cvrx.com/wp-content/uploads/2015/11/900097-GER-D1_BarostimTherapy-Reference-Guide-for-Heart-Failure-and-Hypertension_CE-marking.pdf (Zugriff am 18.06.2016)

(Cybulsky 2010) $=$

Cybulsky AV (2010): Endoplasmic reticulum stress in proteinuric kidney disease. Kidney Int $\underline{77}$ (3), 187-193

(D’Amico und Bazzi 2003) =

D’Amico G, Bazzi C (2003): Pathophysiology of proteinuria. Kidney Int $\underline{63}$ (3), 809-825

\section{(de Beus 2014) $=$}

de Beus E, de Jager R, Joles JA, Grassi G, Blankestijn PJ (2014): Sympathetic activation secondary to chronic kidney disease: Therapeutic target for renal denervation. J Hypertens $\underline{32}$ (9), 1751-1761

(Delpino und Castelli 2002) $=$

Delpino A, Castelli M (2002): The $78 \mathrm{kDa}$ glucose-regulated protein (GRP78/BIP) is expressed on the cell membrane, is released into cell culture medium and is also present in human peripheral circulation. Biosci Rep $\underline{22}$ (3-4), 407-420

\section{(Deutsche Hochdruckliga und Deutsche Gesellschaft für Kardiologie-Leitlinie 2013) $=$}

„Leitlinie Management der arteriellen Hypertonie 2013“: Deutsche Hochdruckliga und Deutsche Gesellschaft für Kardiologie 2013

URL: http://leitlinien.dgk.org/files/2014_Pocket-Leitlinien_Arterielle_Hypertonie.pdf (Zugriff am 13.06.2015)

(Dihazi 2009) =

Dihazi H (2009): The urinary proteomics: A tool to discover new and potent biomarkers for kidney damage. EJIFCC $\underline{20}$, 83-82

(Dihazi und Müller 2007) =

Dihazi H, Müller GA (2007): Urinary proteomics: A tool to discover biomarkers of kidney damage. Expert Rev Proteomics 4 (1), 39-50

(Dihazi et al. 2013) $=$

Dihazi H, Dihazi GH, Bibi A, Eltoweissy M, Müller CA, Asif AR, Rubel D, Vasko R, Müller GA (2013): Secretion of ERp57 is important for extracellular matrix accumulation and progression of renal fibrosis, and is an early sign of disease onset. J Cell Sci $\underline{126}$ (15), 3649-3663 
(Durand et al. 2009) =

Durand MT, Fazan R, Salgado MCO, Salgado HC (2009): Acute and chronic electrical activation of baroreceptor afferents in awake and anesthetized subjects. Braz $\mathrm{J}$ Med Biol Res $\underline{42}$ (1), 53-60

(Eggleton und Llewellyn 1999) $=$

Eggleton P, Llewellyn DH (1999): Pathophysiological roles of calreticulin in autoimmune disease. Scand J Immunol $\underline{49}$ (5), 466-473

$($ Enzo Life Sciences 2016) $=$

Enzo Life Sciences (2016): GRP78/BiP ELISA Kit- Product Manual.

URL: http://static.enzolifesciences.com/fileadmin/files/manual/ADI-900-214_insert.pdf (Zugriff am 04.08.2016)

\section{$($ ESC/ESH-Leitlinie 2013) $=$}

"Leitlinie arterielle Hypertonie 2013“: Guidelines for the management of arterial hypertension of the European Society of Hypertension (ESH) and of the European Society of Cardiology (ESC). J Hypertens $\underline{31}$, 1281-1357

\section{(EuroKup und HKUPP 2009) =}

EuroKup und HKUPP (2009): Standard protocol for urine collection.

URL: http://www.eurokup.org/node/137 (Zugriff am 13.07.2016)

\section{(Fornara und Fischer 2007) $=$}

Fornara P, Fischer K: Labordiagnostik. In: Joachim D, Miller K (Hrsg.): Praxis der Urologie. 3. Auflage; Georg Thieme Verlag, Stuttgart 2007, 30-32

\section{(GE Healthcare Life Sciences) $=$}

GE Healthcare Life Sciences: Vivaspin Sample Concentrators. o. Verf., o. J.

URL: http://www.gelifesciences.com/webapp/wcs/stores/servlet/catalog/de/GELifeScie nces/products/AlternativeProductStructure_17079/28932218 (Zugriff am 26.07.2016)

(Georgakopoulos et al. 2011) =

Georgakopoulos D, Little WC, Abraham WT, Weaver FA, Zile MR (2011): Chronic baroreflex activation: A potential therapeutic approach to heart failure with preserved ejection fraction. J Card Fail $\underline{17}$ (2), 167-178

(Gey 2008) =

Gey MH: Instrumentelle Analytik und Bioanalytik, 2. Auflage; Springer-Verlag, Heidelberg 2008

(Gold et al. 2010) =

Gold LI, Eggleton P, Sweetwyne MT, Van Duyn LB, Greives MR, Naylor SM, Michalak M, Murphy-Ullrich JE (2010): Calreticulin: Non-endoplasmic reticulum functions in physiology and disease. FASEB J $\underline{24}$ (3), 665-683 
(Hart et al. 2015) =

Hart PD, Gosain P, Bakris G: Renal denervation therapy and baroreceptor activation therapy: Emerging tools for treating resistant hypertension. In: Ferdinand KC (Hrsg.): Hypertension in high risk African Americans- current concepts, evidence-based therapeutics and future considerations; Humana Press, New York 2015, 163-184

(Hewitt et al. 2004) =

Hewitt SM, Dear J, Star RA (2004): Discovery of protein biomarkers for renal diseases. J Am Soc Nephrol 15 (7), 1677-1689

(Hoberg et al. 2007) $=$

Hoberg E, Galle JC, Bjarnason-Wehrens B, Cordes C, Karoff M, Klein G, Willemsen D, Wirth A, Witt T, Völler H (2007): Umsetzungsempfehlungen von Diagnose- und Therapieleitlinien bei chronischen Nierenerkrankungen. Herzmedizin 24 (3), 136-146

(Hofmann et al. 2001) =

Hofmann W, Edel HH, Guder WG, Ivandic M, Scherberich JE (2001): Harnuntersuchungen zur differenzierten Diagnostik einer Proteinurie: Bekanntes und Neues zu Teststreifen und Harnproteinen. Dtsch Arzteblatt $\underline{98}$ (12)

(Holewinski et al. 2013) =

Holewinski RJ, Jin Z, Powell MJ, Maust MD, Van Eyk JE (2013): A fast and reproducible method for albumin isolation and depletion from serum and cerebrospinal fluid. Proteomics $\underline{13}$ (5), 743-750

(Holoshitz et al. 2010) $=$

Holoshitz J, De Almeida DE, Ling S (2010): A role for calreticulin in the pathogenesis of rheumatoid arthritis. Ann N Y Acad Sci 1209, 91-98

(Hoppe et al. 2012) $=$

Hoppe UC, Brandt MC, Wachter R, Beige J, Rump LC, Kroon AA, Cates AW, Lovett EG, Haller H (2012): Minimally invasive system for baroreflex activation therapy chronically lowers blood pressure with pacemaker-like safety profile: Results from the Barostim neo trial. J Am Soc Hypertens $\underline{6}$ (4), 270-276

(Inagi 2009) =

Inagi R (2009): Endoplasmic reticulum stress in the kidney as a novel mediator of kidney injury. Nephron Exp Nephrol 112 (1), 1-9

(Jia et al. 2009) =

Jia L, Zhang L, Shao C, Song E, Sun W, Li M, Gao Y (2009): An attempt to understand kidney's protein handling function by comparing plasma and urine proteomes. PLoS One $\underline{4}(4)$ 
(Johnson 2012) =

Johnson M (2012): Loading controls for Western Blots. Mather Methods $\underline{2}, 114$

(Johnson et al. 2001) =

Johnson S, Michalak M, Opas M, Eggleton P (2001): The ins and outs of calreticulin: From the ER lumen to the extracellular space. Trends Cell Biol 11 (3), 122-129

(Joshi et al. 2009) $=$

Joshi N, Taylor J, Bisognano JD (2009): Implantable device therapy for the treatment of resistant hypertension. J Cardiovasc Transl Res $\underline{2}$ (2), 150-153

(Kageyama et al. 2004) $=$

Kageyama S, Isono T, Iwaki H, Wakabayashi Y, Okada Y, Kontani K, Yoshimura K, Terai A, Arai Y, Yoshiki T (2004): Identification by proteomic analysis of calreticulin as a marker for bladder cancer and evaluation of the diagnostic accuracy of its detection in urine. Clin Chem $\underline{50}$ (5), 857-866

(Kalantari et al. 2015) $=$

Kalantari S, Jafari A, Moradpoor R, Ghasemi E, Khalkhal E (2015): Human urine proteomics: Analytical techniques and clinical applications in renal diseases. Int $\mathrm{J}$ Proteomics, Artikel-ID 782798

(KDIGO CKD Work Group-Leitlinie 2012) =

"Leitlinie Evaluation und Management der CKD 2012": Kidney Disease: Improving Global Outcomes (KDIGO) CKD Work Group (2012): KDIGO 2012 Clinical Practice Guideline for the Evaluation and Management of Chronic Kidney Disease. Kidney Int Suppl $2013 \underline{3}$ (1), 1-150

(Kitamura 2008a) =

Kitamura M (2008a): Endoplasmic reticulum stress in the kidney. Clin Exp Nephrol 12 (5), 317-325

(Kitamura 2008b) =

Kitamura M (2008b): Endoplasmic reticulum stress and unfolded protein response in renal pathophysiology: Janus faces. Am J Physiol Renal Physiol 295 (2), 323-334

(Köhler und Seitz 2012) =

Köhler K, Seitz H (2012): Validation processes of protein biomarkers in serum- a cross platform comparison. Sensors $\underline{12}$ (9), 12710-12728

$($ Koomans et al. 2004) $=$

Koomans HA, Blankestijn PJ, Joles JA (2004): Sympathetic hyperactivity in chronic renal failure: A wake-up call. J Am Soc Nephrol 15 (3), 524-537 


\section{(Koziolek und Wallbach 2013) $=$}

Koziolek MJ, Wallbach M (2013): Application for research funding (unveröffentlichtes Dokument; Projekt "Impact of Baroreceptor stimulation therapy on epigenetic factors and urine proteomics")

(Kragh-Hansen 1990) $=$

Kragh-Hansen U (1990): Structure and ligand binding properties of human serum albumin. Dan Med Bull 37 (1), 57-84

(Kushnir et al. 2009) $=$

Kushnir MM, Mrozinski P, Rockwood AL, Crockett DK (2009): A depletion strategy for improved detection of human proteins from urine. J Biomol Tech $\underline{20}$ (2), 101-108

(Lea et al. 2005) $=$

Lea J, Greene T, Hebert L, Lipkowitz M, Massry S, Middleton J, Rostand SG, Miller E, Smith W, Bakris GL (2005): The relationship between magnitude of proteinuria reduction and risk of end-stage renal disease: Results of the African American study of kidney disease and hypertension. Arch Intern Med 165 (8), 947-1053

(Leach und Williams 2003) $=$

Leach MR, Williams DB: Calnexin and Calreticulin, molecular chaperones of the endoplasmic reticulum. In: Michalak M und Eggleton P (Hrsg.). 2. Auflage; Springer US 2003, 49-62

$($ Lee 2005) $=$

Lee AS (2005): The ER chaperone and signaling regulator GRP78/BiP as a monitor of endoplasmic reticulum stress. Methods $\underline{35}$ (4), 373-381

(Lee 2007) $=$

Lee AS (2007): GRP78 induction in cancer: Therapeutic and prognostic implications. Cancer Res $\underline{67}$ (8), 3496-3499

(Lee et al. 2008) $=$

Lee RS, Monigatti F, Briscoe AC, Waldon Z, Freeman MR, Steen H (2008): Optimizing sample handling for urinary proteomics. J Proteome Res $\underline{7}$ (9), 4022-4030

(Lehnig 2016) $=$

Lehnig LY: Analyse organoprotektiver Effekte durch eine Barorezeptorstimulationstherapie zur Behandlung der Therapie-refraktären arteriellen Hypertonie. Med. Diss. Göttingen 2016

(Leitlinie arterielle Hypertonie 2013) $=$

Siehe ESH/ESC-Leitlinie 2013 
(Leitlinie CKD 2002) =

Siehe National Kidney Foundation-Leitlinie 2002

(Leitlinie der Deutschen Adipositas-Gesellschaft 2014) =

„Leitlinie Prävention und Therapie der Adipositas 2014“: Interdisziplinäre Leitlinie der Qualität S3 zur "Prävention und Therapie der Adipositas“. Deutsche AdipositasGesellschaft 2014.

URL: http://www.adipositasgesellschaft.de/fileadmin/PDF/Leitlinien/S3_Adipositas_Pra evention_Therapie_2014.pdf (Zugriff am 13.08.2016)

(Leitlinie Evaluation und Management der CKD 2012) =

Siehe KDIGO CKD Work Group-Leitlinie 2012

(Leitlinie Hypertonie und CKD 2004) =

Siehe National Kidney Foundation-Leitlinie 2004

(Leitlinie Management der arteriellen Hypertonie 2013) =

Siehe Deutsche Hochdruckliga und Deutsche Gesellschaft für Kardiologie-Leitlinie 2013

(Leitlinie Prävention und Therapie der Adipositas 2014) =

Siehe Leitlinie der Deutschen Adipositas-Gesellschaft 2014

(Li und Shen 2013) =

Li R, Shen Y (2013): An old method facing a new challenge: Re-visiting housekeeping proteins as internal reference control for neuroscience research. Life Sci $\underline{92}$ (13), 747751

(Lilley und Friedman 2004) $=$

Lilley KS, Friedman DB (2004): All about DIGE: Quantification technology for differential-display 2D-gel proteomics. Expert Rev Proteomics 1 (4), 401-409

$($ Maattanen et al. 2006) $=$

Maattanen P, Kozlov G, Gehring K, Thomas DY (2006): ERp57 and PDI: Multifunctional protein disulfide isomerases with similar domain architectures but differing substrate-partner associations. Biochem Cell Biol $\underline{84}$ (6), 881-889

(Machleidt und Walb 2003) $=$

Machleidt C und Walb D: Chronisches Nierenversagen. In: Böhler J, Kuhlmann U, Luft FC, Walb D (Hrsg.): Nephrologie: Pathophysiologie- Klinik- Nierenersatzverfahren. 4. Auflage; Georg Thieme Verlag, Stuttgart 2003, 371-394

(Mahfoud et al. 2011) =

Mahfoud F, Himmel F, Ukena C, Schunkert H, Böhm M, Weil J (2011): Treatment strategies for resistant arterial hypertension. Dtsch Arztebl Int 108 (43), 725-731 
(Mahfoud et al. 2013) =

Mahfoud F, Ukena C, Schmieder RE, Cremers B, Rump LC, Vonend O, Weil J, Schmidt M, Hoppe UC, Zeller T (2013): Ambulatory blood pressure changes after renal sympathetic denervation in patients with resistant hypertension. Circulation 128 (2), $132-140$

$($ Mahmood und Yang 2012) $=$

Mahmood T, Yang PC (2012): Western Blot: Technique, theory and trouble shooting. N Am J Med Sci 4 (9), 429-434

(Marimuthu et al. 2011) =

Marimuthu A, O'Meally RN, Chaerkady R, Subbannayya Y, Nanjappa V, Kumar P, Kelkar DS, Pinto SM, Sharma R, Renuse S, Goel R (2011): A comprehensive map of the urinary proteome. J Proteome Res 10 (6), 2734-2743

(Menne et al. 2013) $=$

Menne J, Jordan J, Linnenweber-Held S, Haller H (2013): Resistant hypertension: Baroreflex stimulation as a new tool. Nephrol Dial Transplant $\underline{28}$ (2), 288-295

(Mettang und Kuhlmann 2003) =

Mettang T, Kuhlmann: Chronisches Nierenversagen. In: Kuhlmann U (Hrsg.): Nephrologie: Pathophysiologie-Klinik-Nierenersatzverfahren. 4. Auflage; Georg Thieme Verlag, Stuttgart 2003, 371-394

(Michalak et al. 2009) $=$

Michalak M, Groenendyk J, Szabo E, Gold LI, Opas M (2009): Calreticulin, a multiprocess calcium-buffering chaperone of the endoplasmic reticulum. Biochem $\mathrm{J} \underline{417}$ (3), 651-666

(Müller et al. 2007) =

Müller GA, Müller CA, Dihazi H (2007): Clinical proteomics- on the long way from bench to bedside?. Nephrol Dial Transplant 22 (5), 1297-1300

(Müller und Graeve 2014) =

Müller M, Graeve L: Proteine- Transport, Modifikation und Faltung. In: Heinrich PC, Müller M, Graeve L (Hrsg.): Biochemie und Pathobiochemie. 9. Auflage; SpringerVerlag, Heidelberg 2014, 615-618

(MyBioSource) $=$

MyBioSource: Human protein disulfide-isomerase A3 (PDIA3) ELISA Kit. o. Verf., o. J. URL: http://www.mybiosource.com/images/tds/protocol_others/MBS700585.pdf (Zugriff am 08.08.2016)

(National Kidney Foundation-Leitlinie 2002) = "Leitlinie CKD 2002“: K/DOQI Clinical practice guidelines for chronic kidney disease: Evaluation, classification and stratification. J Kidney Dis $\underline{39}$, 1-266 
(National Kidney Foundation-Leitlinie 2004) =

"Leitlinie Hypertonie und CKD 2004“: K/DOQI Clinical practice guidelines on hypertension and antihypertensive agents in chronic kidney disease. Am J Kidney Dis $\underline{43}, 1-290$

(Nesto 2004) =

Nesto RW (2004): Correlation between cardiovascular disease and diabetes mellitus: Current concepts. Am J Med $\underline{8}, 11-22$

(Ní Fhlathartaigh et al. 2013) =

Ní Fhlathartaigh M, McMahon J, Reynolds R, Connolly D, Higgins E, Counihan, Fitzgerald $U$ (2013): Calreticulin and other components of endoplasmic reticulum stress in rat and human inflammatory demyelination. Acta Neuropathol Commun 1, 37

(Niiranen et al. 2014) =

Niiranen TJ, Mäki J, Puukka P, Karanko H, Jula AM (2014): Office, home, and ambulatory blood pressures as predictors of cardiovascular risk. Hypertension $\underline{64}$ (2), 281-286

(Paivanas et al. 2015) =

Paivanas N, Bisognano JD, Gassler JP (2015): Carotid baroreceptor stimulation and arteriovenous shunts for resistant hypertension. Methodist Debakey Cardiovasc $\mathrm{J} \underline{11}$ (4), 223-227

(Park 2012) $=$

Park J (2012): Cardiovascular risk in chronic kidney disease: Role of the sympathetic nervous system. Cardiol Res Pract 2012

$($ Peterson et al. 1995) $=$

Peterson JC, Adler S, Burkart JM, Greene T, Hebert LA, Hunsicker LG, King AJ, Klahr S, Massry SG, Seifter JL (1995): Blood pressure control, proteinuria, and the progression of renal disease. The Modification of diet in renal disease study. Ann Intern Med $\underline{123}$ (10), 754-762

(Pimentel et al. 1995) $=$

Pimentel JL, Sundell CL, Wang S, Kopp JB, Montero A, Martinez-Maldonado M (1995): Role of angiotensin II in the expression and regulation of transforming growth factorbeta in obstructive nephropathy. Kidney Int $\underline{48}$ (4), 1233-1246

(Pockley et al. 1998) $=$

Pockley AG, Shepherd J, Corton JM (1998): Detection of heat shock protein 70 (Hsp 70) and anti-Hsp70 antibodies in the serum of normal individuals. Immunol Invest $\underline{27}$ (6), 367-377 
(Price et al. 2005) $=$

Price CP, Newall RG, Boyd JC (2005): Use of protein:creatinine ratio measurements on random urine samples for prediction of significant proteinuria: A systematic review. Clin Chem $\underline{51}$ (9), 1577-1586

(Rauch et al. 2005) $=$

Rauch P, Zellmer A, Dankbar N, Specht C, Sperling D (2005): Assayoptimierung: Störeffekte bei Immunoassays erkennen und vermeiden. Laborwelt $\underline{4}$ (6), 2-6

$($ Ravera et al. 2006) $=$

Ravera M, Re M, Deferrari L, Vettoretti S, Deferrari G (2006): Importance of blood pressure control in chronic kidney disease. J Am Soc Nephrol 17 (4), 98-103

$($ Regeniter et al. 2009) $=$

Regeniter A, Freidank H, Dickenmann M, Boesken WH, Siede WH (2009): Evaluation of proteinuria and GFR to diagnose and classify kidney disease: Systematic review and proof of concept. Eur J Intern Med $\underline{20}$ (6), 556-561

(Richter 2003) =

Richter G: Proteine- Analyse der Polypeptidstruktur. In: Richter G (Hrsg.): Praktische Biochemie- Grundlagen und Techniken. 1. Auflage; Georg Thieme Verlag, Stuttgart 2003, 203-204

$($ Rosa et al. 2015) $=$

Rosa J, Widimský P, Toušek P, Petrák O, Čurila K, Waldauf $P$, Bednář $F$, Zelinka $T$, Holaj R, Štrauch B et al. (2015): Randomized comparison of renal denervation versus identified pharmacotherapy including spironolactone in true-resistant hypertension: Sixmonth results from the Prague-15 study. Hypertension $\underline{65}$ (2), 407-413

(Ruiz-Ortega et al. 1995) =

Ruiz-Ortega M, González S, Serón D, Condom E, Bustos C, Largo R, González E, Ortiz A, Egido J (1995): ACE inhibition reduces proteinuria, glomerular lesions and extracellular matrix production in a normotensive rat model of immune complex nephritis. Kidney Int $\underline{48}$ (6), 1778-1791

(Sartorius Stedim Biotech GmbH 2014) =

Sartorius Stedim Biotech $\mathrm{GmbH}$ (2014): Technical data and operating instructionsManual Vivaspin $500 \mu \mathrm{l}$ and $2 \mathrm{ml}$.

URL: http://www.vivaproducts.com/downloads/vivaspin-2-500-operating-

instructions.pdf (Zugriff am 26.07.2016)

(Schaller und Wolzt 2006) =

Schaller G, Wolzt M (2006): Maligne und therapierefraktäre Hypertonie. Wien Med Wochenschr 156, 488-493 
(Schlaich et al. 2009) =

Schlaich MP, Socratous F, Hennebry S, Eikelis N, Lambert EA, Straznicky N, Esler MD, Lambert GW (2009): Sympathetic activation in chronic renal failure. J Am Soc Nephrol $\underline{20}$ (5), 933-939

$($ Schmieder 2010) $=$

Schmieder RE (2010): Hypertoniebedingte Endorganschäden. Dtsch Arztebl Int 107 (49), 866-873

(She et al. 2009) $=$

She X, Rohl CA, Castle JC, Kulkarni AV, Johnson JM, Chen R (2009): Definition, conservation and epigenetics of housekeeping and tissue-enriched genes. BMC Genomics $\underline{10}, 269$

(Siu et al. 2011) $=$

Siu WK, Mak CM, Lee HC, Tam S, Lee J, Chan TM, Fung KS, Tong KL, Chan YW (2011): Correlation study between spot urine protein-to-creatinine ratio and 24-hour urine protein measurement in 174 patients for proteinuria assessment. Hong Kong Journal of Nephrology 13, 51-54

(Sobotka et al. 2011) $=$

Sobotka PA, Mahfoud F, Schlaich MP, Hoppe UC, Böhm M, Krum H (2011): Sympatho-renal axis in chronic disease. Clin Res Cardiol 100 (12), 1049-1057

(Soundy und Harvey 2005) $=$

Soundy P, Harvey B: Western Blotting as a diagnostic method. In: Walker JM, Rapley R (Hrsg.): Medical Biomethods Handbook; Humana Press, Totowa 2005, 43-62

(Taylor und Posch 2014) =

Taylor SC, Posch A (2014): The design of a quantitative Western Blot Experiment. Biomed Res Int, Volume 2014, 1-8

(Taylor et al. 2013) =

Taylor SC, Berkelman T, Yadav G, Hammond M (2013): A defined methodology for reliable quantification of western blot data. Mol Biotechnol $\underline{55}$ (3), 217-226

(Thomas et al. 2012) =

Thomas G, Shishebor, MH, Bravo EL, Nally JV (2012): Renal denervation to treat resistant hypertension: Guarded optimism. Cleve Clin J Med $\underline{79}$ (7), 501-510

(Thongboonkerd 2010) $=$

Thongboonkerd V (2010): Current status of renal and urinary proteomics: Ready for routine clinical application?. Nephrol Dial Transplant $\underline{25}$ (1), 11-16 
(Thongboonkerd und Malasit 2005) =

Thongboonkerd V, Malasit P (2005): Renal and urinary proteomics: Current applications and challenges. Proteomics $\underline{5}$ (4), 1033-1042

(Thongboonkerd et al. 2005) =

Thongboonkerd V, Chutipongtanate S, Kanlaya R (2005): Systematic evaluation of sample preparation methods for gel-based human urinary proteomics: Quantity, quality, and variability. J Proteome Res $\underline{5}$ (1), 183-191

(Tuncel et al. 2002) =

Tuncel M, Augustyniak R, Zhang W, Toto RD, Victor RG (2002): Sympathetic nervous system function in renal hypertension. Curr Hypertens Rep 4 (3), 229-236

(Turano et al. 2002) =

Turano C, Coppari S, Altieri F, Ferraro A (2002): Proteins of the PDI-family: Unpredicted non-ER locations and functions. J Cell Physiol 193 (2), 154-163

(Upledger 2003) =

Upledger JE: Cell Talk: Talking to your cell. North Atlantic Books, Berkeley 2003

(Wallbach und Koziolek 2015) =

Wallbach M, Koziolek MJ (2015): Nephroprotektion durch Barorezeptoraktivierungstherapie. DZKF 2 , 27-31

(Wallbach et al. 2016) =

Wallbach M, Lehnig LY, Schroer C, Lüders S, Böhning E, Müller GA, Wachter R, Koziolek M (2016): Effects of baroreflex activation therapy on ambulatory blood pressure in patients with resistant hypertension. Hypertension $\underline{67}$ (4), 701-709

(Wang et al. 2009) =

Wang M, Wey S, Zhang Y, Ye R, Lee AS (2009): Role of the unfolded protein response regulator GRP78/BiP in development, cancer, and neurological disorders. Antioxid Redox Signal 11 (9), 2307-2316

(Wang et al. 2017) =

Wang Y, Xie J, Liu Z, Fu H, Huo Q, Gu Y, Liu Y (2017): Association of calreticulin expression with disease activity and organ damage in systemic lupus erythematosus patients. Exp Ther Med $\underline{13}$ (5), 2577-2583

\section{(Wessel und Flügge 1984) $=$}

Wessel D, Flügge UI (1984): A method for the quantitative recovery of protein in dilute solution in the presence of detergents and lipids. Anal Biochem 138 (1), 141-143

\section{(Williams 2006) $=$}

Williams DB (2006): Beyond lectins: The calnexin/calreticulin chaperone system of the endoplasmic reticulum. J Cell Sci 119 (4), 615-623 
(Williams et al. 2015) $=$

Williams B, MacDonald TM, Morant S, Webb DJ, Sever P, Mclnnes G, Ford I, Kennedy Cruickshank J, Caulfield MJ, Salsbury J et al. (2015): Spironolactone versus placebo, bisoprolol, and doxazosin to determine the optimal treatment for drug-resistant hypertension (PATHWAY-2): A randomised, double-blind, crossover trial. Lancet $\underline{386}$, 2059-2068

$($ Xin et al. 2004) $=$

Xin G, Wang M, Jiao LL, Xu GB, Wang HY (2004): Protein-to-creatinine ratio in spot urine samples as a predictor of quantitation of proteinuria. Clin Chim Acta $\underline{350}$ (1-2), 35-39

(Zoja et al. 1997) =

Zoja C, Donadelli R, Corna D, Testa D, Facchinetti D, Maffi R, Luzzana E, Colosio V, Bertani T, Remuzzi G (1997): The renoprotective properties of angiotensin-converting enzyme inhibitors in a chronic model of membranous nephropathy are solely due to the inhibition of angiotensin II: Evidence based on comparative studies with a receptor antagonist. Am J Kidney Dis $\underline{29}$ (2), 254-264 


\section{Danksagung}

Mein besonderer Dank gilt meinem Doktorvater Herrn Professor Dr. M. Koziolek für die Vergabe des interessanten und herausfordernden Themas sowie die exzellente Betreuung. Kritische Diskussionen, wertvolle Ratschläge und ausführliches Korrekturlesen haben ganz wesentlich zur Fertigstellung meiner Dissertation beigetragen.

Zudem danke ich Herrn Professor Dr. G. A. Müller für die Möglichkeit, meine Promotion in seiner Abteilung durchführen zu können.

Bei Herrn Professor Dr. rer nat. H. Dihazi und seinem Laborteam bedanke ich mich vor allem für die gute Zusammenarbeit, die produktive Arbeitsatmosphäre sowie Nutzung der Laborräume. Ein großer Dank für die kompetente Einarbeitung und freundliche Unterstützung während meiner Laborzeit richtet sich an Frau Elke Brunst-Knoblich. Zudem möchte ich mich bei allen Doktoranden für die Hilfsbereitschaft und Diskussionsfreudigkeit bedanken.

Darüber hinaus danke ich Herrn PD Dr. M. Wallbach ganz herzlich für seine kompetente Unterstützung während meiner gesamten Arbeit. Vielen Dank für das große Engagement beim Erlernen des ELISA, die Hilfe bei der Datenauswertung und der Ausarbeitung meines Vortrages für die Jahrestagung der Deutschen Gesellschaft für Nephrologie 2015 in Berlin. 